\title{
The Balanced Counseling Strategy Plus: A Toolkit for Family Planning Service Providers Working in High HIV/STI Prevalence Settings (with Zika information)
}

Population Council

Follow this and additional works at: https://knowledgecommons.popcouncil.org/departments_sbsr-rh

Part of the International Public Health Commons, Obstetrics and Gynecology Commons, Public Health and Community Nursing Commons, and the Women's Health Commons How does access to this work benefit you? Let us know!

\section{Recommended Citation}

Population Council. 2015. "The Balanced Counseling Strategy Plus: A Toolkit for Family Planning Service Providers Working in High HIV/STI Prevalence Settings (with Zika information)." Washington, DC:

Population Council. 
The Balanced Counseling Strategy Plus

A Toolkit for Family Planning Service Providers Working in High STI/HIV Prevalence Settings

\section{USER'S GUIDE}

Third Edition, 2015 
(C) 2008, 2011, 2015 The Population Council, Inc.

The Population Council confronts critical health and development issues - from stopping the spread of HIV to improving reproductive health and ensuring that young people lead full and productive lives. Through biomedical, social science, and public health research in 50 countries, we work with our partners to deliver solutions that lead to more effective policies, programs, and technologies that improve lives around the world. Established in 1952 and headquartered in New York, the Council is a nongovernmental, nonprofit organization governed by an international board of trustees.

Any part of this publication may be photocopied without permission from the publisher provided that copies are distributed without charge and that full source citation is provided. The Population Council would appreciate receiving a copy of any materials in which the text is used.

Suggested citation: Population Council. 2015. Balanced Counseling Strategy Plus User's Guide Third Edition, part of The Balanced Counseling Strategy Plus: A Toolkit for Family Planning Service Providers Working in High STI/HIV Prevalence Settings, Third Edition, Washington, DC.

Note: This publication is part of a larger publication titled The Balanced Counseling Strategy Plus: A Toolkit for Family Planning Service Providers Working in High STI/HIV Prevalence Settings. The Balanced Counseling Strategy Plus Toolkit includes the following:

- Algorithm

- Counseling cards

- Method brochures

- User's Guide

- Trainer's Guide

- WHO Medical Eligibility Criteria Wheel

If any part is missing, please contact the Population Council at publications@popcouncil.org. 


\section{Preface to the Third Edition}

The Balanced Counseling Strategy Plus (BCS+) toolkit, developed and tested in Kenya (2005 to 2007) and South Africa (2004 to 2006) because both countries have high rates of STIs, including HIV, and their contraceptive prevalence rates are relatively high for the region. The BCS+ provides the information and materials that healthcare facility providers need so they can offer complete, high-quality family planning counseling to clients living in areas with high rates of HIV and STIs. The BCS+ was adapted from the Balanced Counseling Strategy (León 1999; León et al. 2003a, b, c; León, Vernon, Martin, and Bruce 2008). First edition of the Balanced Counseling Strategy and Balanced Counseling Strategy Plus toolkits are products of the Population Council's FRONTIERS program, supported by the United States Agency for International Development (USAID), Cooperative Agreement HRN-A-00-98-00012-00.

The Second Edition was updated based on the 2010 WHO Medical Eligibility Criteria (MEC) as well as recommendations from authors and partners who have experienced and evaluated implementation of the tool in settings and scenarios around the world and validated through the Integra Initiative, supported by the Bill and Melinda Gates Foundation. It included additional counseling cards on cervical cancer screening, postpartum and infant health.

This Third Edition of the BCS+ includes content updated according to the latest WHO Medical Eligibility Criteria (2015). It incorporates the most up-to-date evidence on clinical indications for the provision of family planning methods, including new methods (Caya ${ }^{\circledR} /$ SILCS diaphragm and Progesterone Vaginal Ring), and includes six new counseling cards that address Adolescent Counseling, Male Services, Post Abortion Care, and Women's Support and Safety, Breast Cancer Information and Awareness, and Zika Prevention and Treatment. The updated cards include instructions for providers, guiding them through supplemental counseling and services that family planning clients may need. Development of this Third Edition of the BCS+ toolkit was funded by the Evidence Project, USAID Cooperative agreement AID-OAA-A-13-00087 and the Bill and Melinda Gates Foundation supported Integra Initiative at the Population Council. 
Development of The Balanced Counseling Strategy Plus (BCS+) could not have been possible without the invaluable support of the service providers who tested the toolkit and the program directors who authorized and supervised its application. The authors wish to thank the Department of Health in South Africa and the Division of Reproductive Health and the National AIDS and STD Control Program of the Ministry of Health in Kenya. We would also like to thank the trainers at the Reproductive Health and HIV Research Unit (RHRU) of the University of Witwatersrand for their contribution to the study in South Africa.

Development and production of the third edition of The Balanced Counseling Strategy Plus was supported by the Population Council. Authors would like to acknowledge the following individuals for providing their technical expertise and invaluable contributions to this updated edition of the BCS+: Megan Christofield, Heather Clark, Mychelle Farmer, Kamlesh Giri, Joanne Gleason, Mark Hathaway, Anushka Kalyanpur, Maggie Kilbourne-Brook, Karen R. Kirk, Ricky Lu, Ruth Merkatz, Charity Ndigwa, Anne Pfitzer, Saumya RamaRao, Naomi Rijo, Elizabeth Rochette, Jill Schwartz, Leigh Stefanik, John Townsend, Chi-Chi Undie, Katie Unthank, Anneka Van Scoyoc, Charlotte Warren, Ellen Weiss, and Kelsey Wright. 


\section{乌 Contents}

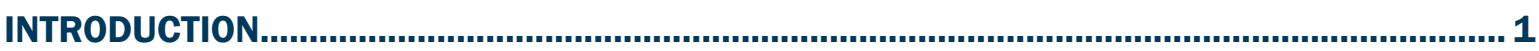

Algorithm for Using the Balanced Counseling Strategy Plus..............................................5

GUIDE TO COUNSELING CLIENTS USING THE BCS+ TOOLKIT ................................................ 7

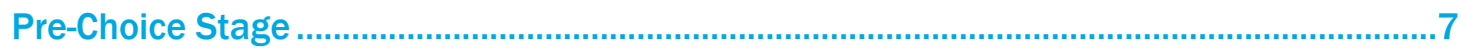

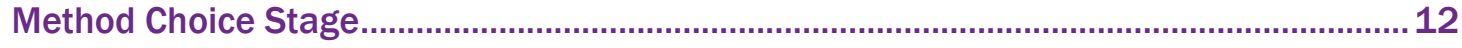

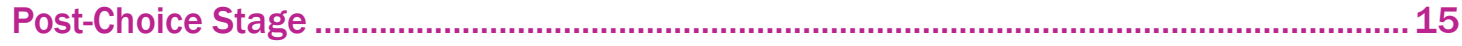

Systematic Screening for Other Services Stage ..................................................................... 17

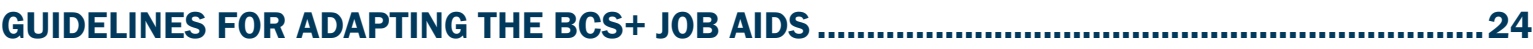

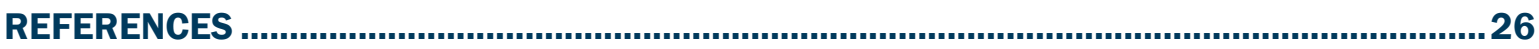




\section{Introduction}

In the late 1990s, the Population Council's USAID-funded FRONTIERS in Reproductive Health Program (FRONTIERS) worked in collaboration with Ministries of Health in several Latin American countries to develop and test a practical, interactive, and client-friendly strategy for improving counseling within family planning consultations. This strategy is called the Balanced Counseling Strategy (BCS) (León 1999; León et al. 2004). The BCS uses key job aids for counseling clients about family planning: an algorithm to guide the provider through the counseling process, a set of counseling cards for contraceptive methods, and corresponding brochures for each method. The strategy, tested and refined in several countries, comprises a series of steps to determine the contraceptive method that best suits the client according to her/his preferences and needs. This strategy improves the quality of the provider's counseling and allows the client to take ownership of the decision.

The BCS proved effective as a tool to assist family planning providers to improve the quality of care (León et al. 2003a, b, c). The approach is practical, low cost, and easy to adapt to local contexts. The Balanced Counseling Strategy: A Toolkit for Family Planning Service Providers was published to provide the information and tools needed for health care facility managers, supervisors, and service providers to implement the BCS in their family planning services (León, Vernon, Martin, and Bruce 2008).

\section{WHY THE BALANCED COUNSELING STRATEGY PLUS?}

In response to the need to incorporate counseling, screening, and services for sexually transmitted infections (STIs), including HIV, within routine family planning consultations in settings characterized by high prevalence of these infections, the BCS was revised to integrate STI/HIV prevention counseling, risk assessment, and HIV counseling and testing (HCT). The resulting Balanced Counseling Strategy Plus (BCS+) toolkit improves the quality of the family planning service and enables providers to address clients' needs related to STIs and HIV during the same consultation.

Integration of health services has been defined as offering a range of services that can meet several needs simultaneously, usually in the same venue and through the same provider. Referrals to, or linkages with, related services enable a client to receive a range of needed services, even if the services are not received simultaneously (Askew 2007). In reproductive health, the push for integration or linkage is guided both by many clients having the need for several services simultaneously (and so missed opportunities can be reduced) and by the expectation that the component services can be provided more efficiently when integrated or linked than when delivered individually. Despite many calls for greater attention to integrating such services in high STI/HIV settings, surprisingly little attention has been paid to the development and empirical testing of practical tools that providers can use to strengthen their capacity to offer integrated services.

The FRONTIERS program developed and piloted the BCS+ in Kenya (2005 to 2007) and South Africa (2004 to 2006) because both countries have high rates of STIs, including HIV, and their contraceptive prevalence rates are relatively high for the region. This situation provides opportunities to reach a substantial proportion of the sexually active population (albeit predominantly female) that is seeking to prevent pregnancy and that also may be at risk of exposure to an STI/HIV. As in most countries, their family planning and STI/HIV programs are implemented separately, although both countries are actively seeking ways to integrate services. Thus, both Ministries of Health were keen to develop practical tools for increasing the quality of services and numbers of clients receiving integrated services.

The study findings are described more fully elsewhere (see Liambila et al. 2008; Mullick et al. 2008), but both studies showed that:

- Integrating STI/HIV prevention counseling and risk assessment with offering HCT during family planning consultations is feasible and acceptable to clients and providers. 
- The quality of care for both family planning and STI/HIV counseling improved significantly with the use of the BCS+ tools.

- Counseling on HCT increased substantially. In Kenya, more than 40 percent of clients were offered HCT services, with almost half of these deciding to be tested, either on site or through referral. In South Africa, those offered testing increased to 29 percent. Furthermore, an overall increase in testing was observed in the district with a doubling of individuals tested.

- Use of the BCS+ tools facilitated greater risk assessment for STIs and HIV. Also, decisions about contraceptive method choice were made with a better understanding of their relationship to infection prevention.

- Despite the concern that adding these services may have a negative impact on the family planning service, improved quality of counseling and no evidence of a decline in utilization showed that this concern was unfounded.

\section{THE BALANCED COUNSELING STRATEGY PLUS}

The BCS+ is divided into four counseling stages. Each stage contains a sequence of steps to follow. The BCS + assumes that the motive of a client's visit is family planning but serves to also offer the client additional counseling and services in the same facility or through referral. The BCS+ integrates postpartum counseling messages to ensure health of the mother and the infant; an opportunity to discuss healthy timing and spacing of pregnancies; counseling on STI/HIV transmission and prevention; screening for reproductive cancers; violence prevention; post-abortion care; and male and adolescent services. Information on the cards instructs providers through conducting an STI/ HIV risk assessment, discussing dual protection and positive health, and discussing and offering the client HIV counseling and testing. The BCS+ process can be summarized as a decision-making algorithm, which is described on the next three pages. Below is a summary of the four counseling stages:

- Pre-Choice Stage: During this stage, the provider creates the conditions that help a client select a family planning method. The provider cordially greets the client. The provider emphasizes to the client that, during the consultation, other reproductive health issues will be addressed depending on her/his individual circumstance. The provider reviews the client's fertility intentions and counsels her/him on healthy timing and spacing of pregnancy. Pregnancy is ruled out using the counseling card with the checklist of questions. If the client is not pregnant, the provider displays all the method cards and asks questions described in the algorithm. As the client responds to each question, the provider sets aside the cards of the methods that are not appropriate for the client. Setting aside these cards helps to avoid giving information on methods that are not relevant to the client's needs.

If pregnancy cannot be ruled out, the provider skips to steps 13 to 19 to discuss other relevant services the client may need. The client is given a back-up method, such as condoms, and asked to return when she has her menstruation.

- Method Choice Stage: During this stage, the provider offers more extensive information about the methods that have not been set aside, including their effectiveness. This helps the client select a method suited to her/his reproductive needs. Following the steps in the BCS+ algorithm, the provider continues to narrow down the number of counseling method cards until a method is chosen.

- Post-Choice Stage: During this stage, the provider uses the method brochure to give the client complete information about the method that $\mathrm{s} / \mathrm{he}$ has chosen. If the client has conditions where the method is not advised or is not satisfied with the method, the provider returns to the Method Choice Stage to help the client select another method. The provider also encourages the client to involve her/his partner(s) in decisions about contraception, either through discussion or visit to the clinic.

- Systematic Screening for Other Services Stage: During this stage, the provider uses information collected previously and targeted questions to determine additional health services and counseling that the family planning client may need. Using the remaining counseling cards, 
the provider may review important information for a postpartum mother or infant; may refer him/her to well-child services; discuss and offer cervical screening tests; discuss breast cancer; offer adolescent or male service counseling; discuss women's support and safety; offer post-abortion care as appropriate; discuss STI/HIV and Zika ${ }^{1}$ transmission and prevention; conduct a risk assessment; discuss dual protection and positive health; and offer the client HIV counseling and testing. The provider offers HIV testing to the client, following national protocols, and encourages the client to disclose her/his STI/HIV status to her/his partner(s), letting the client know both the benefits and risks of disclosure. Upon completion of the counseling session, the provider gives follow-up instructions on the chosen contraceptive method, the method brochure, and a condom brochure. The provider and client also fix a date for a follow-up visit.

\section{WHAT IS INCLUDED IN THIS TOOLKIT?}

The BCS+ job aids and guides are intended for reproductive health programs interested in both strengthening the quality of family planning counseling and responding to the additional service and counseling needs of clients. In addition to adding further guidance on other integrated services, the second edition incorporated an additional job aid, the World Health Organization's Medical Eligibility Criteria Wheel, to complement existing provider tools and facilitate comprehensive family planning service provision. Below is a list of the toolkit components:

1. BCS+ User's Guide on how to implement the BCS+. It explains how to use the job aids and can be distributed during training on the BCS+ or used for self-teaching with the BCS+ job aids.

2. BCS+ job aids, including:

- The BCS+ algorithm that summarizes the 19 steps recommended to implement the BCS+ during a family planning consultation. These steps are organized under four stages of the consultation: pre-choice needs assessment; method choice; post-choice actions; and systematic screening for other services. During each stage of the consultation, the provider is given step-by-step guidance on how to use the BCS+ job aids. Depending on the client's response to the issues discussed, the algorithm outlines which actions to take. The BCS+ algorithm can be found on pages 6 to 8 as well as separately with the other job aids in the toolkit.

- Counseling cards that the provider uses during a counseling session. There are 34 counseling cards. The first card contains 6 questions that the service provider asks to rule out whether a client is pregnant (adopted from those developed by Stanback et al. 1999). There are 18 method-specific cards that contain information about each family planning method. Each method card has an illustration of the contraceptive method on the front side. The back of the card contains a list of key features of the method and describes the method's use, indications, risk factors, and level of effectiveness. These cards are used to first exclude those methods that are inappropriate for the client's reproductive intentions and then to narrow the choice to reach a final decision. Fifteen (15) counseling cards provide information on additional counseling and services that a family planning client may need. These are: healthy timing and spacing of pregnancies; promoting healthy postpartum period for the mother; post abortion care; promoting newborn and infant health; STI/HIV transmission and prevention; Zika transmission and prevention; STI/HIV risk assessment; positive health, dignity and prevention; dual protection; HIV counseling and testing; screening for cervical cancer; adolescent counseling; women's support and safety; male services; and breast cancer information and awareness. These cards are used during the fourth stage of the consultation-systematic screening for other services.

- Method brochures on each of the 18 contraceptive methods. They are designed to help the client better understand the method chosen. The provider gives the client the brochure for the selected method and a brochure with information on condoms to take home. Pro-

${ }^{1}$ and any other emergency infectious disease that may be transmitted sexually 
viders should encourage low-literate or illiterate clients to take the brochure home so that their partner or other trusted friend can review the brochure with them again.

- WHO Medical Eligibility Criteria (MEC) Wheel (2015) which is a provider job aid based on the four eligibility categories for contraceptive use in relation to medical conditions described in the document Medical Eligibility Criteria for contraceptive use, Fifth edition, published by Department of Reproductive Health, World Health Organization. This tool guides providers through medical conditions and medications that may be contraindications to use of particular contraceptive methods. The job aid has been field-tested in three countries by WHO, and is found to be very useful to providers who used it.

3. BCS+ Trainer's Guide that supervisors and others can use to train providers on how to use the BCS+. The guide includes exercises and activities to increase participants' comprehension and proper utilization of the BCS+ toolkit.

The BCS+ job aids BCS+ Trainer's Guide and BCS+ User's Guide incorporate the latest international family planning and STI/HIV norms and guidance as recommended by the World Health Organization (WHO), including Medical Eligibility Criteria for Contraceptive Use (WHO 2015), Family Planning: A Global Handbook for Providers (WHO/RHR and JHU/CCP, INFO Project 2011 update), Contraceptive Technology (Hatcher et al. 2011), Sexually Transmitted and Other Reproductive Tract Infections: A Guide to Essential Practice (WHO 2005), and Guidelines for the Management of Sexually Transmitted Infections (WHO 2003).

These job aids can be revised depending on national and/or regional $\mathrm{g}$ be easily printed or adapted to meet local needs.

\section{HOW SHOULD THIS TOOLKIT BE USED?}

1. Read this entire BCS+User's Guide on how to implement the Balanced Counseling Strategy Plus.

2. Refer to the BCS+ algorithm as a reminder of the 19 steps used to implement the BCS+. It is helpful to have a copy available on the provider's desk or on a wall in the consultation area so that the provider can refer to it easily.

3. Use the BCS + counseling cards and WHO MEC Wheel to help a client choose a method based on her/his reproductive intentions. Use the first counseling card to rule out whether the client is pregnant. If she is not, use the method cards to help the client choose a contraceptive method best suited to her/his reproductive health intentions by discarding those that are inappropriate. Emphasize dual protection throughout the counseling.

4. Once the client has chosen a contraceptive method, use the corresponding BCS+ method brochure to discuss contraindications to the chosen method. If there are none, review the rest of the brochure with the client to reinforce information about the method chosen and to respond to questions. This helps to ensure that the client understands the method. Give the brochure to the client. S/he can refer to it at home or use it to talk to her/his partner.

5. Use the counseling cards to discuss additional reproductive health services that the family planning client may need during and after s/he has selected a contraceptive method. These include counseling on postpartum health for the mother and infant, cervical cancer screening, breast cancer, adolescent needs, women's support and safety, post-abortion care, male services, STI/HIV transmission and prevention, Zika transmission and prevention, conducting a risk assessment, defining dual protection, and discussing and offering HIV counseling and testing.

6. For trainers, use the BCS + Trainer's Guide to familiarize health care staff with this new counseling approach and to build capacity to effectively use the BCS+. The exercises in the BCS+ Trainer's Guide can be given all together in a workshop and/or used separately during staff meetings or on-the-job training during supervisory visits.

7. The four BCS + job aids, BCS + User's Guide, and BCS+ Trainer's Guide are also available as electronic files on Population Council's website, at http://www.popcouncil.org/research/ the-balanced-counseling-strategy-plus-a-toolkit-for-family-planning-service. Adapt these materials for use in your region or country as needed. 


\section{Algorithm for Using the Balanced Counseling Strategy Plus}

\section{PRE-CHOICE STAGE}

(1) Establish and maintain a warm, cordial relationship.

(2) Inform client (and partner, if present) that there will be opportunities to address both health needs and family planning needs during this consultation.

(3) Ask client about current family size and current contraceptive practices. Counsel client on Healthy Timing and Spacing of Pregnancy using counseling card.

a) If client is currently using a family planning method or delaying pregnancy, ask about her/his satisfaction with it and interest in continuing or changing the method.

b) If partner is present, use the male services and support card.

(4) Rule out pregnancy using the Checklist to Make Reasonably Sure a Woman is not Pregnant card to be reasonably sure the woman is not pregnant.

(5) Display all of the method cards. Ask client if she/he wants a particular method.

6 Ask all of the following questions. Set aside method cards based on the client's responses.

a) Do you wish to have children in the future?

If "Yes," set aside vasectomy and tubal ligation cards. Explain Why.

If "No," keep all cards and continue.

b) Have you given birth in the last 48 hours?

If "Yes," set aside combined oral contraceptives (the Pill) and combined injectables. Explain why.

If "No," continue with the next question.

c) Are you breastfeeding an infant less than 6 months old?

If "Yes," set aside the combined oral contraceptives (the Pill) and combined injectable cards.

Explain why.

If "No," or she has begun her monthly bleeding again, set aside the lactational amenorrhea (LAM) card. Explain why.

d) Does your partner support you in family planning?

If "Yes," continue with the next question

If "No," set aside the following cards: female condom, male condom, Standard Days Method@, Two Days Method C, and withdrawal. Explain why.

e) Do you have any medical conditions? Are you taking any medications?

If "Yes," ask further about which conditions or medications. Refer to WHO Medical Eligibility Criteria

Wheel or current national guidelines and set aside all contraindicated method cards. Explain why.

If "No," keep all the cards and continue.

f) Are there any methods that you do not want to use or have not tolerated in the past?

If "Yes," set aside the cards the client does not want.

If "No," keep the rest of the cards.

\section{METHOD CHOICE STAGE}

(7) Briefly review the methods that have not been set aside and indicate their effectiveness.

a) Arrange the remaining cards in order of effectiveness (see back of each card).

b) In order of effectiveness (highly effective to not effective), briefly review the attributes on each method card.

(8) Ask the client to choose the method that is most convenient for her/him.

a) If client is adolescent use the counseling card to inform her that she can get any method

(9) Using the method-specific brochure, check whether the client has any condition for which the method is not advised.

a) Review "Method not advised if you..." section in the brochure

b) If the method is not advisable, ask the client to select another method from the cards that remain.

Repeat the process from Step 8. 


\section{POST-CHOICE STAGE}

(10) Discuss the method chosen with the client, using the method-specific brochure as a counseling tool. Determine the client's comprehension and reinforce key information.

(11) Make sure the client has made a definite decision. Give her/him the method chosen, a referral, and a back-up method depending on the method selected.

(12) Encourage the client to involve partner(s) in decisions about/practice of contraception through discussion or a visit to the clinic.

П SYSTEMATIC SCREENING FOR OTHER SERVICES STAGE

(13) Using information collected previously, determine client's need for postpartum, newborn, infant care, well-child services or post abortion care.

a) If client reported giving birth recently, review the Promoting Healthy Postpartum Period and Promoting Newborn and Infant Health card with client. Provide or refer for services, if needed.

b) For clients with children less than 5 years of age, ask if children have been taken to well-child services. Provide or refer for immunizations and growth monitoring services, if needed.

c) If client reported a recent abortion, review the Post Abortion Care card with the client. Provide or refer post abortion care services, if needed.

14. Ask client when she had her last screening for cervical cancer (VIA/VILI or pap smear) or breast cancer.

a) If her last Cervical Cancer screening was more than 3 years ago ( $* 6-12$ months if she is HIV positive) or she doesn't know, ask if she would like to have a screening today. Review the Screening for Cervical Cancer card. Provide or refer for services.

b) If her last Cervical Cancer screening was less than 3 years ago continue with next question.

c) Review Breast Cancer Information and Awareness counseling card with client.

15. Discuss STI/HIV Transmission \& Prevention and Dual Protection counseling cards with client. Offer condoms and instructions on correct and consistent use.

a) In regions with active Zika virus, discuss Zika Transmission \& Prevention counseling card with client.

(16) Conduct STI and HIV risk assessment using the counseling card. If symptoms are identified, treat her/him syndromically.

(17) Ask client whether s/he knows her/his HIV status.

a) If client knows $s /$ he is living with HIV,

- Review Positive Health, Dignity, \& Prevention counseling card with client.

- Refer client to center for wellness care and treatment.

b) If client knows $s /$ he is HIV negative,

- Discuss a time frame for repeat testing.

c) If client does not know her/his status,

- Discuss HIV Counseling and Testing (HCT) with client, using counseling card.

- Offer or initiate testing with client, according to national protocols.

- Counsel client on test results. If client is living with HIV, review Positive Health, Dignity, \& Prevention counseling card and refer client to center for wellness care and treatment.

d) Counsel client using Women's Support \& Safety Card.

- If client shows any major Intimate Partner Violence (IPV) triggers, refer her for specialized services.

18 Give follow-up instructions, a condom brochure, and the brochure for the method chosen. Set a date for next visit.

(19) Thank her/him for the visit. Complete the counseling session. 


\section{Guide to Counseling Clients Using the BCS+ Toolkit}

\section{Pre-Choice Stage}

During this stage, the provider creates the necessary conditions to help the client select a method.

STEP 1. ESTABLISH AND MAINTAIN A WARM, CORDIAL RELATIONSHIP.

- Establish a formal but friendly manner.

- Call the client by her/his name.

- Demonstrate interest in what the client tells you.

- Establish eye contact with the client.

- Listen to and answer her/his questions.

- Show support and understanding without judgment.

- Ask questions to encourage participation in the discussion.

STEP 2. INFORM CLIENT THAT (AND PARTNER, IF PRESENT) THERE WILL BE AN OPPORTUNITY TO ADDRESS BOTH HEALTH NEEDS AND FAMILY PLANNING NEEDS DURING THIS CONSULTATION.

- Inform client of other services available at your facility or available through referral.

- Inquire and take note of other services she/he may be interested in receiving.

- Ask whether the client would like a family planning method.

\section{STEP 3. ASK CLIENT ABOUT CURRENT FAMILY SIZE, DESIRE TO HAVE MORE CHILDREN, AND CURRENT CONTRACEPTIVE PRACTICES. COUNSEL THE CLIENT ON HEALTHY TIMING AND SPACING OF PREGNANCY USING COUNSELING CARD.}

- Ask client how many children she/he has.

- Ask client how many children she/he and her (his) partner wants.

- Ask about client's current use of contraception.

- If client is currently using contraception or is delaying pregnancy, ask about her/his satisfaction with it, and interest in continuing or changing the method.

- Using the counseling card, explain the following points with the client:

For women who desire to have more children after a live birth, advise

For women who decide to have a child after a miscarriage or abortion, advise

For adolescents, advise
- For the health of the mother and her baby, wait at least 2 years (24 months) but not more than 5 years before trying to become pregnant again.

- Use of a family planning method of her choice allows her to plan for a healthy pregnancy.

- For the health of the mother and her baby, wait at least 6 months before trying to become pregnant again.

- Use of a family planning method of her choice allows her to plan for a healthy pregnancy.

- For the health of the mother and her baby, wait until at least 18 years of age before trying to become pregnant.

- If she is sexually active, use of a family planning method of her choice allows her to prevent unintended pregnancy.

- If client's partner is present, counsel using the Male Services \& Support card. 


\section{STEP 4. RULE OUT PREGNANCY USING THE PREGNANCY CHECKLIST CARD WITH 6 QUESTIONS.}

Pregnancy is a contraindication for the use of most family planning methods, except barrier methods such as condoms. It is important to rule out the possibility of the client being pregnant, which can be done by asking the 6 questions on the pregnancy checklist card.

\section{Checklist to be reasonably sure a woman is not pregnant:}

- Did you have a baby less than 6 months ago? If so, are you fully or nearly fully breastfeeding? Have you had no monthly menstrual bleeding since giving birth?

- Have you abstained from unprotected sex (no method of family planning) since your last menstrual bleeding or delivery?

- Have you given birth during the last 4 weeks?

- Did your last menstrual bleeding start within the past 7 days (or within 12 days if you plan to use an intrauterine device (IUD)?

- Have you had a miscarriage or abortion in the last 7 days?

- Have you been using a reliable contraceptive method consistently and correctly?

Rule out pregnancy using the table below.

If the client...
"Yes" to any of the questions and is free of
signs and symptoms of pregnancy
*Once the client has answered yes to one
of the questions, it is not necessary to
continue asking the remaining questions

"No" to all of the questions

\section{Then...}

1.Pregnancy if unlikely.

2.Continue to Step 5.

\section{Pregnancy cannot be ruled out.}

2. Give client pregnancy test if available, or refer her to an antenatal clinic.

3. Provide her with a back-up method, such as condoms, to use until she has her menstrual bleeding.

4.Provide in advance her preferred method (where possible) to use on the 1st day of her menses OR request that she return at that point to receive her preferred method.

5. Go to Step 13.

\section{STEP 5. DISPLAY ALL OF THE METHOD CARDS. ASK CLIENT IF SHE/HE WANTS A PARTICULAR METHOD.}

1. Display all the method cards on a desk or table, grouped by method type (temporary, fertility awareness, permanent) as shown in Figure 1 below.

2. Each card has information about a different family planning method.

3. Ask whether the client has a particular method in mind.

\begin{tabular}{|c|c|}
\hline If the client... & Do this... \\
\hline Answers "no" & Continue to Step 6 \\
\hline Answers “yes" & $\begin{array}{l}\text { 1.Ask which method s/he wants. } \\
\text { 2.Ask what the client knows about the method. } \\
\text { 3.If the information is correct, go to Step } 9 \text {. }\end{array}$ \\
\hline $\begin{array}{l}\text { Gives incomplete information about the } \\
\text { method } \mathrm{s} / \text { he has chosen } \\
\text { OR } \\
\text { Does not know other alternatives that } \\
\text { might be more convenient }\end{array}$ & $\begin{array}{l}\text { 1. Correct any misinformation. } \\
\text { 2.If necessary, go to Step } 6 \text { to help the client choose a } \\
\text { method. }\end{array}$ \\
\hline
\end{tabular}



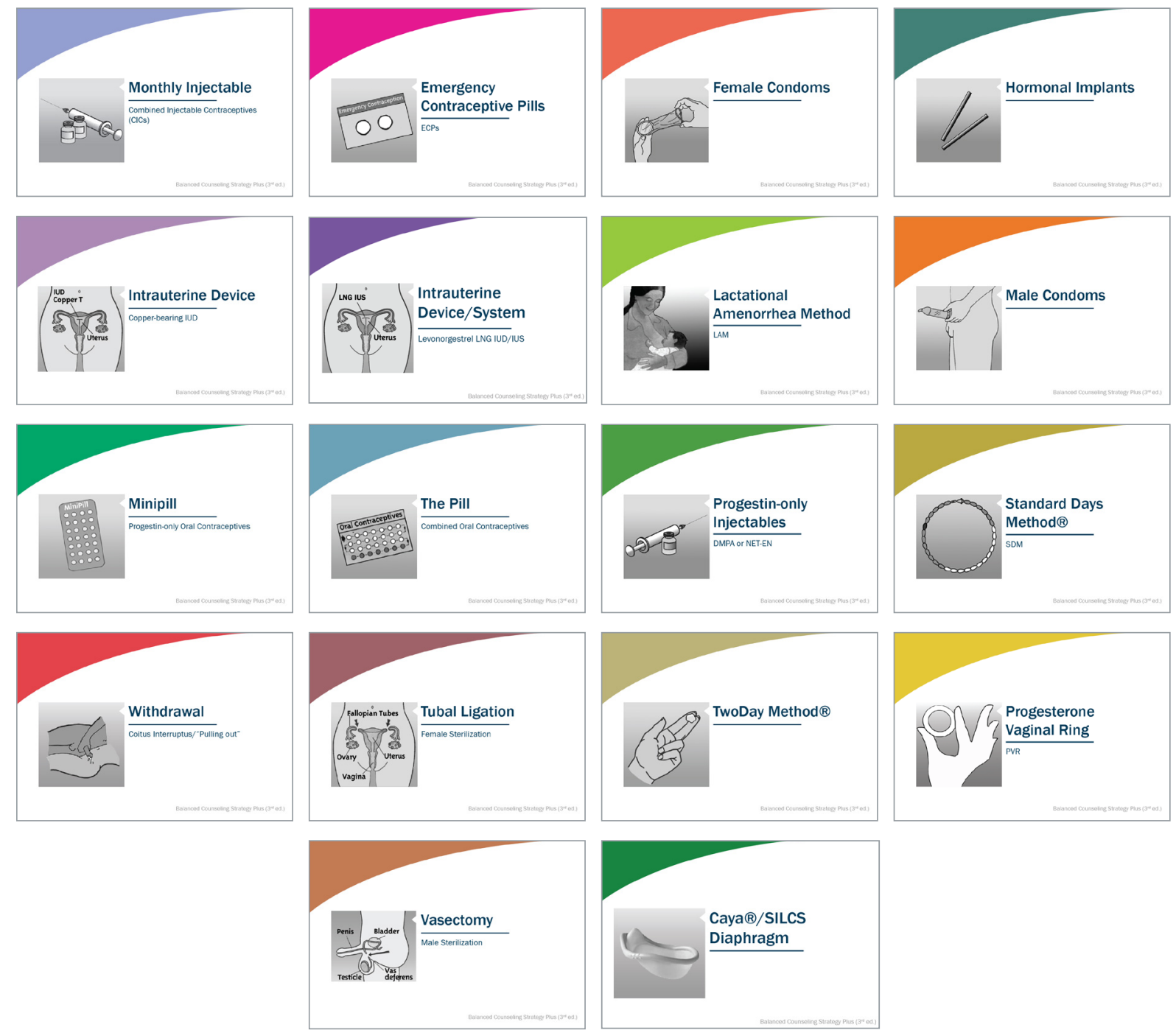

\section{STEP 6. ASK ALL OF THE FOLLOWING QUESTIONS. SET ASIDE METHOD CARDS BASED ON THE CLIENT'S RESPONSES.}

1. Using the display of method cards, begin the process by saying something like, "Now we are going to discuss your contraceptive needs. We will narrow down the number of methods that might be best for you. Then, I will discuss the key features of each method with you. This will help us to find the right method for your needs."

2. Ask the 6 questions below. Based on the client's responses, set aside the method cards that do not suit her/his needs.

a. Do you wish to have children in the future?

\begin{tabular}{l|l}
\hline If the client... & Do this... \\
\hline Answers "yes" & $\begin{array}{l}\text { 1. Set aside the vasectomy and tubal ligation cards. } \\
\text { 2. Explain that sterilization is permanent and not suitable for } \\
\text { someone who thinks s/he might want to have another child. }\end{array}$ \\
\hline Answers "no" & Keep all cards and continue
\end{tabular}


b. Have you given birth in the last 48 hours?

\begin{tabular}{l|l}
\hline If the client... & Do this... \\
\hline Answers "yes" & $\begin{array}{l}\text { 1.Set aside combined oral contraceptives (the Pill), monthly } \\
\text { injectable, implants, and tubal ligation cards. } \\
\text { 2. Explain that combined hormonal methods and tubal } \\
\text { ligation are not safe for women to use immediately after } \\
\text { giving birth. }\end{array}$ \\
\hline Answers "no" & Keep all cards and continue \\
\hline
\end{tabular}

c. Are you breastfeeding an infant less than 6 months old?

\begin{tabular}{l|l}
\hline If the client... & Do this... \\
\hline Answers "yes" & $\begin{array}{l}\text { 1.Set aside the combined oral contraceptives (the Pill) and } \\
\text { combined injectable contraceptive (CIC) cards. } \\
\text { 2. Explain that the hormones in these methods affect breast- } \\
\text { feeding. }\end{array}$ \\
\hline Answers "no" & $\begin{array}{l}\text { 1.Set aside the combined oral contraceptives (the Pill) and } \\
\text { combined injectable contraceptive (CIC) cards. }\end{array}$ \\
& 2. Explain that the hormones in these methods affect breast- \\
feeding.
\end{tabular}

d. Does your partner support you in family planning?

\begin{tabular}{|c|c|}
\hline If the client... & Do this... \\
\hline Answers “yes" & Continue with the next question \\
\hline Answers “no” & $\begin{array}{l}\text { 1.Set aside female condom, male condom, Standard Days } \\
\text { Method } ₫ \text {, TwoDay® Method, and withdrawal cards. } \\
\text { 2. Explain that these methods require partner cooperation. }\end{array}$ \\
\hline
\end{tabular}

3. Invite the client to bring her/his partner to a counseling session to discuss family planning with a provider.

4. Point out that male and female condoms are important for protecting against STIs, including HIV.

5. Continue with the next question.

e. Do you have any medical conditions? Are you taking any medications?

\begin{tabular}{l|l} 
If the client... & Do this... \\
\hline & $\begin{array}{l}\text { 1.Ask further about which medical conditions the client has } \\
\text { or medications she/he is taking. } \\
\text { 2. Refer to the WHO Medical Eligibility Criteria Wheel (includ- } \\
\text { ed), or current national guidelines, to identify contraindi- } \\
\text { cated methods. } \\
\text { 3.Set aside all contraindicated method cards. } \\
\text { 4. Explain to client the reason for setting aside method } \\
\text { cards, according to information provided in guidelines. }\end{array}$ \\
\hline Answers "no" & Continue with next question
\end{tabular}




\section{NOTE}

The Medical Eligibility Criteria Wheel is a provider job aid guiding providers through client's eligibility for contraceptive use according to medical conditions the client may have. The wheel includes two discs stacked upon one another; the outer disc lists medical conditions around its outside and the inner disc identifies eligibility for particular methods. By rotating and lining up the two discs according to a particular condition, the provider can interpret the appropriateness of the desired method according to four eligibility categories (1 through 4). Further instruction on the MEC Wheel is available on its reverse side.

f. Are there any methods that you do not want to use or have not tolerated in the past?

\begin{tabular}{|l|l|}
\hline If the client... & Do this... \\
\hline Answers "yes" & $\begin{array}{l}\text { 1.Ask which methods s/he has used and her/his experience } \\
\text { with each. } \\
\text { 2.Set aside the cards for the methods the client does not } \\
\text { want. }\end{array}$ \\
\hline Answers "no" & Keep the rest of the cards \\
\hline $\begin{array}{l}\text { The client has eliminated a method be- } \\
\text { cause of rumors or false information. }\end{array}$ & $\begin{array}{l}\text { 1.Provide the correct information. } \\
\text { 2.Do not set aside the card for that method. }\end{array}$ \\
\hline
\end{tabular}

6. If certain methods, such as the IUD, implants, tubal ligation, or vasectomy, are never offerred at your health care facility, still talk to the clients bout these methods, and provide a referral to another facility if selected. 


\section{Method Choice Stage}

\section{STEP 7. BRIEFLY REVIEW THE METHODS THAT HAVE NOT BEEN SET ASIDE AND INDICATE THEIR EFFECTIVENESS.}

1. Arrange the remaining method cards that have not been set aside on your desk or table according to their level of effectiveness. See Figure 2 below.

\section{FIGURE 2. METHOD CARDS ARRANGED ACCORDING TO EFFECTIVENESS}

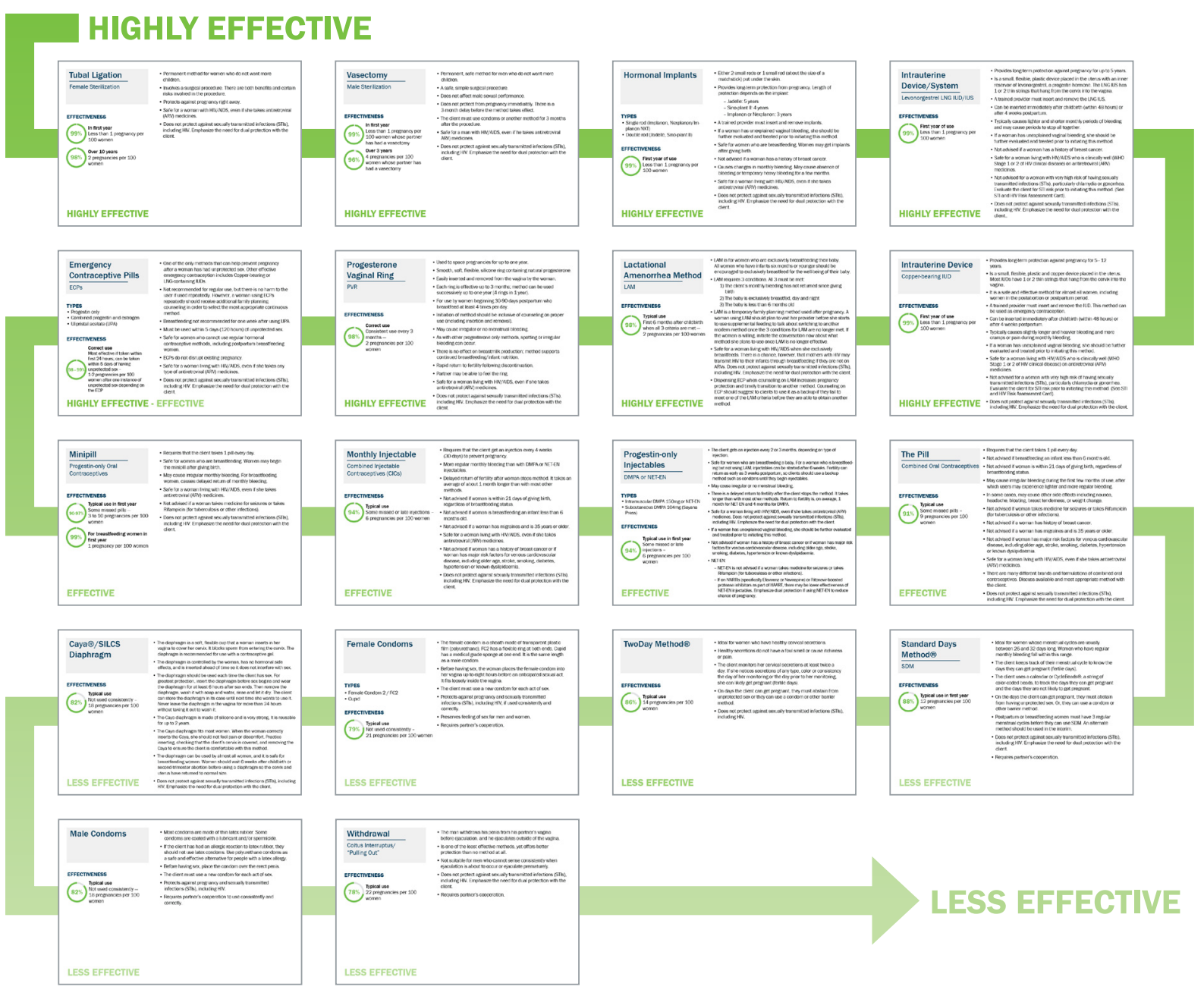

2. Display them with the lowest percentages first and the highest percentages last. (The percentage is on the left-hand side of the back of the card and indicates the effectiveness of the method. The effectiveness of the method is also indicated by the green word in the bottom-left corner of the card: "highly effective," "effective," or "less effective.")

3. Explain the effectiveness of the methods. Effectiveness is measured as the number of pregnancies among 100 women in the first year of use. The higher the percentage, the more effective the method and the fewer women get pregnant using the method. See Figure 3 for example. 


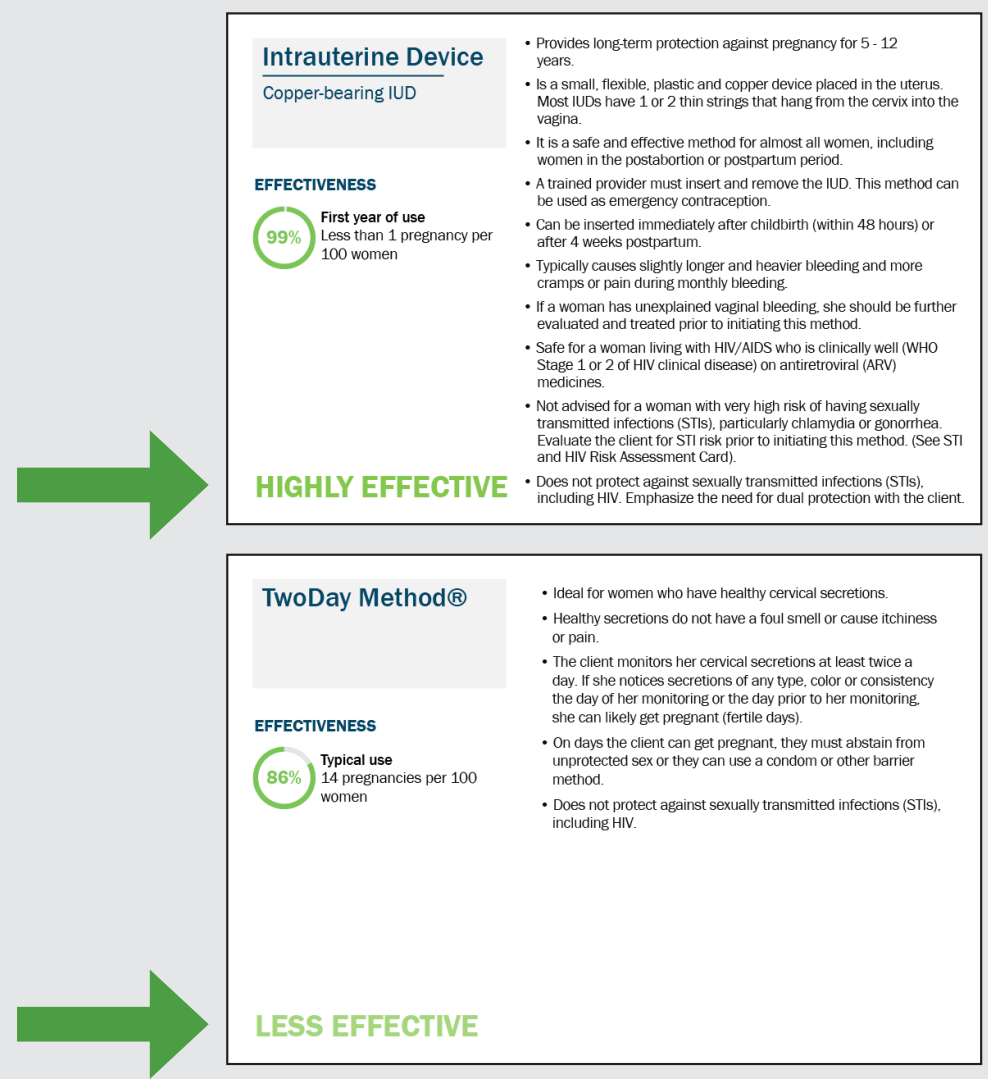

4. Begin with the card with the highest percentage. Read the key features of each method written on the cards displayed. You may also ask the client to read these attributes her/himself.

5. Explain that the condom (male and female) is the only method that provides dual protection against pregnancy and STIs, including HIV. Emphasize the following:

- Male and female condoms significantly reduce the risk of infection with STIs, including HIV, when used correctly and consistently with every act of sex.

- When used consistently and correctly, condom use prevents 80 percent to 95 percent of HIV transmission that would have occurred without condoms.

- Condoms reduce the risk of becoming infected with many STIs when used consistently and correctly:

- Protect best against spread of STIs by discharge, such as HIV, gonorrhea, and chlamydia.

- Also protect against spread of STIs from skin-to-skin contact, such as herpes and human papillomavirus (HPV).

\section{STEP 8. ASK THE CLIENT TO CHOOSE THE METHOD THAT IS MOST CONVENIENT FOR HER/HIM.}

1. If the client is an adolescent use the Adolescent Counseling card to inform her that she can get any method.

2. Ask the client whether $\mathrm{s} /$ he has any questions or comments about the methods discussed. Respond to any questions. Resolve any doubts before proceeding.

3. Ask the client to choose a method that is most convenient for her $/ \mathrm{him}$.

4. If the client asks that you choose the method, explain that $\mathrm{s} / \mathrm{he}$ is the only person who knows her/his needs. You may give recommendations about a method, but allow the client to make the final choice. 
5. Once the client selects a method, do not take the remaining method cards off the table. You may need to return to them if the method chosen is not advised or the client changes her/ his mind.

6. If the client does not like any of the methods discussed or cannot make up her/his mind, give the client a back-up method, such as condoms, to use until s/he decides on a method of choice. Condoms can provide dual protection against pregnancy and STIs until the client has another or an additional method. Go to Step 13.

\section{STEP 9. USING THE METHOD-SPECIFIC BROCHURE, CHECK WHETHER THE CLIENT HAS ANY CONDITIONS FOR WHICH THE METHOD IS NOT ADVISED.}

1. Select the BCS+ method-specific brochure corresponding to the method chosen by the client.

2. Together with the client, review the section entitled, "Method not advised if you..." in the method brochure. This lists conditions when the method is not advised.

\section{For the Pill:}

Method not advised if you:

- Are breastfeeding an infant less than 6 months old.

- Are within 21 days of giving birth, regardless of breastfeeding status.

- Smoke cigarettes and are 35 years old or older.

- Have high blood pressure, 140/90 or higher.

- Have certain uncommon serious diseases of the heart or blood vessels. Discuss with your provider.

- Have severe liver conditions.

- Have blood clots, deep vein thrombosis, or pulmonary embolism, or are on anticoagulant therapy. Discuss with your provider.

- Have lupus.

- Have gall bladder disease, even if medically-treated. Discuss with your provider.

- Have breast cancer or a history of breast cancer.

- Have migraine headaches (a severe headache that does not go away with paracetamol) and are 35 years old or older.

- Have migraine aura (sometimes seeing a growing bright spot in one eye)

- Take medicine for seizures or take rifampicin (for tuberculosis or other infections).

- Take ritonavir-boosted protease inhibitors as part of HAART.

3. Using simple, clear language, ask probing questions to make sure that the client does not have any conditions for which the method is not advised.

4. Based on the client's response, decide whether to provide the method or return to a previous step.

\section{If the client...}

Has no conditions

Has any condition

Has any condition and reached this step from Step 5 (already had the method in mind)

\section{Do this...}

Go to Step 10

1. Explain the need to choose another method.

2. Return to Step 7.

1. Explain the need to choose another method.

2. Return to Step 6. 


\section{Post-Choice Stage}

STEP 10. DISCUSS THE METHOD CHOSEN WITH THE CLIENT, USING THE METHOD BROCHURE AS A COUNSELING TOOL. DETERMINE CLIENT'S COMPREHENSION AND REINFORCE KEY INFORMATION

1. Use the method brochure as a counseling tool to review all the information about the method chosen by the client. Begin by saying something like, "Mrs./Mr. (name), this brochure is for you to take home. Before you go, I would like to review the information with you."

2. Using clear, simple language review the information about the method presented in the brochure:

- General information (This is the same information as on each BCS+ method card.)

- How the method works

- Important facts about the method

- When the method is not advised

- Side effects

- Health benefits (if applicable)

- How to use

- Follow-up (if applicable)

- When to return to the health care facility

3. Make sure the client fully understands all aspects of the method s/he has chosen. Comprehension is key to healthy, effective use of the method.

4. Give the client the brochure. Encourage her/him to review the brochure again at home and when $\mathrm{s} /$ he needs to remember anything about the method.

5. Validate comprehension by asking the client to answer the following questions in her/his own words. (S/he may refer to the brochure.)

- How do you use the method you have chosen?

- What side effects might you experience with the method?

- Can the method protect you against getting an STI, including HIV?

- What are the signs indicating when you should return to the health care facility?

6. Assure the client that it is fine if $\mathrm{s} /$ he cannot remember all the details. Make sure the client can find the information in the brochure. (Note: If the client cannot read or has very low literacy skills, ask the client to identify a person at home who can read the information to her/him.)

7. If the client selects a method not available on site, then:

a. Still give client the brochure for the method chosen.

b. Refer the client to a facility or commercial outlet where s/he can obtain the method.

c. Provide client with an alternative, suitable method until s/he can obtain the method of choice.

8. If the client selects a method that is temporarily unavailable (out of stock), then:

a. Give the client a brochure for the method chosen.

b. Refer the client to a facility or commercial outlet where s/he can obtain the method.

c. Provide client with a back-up method until s/he can obtain the method of choice.

d. Ask the client to return when the method is in stock at your health care facility. 
STEP 11. MAKE SURE THE CLIENT HAS MADE A DEFINITE DECISION. GIVE HER/HIM THE METHOD CHOSEN AND/OR A REFERRAL, AND BACK-UP METHOD, DEPENDING ON THE METHOD SELECTED.

1. Ask the client whether her/his choice is definite. Make sure $s /$ he is happy with the choice of method.

\begin{tabular}{|c|c|}
\hline If the client is... & Do this... \\
\hline \multirow{3}{*}{ Happy with the method chosen } & $\begin{array}{l}\text { 1. Give her/him the method and brochure. } \\
\text { 2. If IUD, implant, tubal ligation, or vasectomy is chosen } \\
\text { and not available on site, give a referral for the proce- } \\
\text { dure, if needed. }\end{array}$ \\
\hline & $\begin{array}{l}\text { 3. If the client cannot immediately use the chosen meth- } \\
\text { od, provide a back-up method (e.g., condoms). Give } \\
\text { the BCS+ brochure on condoms. }\end{array}$ \\
\hline & $\begin{array}{l}\text { 4. Suggest that s/he may also abstain from sex until s/ } \\
\text { he obtains the method of choice. }\end{array}$ \\
\hline $\begin{array}{l}\text { Not happy with the method chosen and wish- } \\
\text { es to consider other options }\end{array}$ & $\begin{array}{l}\text { 1. Assure the client that it is fine to change her/his mind. } \\
\text { The client has a right to informed choice. } \\
\text { 2. Return to Step } 7 \text {. }\end{array}$ \\
\hline
\end{tabular}

2. Do not let the client leave empty-handed. If a method is not available, make sure the client has a back-up method (e.g., condoms), a referral, and the BCS+ brochure on condoms.

3. Give the client his/her method brochure.

\section{STEP 12. ENCOURAGE THE CLIENT TO INVOLVE PARTNER(S) IN DECISIONS ABOUT/ PRACTICE OF CONTRACEPTION THROUGH DISCUSSION OR A VISIT TO THE CLINIC.}

1. Encourage the client to discuss her/his contraceptive method with her/his partner.

2. Mention that this can help in the following manner:

- Your partner can remind you of the time to take your method, if taking a method regularly, and follow-up dates.

- You can negotiate condom use to prevent STI, including HIV and Zika.

- You can discuss your plans to have children, regardless of whether you are HIV positive or negative.

- You can discuss and help prevent mother to child transmission (PMTCT) of HIV during pregnancy.

- Your partner can support you if you need wellness and HIV services, including antiretroviral therapy. 


\section{Systematic Screening for Other Services Stage}

Use the fourteen (14) counseling cards to discuss additional information and provide additional counseling and services that the client may need.

\section{STEP 13. USING INFORMATION COLLECTED PREVIOUSLY, DETERMINE CLIENT'S NEED FOR POSTPARTUM, NEWBORN, INFANT CARE, WELL-CHILD SERVICES, OR POST ABORTION CARE.}

1. Consider information that the client has provided previously during the counseling session, including her responses to questions in Step 3 and Step 4.

2. If information was not revealed through previous questions, ask client the following two questions:

- Have you given birth recently?

- Do you have any children less than 5 years of age?

3. Use this information to determine whether the client needs additional information and counseling on postpartum, newborn, and infant care or a referral for well-child services.

4. If client has given birth recently (within the past 6 weeks), review the points below from the Promoting a Healthy Postpartum Period counseling card and provide instructed counseling and services.

\begin{tabular}{l|l}
\hline If the client has... & Do this... \\
\hline \multirow{2}{*}{ Given birth recently } & $\begin{array}{l}\text { 1.Review Promoting a Healthy Postpartum Period for the } \\
\text { Mother counseling card with client. } \\
\text { 2. Review Newborn and Infant Health counseling card } \\
\text { with client. }\end{array}$ \\
\hline 1.Ask if children have been taken to well-child services. \\
Children less than 5 years of age & 2.Ask if children have received all immunizations. \\
& 3.Ask if children have had their height and weight mon- \\
& itored. \\
& 4.Provide or refer to well-child services if needed.
\end{tabular}

- Ensure that the mother has support for the first few days after birth; encourage rest and sleep.

- Recommend a nutritious diet for the mother that includes plenty of fluids and micronutrients (including Vitamin A and iron).

- Discuss normal postpartum bleeding and lochia. Counsel on maternal danger signs, such as bleeding or vaginal discharge that has a foul smell.

- Discuss the need for four postnatal care visits: at 24-48 hours, 3 to 7 days, 4 to 6 weeks, and 4 to 6 months.

- Advise on maintaining personal hygiene, including care of perineum and breasts.

- Counsel on return to sexual activity, which should be whenever the mother feels ready and usually after lochia stops. Advise that she can become pregnant again even before her menses returns, if she is not using contraceptives.

- Counsel on postnatal depression, which may entail: crying easily; feeling tired, agitated, or irritable; lacking motivation; having difficulty sleeping; rejecting the baby.

5. If the client has given birth recently, review the points below from the Promoting Newborn and Infant Health counseling card and provide instructed counseling and services:

- Discuss careful hand washing to prevent infection prior to handling the baby and after changing diapers.

- Counsel the mother on newborn danger signs and when to seek care immediately. Dan- 
ger signs include: difficulty feeding and/or breathing; feeling too hot or too cold; being irritable for extended period of time.

- Discuss the importance of providing good ventilation and keeping the baby warm.

- Encourage exclusive breastfeeding for 6 months. Nothing else is necessary, not even water. Introduce complementary foods at 6 months and continue to breastfeed.

- For infants exposed to HIV:

- Advise mother to give infant anti-retroviral drugs (ARVs) daily while breastfeeding and continue for one week after cessation of breastfeeding (around one year) and advise mother to continue ARV per national protocols.

- Recommend that HIV-exposed infants be tested for HIV at 6 weeks and start co-trimoxazole prophylaxis (CTX).

- Link mother and infant to HIV clinic.

- Explain immunization schedule for infants using national or global guidelines, and include recommendation for Vitamin A at 6 months.

- Discuss the need to attend child-welfare clinic and the importance of receiving timely care and monitoring during the first five years of a child's life. The following services may be included in well-child services:

- Immunizations

- Growth monitoring

- Infant feeding support

- Vitamin A provision at 6 months

- Sick child services (including Integrated Management of Childhood Illnesses (IMCI))

6. If client reported a recent abortion, review the Post Abortion Care card with the client. Provide or refer for post abortion care services, if needed.

7. If not able counsel or provide services, refer her/him to the appropriate facility to receive this information and counseling.

\section{STEP 14. ASK CLIENT WHEN SHE HAD HER LAST SCREENING FOR CERVICAL CANCER (VIA/VILI OR PAP SMEAR) OR BREAST CANCER.}

1. Briefly inform the client about cervical cancer. Explain that cervical cancer:

- Results from uncontrolled, untreated growth of abnormal cells in the cervix.

- Is caused by a sexually-transmitted infection, the human papillomavirus (HPV).

- Takes 10 to 20 years to develop, so there is a long period of opportunity to detect and treat changes and growths before they cause cancer.

2. Explain to the client that screening for cervical cancer:

- Helps to detect any changes and precancerous growths before they become cancer.

- Is simple, quick, and generally not painful.

3. Ask client when she had her last screening for cervical cancer.

4. Review Breast Cancer Information and Awareness counseling card with client.

\section{If the client... \\ Had her last screening more than 3 years ago \\ OR \\ Does not know when her last screening was}

Had her last screening less than 3 years ago

\section{Do this...}

Provide Pap smear or VIA/VILI screening test

OR

Refer for Pap smear or VIA/VILI screening test at appropriate facility when test available

Advise client when to seek next screening 
1. Explain to the client that if $\mathrm{s} / \mathrm{he}$ is having unprotected sex, $\mathrm{s} / \mathrm{he}$ is at risk for getting an STI, including HIV.

2. Review the following points from the counseling card and assess the client's knowledge of STI/HIV.

- A person can become infected with STIs, including HIV, through unsafe or unprotected sexual activity.

- STIs are common. Zika is common in some areas.

- A person living with STIs (including HIV) may have no symptoms, may look healthy, and may not be aware that $\mathrm{s} /$ he is infected.

- Common STI symptoms include vaginal discharge, discharge from the penis, sores in the genital area, burning on urination for men, lower abdominal pain for women.

- Some STIs can be treated. To avoid re-infection, both partners must be treated.

- Risk of infection can be reduced by using a condom, limiting the number of sex partners, and delaying sex (adolescents).

- HIV is a sexually transmitted infection. HIV is transmitted through an exchange of bodily fluids such as semen, blood, breast milk, and during delivery.

- Knowing your HIV status protects you, your partner, and your family.

- Although HIV cannot be cured, early identification and treatment can allow a person to live a long, productive life and prevent his/her partner from becoming infected.

- Male circumcision reduces the risk of heterosexually acquired HIV infection in men by approximately $60 \%$ and should be one element of a comprehensive HIV-prevention package.

- Maternal transmission of HIV to the child can be substantially reduced by identifying women living with HIV and providing treatment or prophylactic ARV medicines during pregnancy.

3. Ask whether the client has any questions.

4. Explain to the client that dual protection is the simultaneous prevention of STIs and pregnancy.

5. Using the counseling card, review dual protection strategies with the client:

- Dual protection is the use of condoms consistently and correctly in combination with another family planning method. This provides added protection against pregnancy in case of condom failure.

- Use a male or female condom correctly and consistently with every act of sex. This one method protects against STIs and pregnancy.

- Engage only in safer sexual intimacy that prevents semen and vaginal fluids from coming in contact with each other's genitals or other vulnerable areas, such as the mouth and anus.

- Delay or avoid sexual activity, especially with a partner whose STI/HIV status is not known.

6. Ask whether the client has any questions.

7. Offer condoms. Ask whether the client knows how to use a condom.

8. Demonstrate use of the condom, if required. Ask the client to do a repeat demonstration.

9. Provide information about where the client can obtain condoms.

1 In regions with active Zika transmission/travelers to active Zika regions, also use the Zika counseling card. 


\section{STEP 16A. CONDUCT STI AND HIV RISK ASSESSMENT USING THE COUNSELING CARD. IF SYMPTOMS ARE IDENTIFIED, TREAT HER/HIM SYNDROMICALLY.}

1. Ask whether the client knows what puts her/his at risk for STIs/HIV.

2. Correct misinformation, fill in gaps, and answer any questions.

3. Using the counseling card, discuss the following risk assessment factors with the client:

- HIV status and HIV status of partner(s). If partner is positive, whether s/he is taking ARV medicines.

- Number of sexual partners, both current and in the past.

- Knowledge of partner's sexual practices and past partners.

- Knowledge of male partner's circumcision status.

- Past and present condom use (including perception of partner's attitude) and whether s/ he is aware that condoms protect against both STIs/HIV and pregnancy.

- Type of sex or sexual activities and behaviors (for example, mutual monogamy, whether partner has other sexual partners, oral sex, anal sex, dry sex, or use of detergents and/or spermicides).

- Home-life situation (for example, partner violence and social support).

- Use of PMTCT services during pregnancy, delivery, and breastfeeding.

4. If the client has STI symptoms, either treat her/him syndromically per national guidelines or refer her/him for tests, if available.

5. Help client make a plan to reduce risk. Strategies may include:

- Reducing the number of sexual partners.

- Using condoms (male or female) correctly and consistently with every act of sex. Condoms are the only method that protects against STIs, including HIV.

- Making condoms available to her/his partner and encourage their use correctly and consistently.

- Avoiding the use of unclean skin-cutting instruments and/or injection needles.

- Having any STI or cervical infection detected and treated immediately.

- Undergoing any procedures involving the genital tract in an aseptic environment.

- Practicing dual protection.

- Knowing your HIV status.

STEP 16B. IN REGIONS WITH ACTIVE TRANSMISSION/TRAVELERS TO ZIKA REGIONS, CONDUCT ZIKA RISK ASSESSMENT USING COUNSELLING CARD.

STEP 17. ASK CLIENT WHETHER SHE/HE KNOWS HER/HIS HIV STATUS.

1. Ask client whether $\mathrm{s} /$ he knows her/his HIV status.

\begin{tabular}{|c|c|}
\hline If the client has... & Do this... \\
\hline $\begin{array}{l}\text { Knows HIV status and is } \\
\text { living with HIV }\end{array}$ & $\begin{array}{l}\text { 1. Review Positive Health, Dignity, \& Prevention counseling card with client. } \\
\text { 2. Ask when the client last attended a health facility for her/his monitoring } \\
\text { visit. } \\
\text { 3. Refer client to center for wellness care and treatment, if necessary. }\end{array}$ \\
\hline $\begin{array}{l}\text { Knows HIV status and is } \\
\text { negative }\end{array}$ & 1. Discuss time frame for repeat testing. \\
\hline $\begin{array}{l}\text { Does not know her/his } \\
\text { status }\end{array}$ & $\begin{array}{l}\text { 1.Discuss HIV Counseling and Testing (HCT) with client, using counseling card. } \\
\text { 2. Offer or initiate HIV testing, according to national protocols. } \\
\text { 3. Counsel client on the test results. } \\
\text { 4. If client is living with HIV, review Positive Health, Dignity \& Prevention coun- } \\
\text { seling card and refer client to center for wellness care and treatment. }\end{array}$ \\
\hline
\end{tabular}


2. Gently inquire whether the client is willing to tell you her/his status

3. Inform the client that you will not share her/his status without consent.

If client knows her/his HIV status and is living with HIV:

1. Review the following points from the Positive Health, Dignity, \& Prevention card with client:

- People living with HIV should always use a condom correctly and consistently with their sexual partners.

- If a woman with HIV wants to get pregnant, the risk of her passing HIV to her newborn may be greatly reduced by taking antiretroviral (ARV) medicines and having a safe delivery. It is important to receive care at an antenatal care clinic and an HIV treatment center.

- People living with HIV need regular health checkups to see if they need ARV medicine, to evaluate how they are doing on ARV medicines, and to rule out other infections or illnesses.

- If client is taking ARV medicine, s/he should attend follow-up clinic visits as recommended by the provider. Visits may be more frequent when ARV medicines are initiated.

- The client should do her/his best to adhere to the medication regimen prescribed and should not share medications.

- Partners should get tested as well. The client can bring her/his partner in for counseling, to talk together, if this will help.

- If currently taking medications for tuberculosis, $\mathrm{s} /$ he should follow up with provider.

- Positive health results from taking care of oneself and being alert to health concerns that warrant attention, which may include physical and mental health issues as well as social support.

2. Provide support and counseling to client on issues around disclosure of HIV status. Encourage client to disclose her/his status to help them:

- Get support from client's spouse, family, and health center.

- Better plan and make appropriate decisions about HIV care and support and family matters.

- Get early access to medicine and support that keeps client healthy.

- Save an HIV-negative partner's and unborn child's life by not infecting them.

- Better negotiate condom use with client partner to prevent them her/his being infected.

- Avoid exposure to repeated infections that will compromise client's health.

3. Ask when the client last attended a health facility for her/his monitoring visit. Encourage client to follow all health and wellness recommendations.

4. Refer client to center for wellness care and treatment.

If client know her/his HIV status and is negative:

1. Discuss time frame for HIV retesting. Consider client's and risk assessment and sexual behaviors to decide the most appropriate frequency for HIV testing.

2. Refer to national guidelines and protocol to determine the appropriate time frame and recommendations for HIV retesting.

3. Emphasize to the client that prevention, early detection, and prompt management of STIs, including HIV, are beneficial to her/him, their partner and family, and the community at large.

\section{If client does not know her/his HIV status:}

1. Using the HIV Counseling and Testing card, discuss the following points with the client:

- Knowing your HIV status can help you make decisions about protecting yourself and your sexual partner(s).

- Testing permits people living with HIV to seek treatment so that they can live a full life. 
The test involves taking a small sample of blood. The test is free and available at clinics, hospitals, and HIV counseling and testing sites.

- Test results are kept confidential.

- When a person is first infected with HIV, it can take 3 or more months for the test to detect the infection. This is called the "window period" and is the reason why repeat testing is important.

- A positive test result means the person is infected with HIV and can transmit the virus to others.

- A negative test result can mean the person is not infected or that $\mathrm{s} / \mathrm{he}$ is in the "window period". Another test should be taken within 3 months. If the second test is still negative, the person is currently not living with HIV but can still become infected with HIV.

- HIV is a sexually transmitted infection (STI). It is important to ask your sexual partner(s) to be tested too.

2. Emphasize to the client that prevention, early detection, and prompt management of STIs, including HIV, are beneficial other/him, their partner and family, and the community at large.

3. Offer or initiate HIV testing, according to national protocols. If testing is not available, refer client to specialized HTC services.

4. Counsel client on results of HIV test.

- If test is positive, review Positive Health, Dignity, \& Prevention counseling card and refer client to center for wellness care and treatment.

\section{Counsel client using Women's Support and Safety Card}

1. If client shows any major Intimate Partner Violence (IPV) triggers, refer her for specialized services.

\section{STEP 18. GIVE FOLLOW-UP INSTRUCTIONS, A CONDOM BROCHURE, AND THE BROCHURE FOR THE} METHOD CHOSEN. SET A DATE FOR NEXT VISIT.

1. Summarize key points discussed about the contraceptive method chosen and about STI/ HIV and other services. Ask the client whether s/he has questions. Answer all questions

\section{NOTE}

In 2007, WHO and UNAIDS issued guidance on provider-initiated HIV testing and counseling (PITC) in health facilities to support increased uptake and improve access to HIV prevention, treatment and care. In order to increase uptake and improve access to HIV prevention, HIV counseling and testing (HTC) should be expanded in antenatal care, STI and TB clinics, and other clinical settings as well as through outreach for most at risk populations.

before proceeding.

2. Provide the client with follow-up instructions for the method chosen and the corresponding method brochure (if the client does not yet have one).

3. Give the client a brochure on condoms. Reiterate the fact that only condoms provide dual protection against both STIs, including HIV, and pregnancy.

4. Make sure the client has his/her method or back-up method/referral, as needed.

5. Reiterate the importance of seeking other recommended services and provide a proper referral to the client.

6. Fix a date for the next visit with the client. The purpose of the appointment may be to:

- Check on how the client is using the method.

- Provide a new supply of the method.

- Provide information and support needed for the client to continue using the method correctly and consistently, or to select another method.

- Bring the partner for further counseling on family planning and/or STI/HIV.

- Have an HIV test. 
7. Encourage the client to return to the facility any time s/he has a question or wishes to change methods.

8. To the extent possible, anticipate the client's future need

\section{REMEMBER}

A client has the right to change her/his reproductive goals and to stop using a family planning method if $\mathrm{s} /$ he wishes or when $\mathrm{s} / \mathrm{he}$ wants to have a child.

\section{EXAMPLE}

Explain to a client using the Pill that, if it is more convenient for her, she can get her supplies at a local pharmacy. Remind her that the pharmacy may have the 21-pill pack instead of the 28-pill pack. In this case, she will need to follow the instructions for use in the pill pack's brochure or package insert.

STEP 19. THANK HER/HIM FOR THE VISIT. COMPLETE THE COUNSELING SESSION.

1. As you end the session, remember to be warm and cordial. This attitude will encourage the client to feel welcome to return. 


\section{Guidelines for Adapting the BCS+ Job Aids}

The BCS+ job aids are generic and can be revised based on a region's or country's needs and norms. Below are guidelines for adapting the job aids.

1. Conduct a technical review of family planning and HCT norms and practices in your region or country. Below are some examples of the kinds of review that will help to give you appropriate information needed to adapt the BCS + and BCS + job aids to your needs.

a. Convene a meeting with representatives from the Ministry of Health and other experts on family planning and HCT to review the BCS+. Determine whether it needs to be adapted to include your country's norms and policies on family planning, integrated health services, and HCT.

b. Ask service providers with experience in counseling clients on family planning and HIV CT to review the BCS+ job aids for content.

c. If the job aids will accompany training, work with the trainers to define the desired competencies (skills) from the training to be incorporated into the job aid.

2. Decide whether there are regional or local issues that you would like to incorporate into the BCS+ strategy (e.g., accessibility of certain methods, vulnerability to HIV and STIs through early marriage, female genital mutilation/cutting, or practice of dry sex).

3. Based on the technical review and local norms of the country, revise the steps in the BCS+, as needed. If the BCS+ is revised, be sure to gather information to adjust the algorithm, counseling cards, and brochures accordingly.

4. Revise the BCS+ job aids based on the technical review. Below are simple guidelines for adapting the job aids:

a. Adhere to the existing format of the BCS+ job aids as much as possible. They are written using a very specific methodology that has been field-tested and proven to help providers effectively act on the instructions.

b. If adding/revising steps to the algorithm, write the steps using action verbs. For example,

- Ask the client whether she has had her monthly bleeding.

- Remind the client to take the pill every day at the same time.

c. Include any sub-steps needed to perform the step. Do not assume that the provider knows how to perform the desired step or task. Begin each sub-step with an action.

\section{EXAMPLE}

Step: Remind a client what to do if she misses taking the pill once.

Sub-steps:

- Take a pill as soon as possible.

- Continue taking pills as usual. (You may end up taking 2 pills at the same time or on the same day.)

d. If a service provider needs to make a decision as part of a step, make a decision table. A decision table has two columns. The first column (the "If" column) describes when to take action. The second column (the "Then" column) is used to describe what action to take. When writing the actions, use the cookbook instruction format of Step 1, Step 2, Step 3, etc. Begin all action steps with action verbs. For example:

\section{If the client is...}

Breastfeeding an infant less than 6 months old

Not breastfeeding an infant

\section{Do this..}

1. Set aside the Combined Oral Contraceptives (the Pill) card and explain that the hormones in the pills affect breastfeeding.

2.Discuss the option of the minipill.

1. Set aside the LAM card.

2. Explain that LAM is not appropriate for women who are not breastfeeding. 
e. If steps and sub-steps are sequential, number them. If the order of the steps is not important, use bullets instead of numbers.

\section{TIP}

Place information that is important, but not an actual step or sub-step, in a box.

5. Pretest (validate) the revised BCS + job aids.

a. Ask service providers experienced in family planning and HCT to use the revised job aids as they counsel several family planning clients.

b. Observe whether they follow the instructions in the job aids.

c. Note any actions the provider does not take (and that were in the job aid). After the counseling session, ask the provider why s/he did not take the described action. Be sure to explore the following:

- Whether s/he understood the step/task.

- Whether s/he disagrees with the step/sub-step and why.

- Whether the instructions were clear or confusing. If they were confusing, inquire how they could be made clearer.

d. Similarly, note any actions that the health worker added to the counseling session that are not in the job aids.

e. Ask why s/he added any extra steps not in the job aid. It is possible that the service provider added a step for clarity. If so, please add the step to the job aid. The idea is to describe the desired behavior of the service provider so she/he can accurately use the revised BCS+.

f. Revise any instructions based on pretests with several service providers.

g. Add or delete any steps/tasks or steps/sub-steps to enable the provider to carry out the BCS + most effectively.

6. Ask two to three less experienced service providers to use the revised BCS+ job aids and observe whether they were able to perform the tasks based on the instructions in the job aids.

7. Revise the job aids accordingly. Take into consideration any additional input service providers give you on how to improve the instructions.

8. If needed, translate revised job aids into the local language. Be sure to have another person reverse- translate them to make sure the meaning has not changed in the translation process.

9. Incorporate the use of the job aids into existing training, or develop a short course to show service providers how to use the job aids.

\section{IMPORTANT!}

A job aid should always be accompanied by training support. 
Askew, Ian. 2007. "Achieving synergies in prevention through linking sexual and reproductive Health and HIV services," in Donta, Balaiah et al. (eds.), Proceedings of the International Conference on Actions to Strengthen Linkages between Sexual and Reproductive Health and HIV/AIDS. Mumbai: Indian Society for the Study of Reproduction and Fertility and World Health Organization.

Central Bureau of Statistics (CBS) [Kenya], Ministry of Health (MOH) [Kenya], and ORC Macro. 2004. Kenya Demographic and Health Survey 2003. Calverton, Maryland: CBS, MOH, and ORC Macro.

Engenderhealth and Planned Parenthood Association of South Africa. 2001. Curriculum entitled: Men As Partners: A Program for Supplementing the Training of Life Skills Educators, 2nd Edition. New York: Engenderhealth and Planned Parenthood of South Africa. 2002.

Hatcher, R.A. et al. 2011. Contraceptive Technology. Twentieth Revised Edition. New York: Ardent Media.

León, Federico R. 1999. "Peru: Providers' compliance with quality of care norms," FRONTIERS Final Report. Washington, DC: Population Council.

León, Federico R. et al. 2001. "Length of counseling sessions and the amount of relevant information exchanged: A study in Peruvian clinics," International Family Planning Perspectives 27(1):28-33, 46.

León, Federico R. et al. 2003a. "Effects of IGSS's job aids-assisted balanced counseling algorithms on quality of care and client outcomes (Guatemala)," FRONTIERS Final Report. Washington, DC: Population Council.

León, Federico R. et al. 2003b. "Enhancing quality for clients: The Balanced Counseling Strategy," FRONTIERS Program Brief No. 3. Washington, DC: Population Council.

León, Federico R. et al. 2003c. "Testing balanced counseling to improve provider-client interaction in Guatemala's MOH clinics,” FRONTIERS Final Report. Washington, DC: Population Council.

León, Federico R. et al. 2004. "One-year client impacts of quality of care improvements achieved in Peru,” FRONTIERS Final Report. Washington, DC: Population Council.

León, Federico, Ricardo Vernon, Antonieta Martin, and Linda Bruce. 2008. The Balanced Counseling Strategy: A Toolkit for Family Planning Service Providers. Washington, DC: Population Council.

Liambila, Wilson et al. 2008. "Feasibility, effectiveness and cost of models of integrating counseling and testing for HIV within family planning services in Kenya," FRONTIERS Final Report. Washington, DC: Population Council.

Mullick, Saiqa, Mantshi Menziwa, Doctor Khoza, and Edwin Maroga. 2008. "Feasibility, effectiveness and cost of models of integrating counseling and testing for HIV within family planning services in North West Province, South Africa," FRONTIERS Final Report. Washington, DC: Population Council.

Stanback, J. et al. 1999. "Checklist for ruling out pregnancy among family-planning clients in primary care," Lancet 354(9178):566.

World Health Organization. 2003. Guidelines for the Management of Sexually Transmitted Infections. Geneva: WHO.

—. 2004. Medical Eligibility Criteria for Contraceptive Use, 3rd ed. Geneva: WHO. 
— . 2005. Sexually Transmitted and Other Reproductive Tract Infections: A Guide to Essential Practice. Geneva: WHO.

— . 2015. Medical Eligibility Criteria for Contraceptive Use. 5th ed. Geneva: WHO.

— . 2010. WHO Technical Consultation on Postpartum and Postnatal Care. Geneva: WHO.

— . 2016. Prevention and Transmission of Zika Virus: Interim Guidance. WHO /ZIKV /MOC/16. 1 Rev. 3

World Health Organization, Department of Reproductive Health and Research (WHO/RHR) and Johns Hopkins Bloomberg School of Public Health/Center for Communication Programs (JHU/CCP) INFO Project. 2011. Family Planning: A Global Handbook for Providers. Baltimore and Geneva: $\mathrm{JHU} / \mathrm{CCP}$ and WHO.

World Health Organization and Joint United Nations Programme on HIV/AIDS (UNAIDS). Guidance on Provider-Initiated HIV Testing and Counseling in Health Facilities. Geneva: WHO. 
The Population Council confronts critical health and development issues-from stopping the spread of HIV to improving reproductive health and ensuring that young people lead full and productive lives. Through biomedical, social science, and public health research in 50 countries, we work with our partners to deliver solutions that lead to more effective policies, programs, and technologies that improve lives around the world. Established in 1952 and headquartered in New York, the Council is a nongovernmental, nonprofit organization governed by an international board of trustees.

For additional information please contact:

Population Council

4301 Connecticut Ave., NW, Suite 280

Washington, DC 20008 USA

Telephone: (202) 237-9400

Facsimile: (202) 237-8410

E-mail: publications@popcouncil.org 
The Balanced Counseling Strategy Plus

A Toolkit for Family Planning Service Providers Working in High STI/HIV Prevalence Settings

\section{TRAINER'S GUIDE}

Third Edition, 2015 
(C) 2008, 2011, 2015 The Population Council, Inc.

The Population Council confronts critical health and development issues - from stopping the spread of HIV to improving reproductive health and ensuring that young people lead full and productive lives. Through biomedical, social science, and public health research in 50 countries, we work with our partners to deliver solutions that lead to more effective policies, programs, and technologies that improve lives around the world. Established in 1952 and headquartered in New York, the Council is a nongovernmental, nonprofit organization governed by an international board of trustees.

Any part of this publication may be photocopied without permission from the publisher provided that copies are distributed without charge and that full source citation is provided. The Population Council would appreciate receiving a copy of any materials in which the text is used.

Suggested citation: Population Council. 2015. Balanced Counseling Strategy Plus Trainer's Guide Third Edition, part of The Balanced Counseling Strategy Plus: A Toolkit for Family Planning Service Providers Working in High STI/HIV Prevalence Settings, Third Edition, Washington, DC.

Note: This publication is part of a larger publication titled The Balanced Counseling Strategy Plus: A Toolkit for Family Planning Service Providers Working in High STI/HIV Prevalence Settings. The Balanced Counseling Strategy Plus Toolkit includes the following:

- Algorithm

- Counseling cards

- Method brochures

- User's Guide

- Trainer's Guide

- WHO Medical Eligibility Criteria Wheel

If any part is missing, please contact the Population Council at publications@popcouncil.org. 


\section{Preface to Third Edition}

The Balanced Counseling Strategy Plus (BCS+) toolkit, developed and tested in Kenya (2005 to 2007) and South Africa (2004 to 2006) because both countries have high rates of STIs, including HIV, and their contraceptive prevalence rates are relatively high for the region. The BCS+ provides the information and materials that healthcare facility providers need so they can offer complete, high-quality family planning counseling to clients living in areas with high rates of HIV and STIs. The BCS+ was adapted from the Balanced Counseling Strategy (León 1999; León et al. 2003a, b, c; León, Vernon, Martin, and Bruce 2008). First edition of the Balanced Counseling Strategy and Balanced Counseling Strategy Plus toolkits are products of the Population Council's FRONTIERS program, supported by the United States Agency for International Development (USAID), Cooperative Agreement HRN-A-00-98-00012-00.

The Second Edition was updated based on the 2010 WHO Medical Eligibility Criteria (MEC) as well as recommendations from authors and partners who have experienced and evaluated implementation of the tool in settings and scenarios around the world and validated through the Integra Initiative, supported by the Bill and Melinda Gates Foundation. It included additional counseling cards on cervical cancer screening, postpartum and infant health.

This Third Edition of the BCS+ includes content updated according to the latest WHO Medical Eligibility Criteria (2015). It incorporates the most up-to-date evidence on clinical indications for the provision of family planning methods, including new methods $\left(\right.$ Caya ${ }^{\circledR} /$ SILCS diaphragm and Progesterone Vaginal Ring), and includes six new counseling cards that address Adolescent Counseling, Male Services, Post Abortion Care, and Women's Support and Safety, Breast Cancer Information and Awareness, and Zika Prevention and Treatment. The updated cards include instructions for providers, guiding them through supplemental counseling and services that family planning clients may need. Development of this Third Edition of the BCS+ toolkit was funded by the Evidence Project, USAID Cooperative agreement AID-OAA-A-13-00087 and the Bill and Melinda Gates Foundation supported Integra Initiative at the Population Council. 
Development of The Balanced Counseling Strategy Plus (BCS+) could not have been possible without the invaluable support of the service providers who tested the toolkit and the program directors who authorized and supervised its application. The authors wish to thank the Department of Health in South Africa and the Division of Reproductive Health and the National AIDS and STD Control Program of the Ministry of Health in Kenya. We would also like to thank the trainers at the Reproductive Health and HIV Research Unit (RHRU) of the University of Witwatersrand for their contribution to the study in South Africa.

Development and production of the third edition of The Balanced Counseling Strategy Plus was supported by the Population Council. Authors would like to acknowledge the following individuals for providing their technical expertise and invaluable contributions to this updated edition of the BCS+: Megan Christofield, Heather Clark, Mychelle Farmer, Kamlesh Giri, Joanne Gleason, Mark Hathaway, Anushka Kalyanpur, Maggie Kilbourne-Brook, Karen R. Kirk, Ricky Lu, Ruth Merkatz, Charity Ndigwa, Anne Pfitzer, Saumya RamaRao, Naomi Rijo, Elizabeth Rochette, Jill Schwartz, Leigh Stefanik, John Townsend, Chi-Chi Undie, Katie Unthank, Anneka Van Scoyoc, Charlotte Warren, Ellen Weiss, and Kelsey Wright. 


\section{贫 Contents}

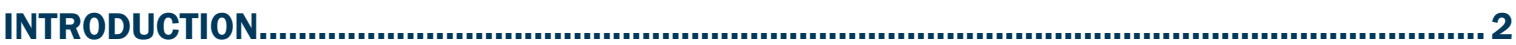

Algorithm for Using the Balanced Counseling Strategy Plus...............................................

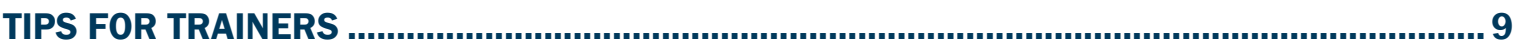

Sample Agenda: BCS+ Training …….......................................................................... 11

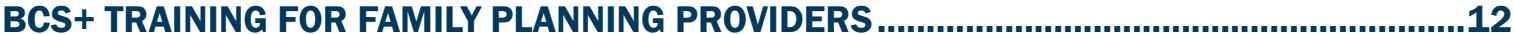

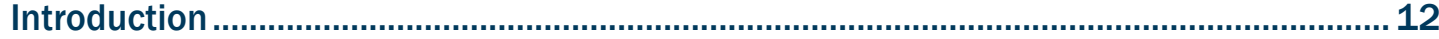

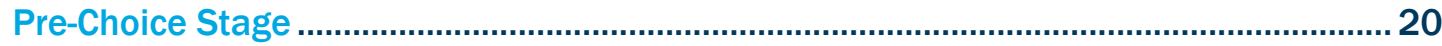

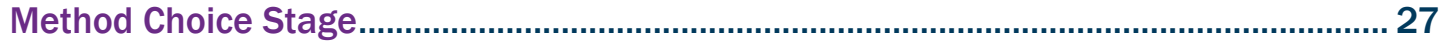

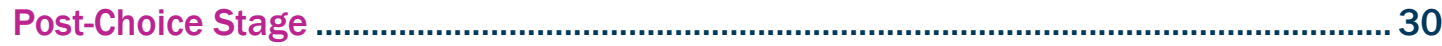

Systematic Screening for Other Services Stage ..................................................................... 33

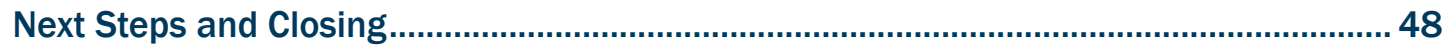

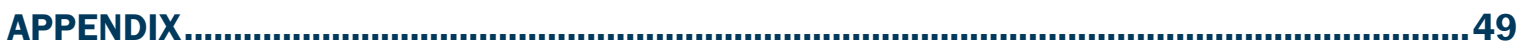

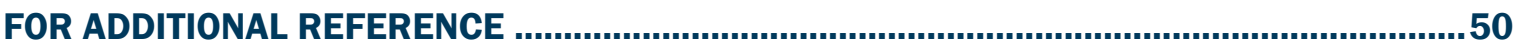

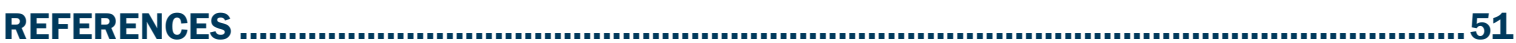


In the late 1990s, the Population Council's USAID-funded FRONTIERS in Reproductive Health Program (FRONTIERS) worked in collaboration with Ministries of Health in several Latin American countries to develop and test a practical, interactive, and client-friendly strategy for improving counseling within family planning consultations. This strategy is called the Balanced Counseling Strategy (BCS) (León 1999; León et al. 2004). The BCS uses key job aids for counseling clients about family planning: an algorithm to guide the provider through the counseling process, a set of counseling cards for contraceptive methods, and corresponding brochures for each method. The strategy, tested and refined in several countries, comprises a series of steps to determine the contraceptive method that best suits the client according to her/his preferences and needs. This strategy improves the quality of the provider's counseling and allows the client to take ownership of the decision.

The BCS proved effective as a tool to assist family planning providers to improve the quality of care (León et al. 2003a, b, c). The approach is practical, low cost, and easy to adapt to local contexts. The Balanced Counseling Strategy: A Toolkit for Family Planning Service Providers was published to provide the information and tools needed for health care facility managers, supervisors, and service providers to implement the BCS in their family planning services (León, Vernon, Martin, and Bruce 2008).

\section{WHY THE BALANCED COUNSELING STRATEGY PLUS?}

In response to the need to incorporate counseling, screening, and services for sexually transmitted infections (STIs), including HIV, within routine family planning consultations in settings characterized by high prevalence of these infections, the BCS was revised to integrate STI/HIV prevention counseling, risk assessment, and HIV counseling and testing (HCT). The resulting Balanced Counseling Strategy Plus (BCS+) toolkit improves the quality of the family planning service and enables providers to address clients' needs related to STIs and HIV during the same consultation.

Integration of health services has been defined as offering a range of services that can meet several needs simultaneously, usually in the same venue and through the same provider. Referrals to, or linkages with, related services enable a client to receive a range of needed services, even if the services are not received simultaneously (Askew 2007). In reproductive health, the push for integration or linkage is guided both by many clients having the need for several services simultaneously (and so missed opportunities can be reduced) and by the expectation that the component services can be provided more efficiently when integrated or linked than when delivered individually. Despite many calls for greater attention to integrating such services in high STI/HIV settings, surprisingly little attention has been paid to the development and empirical testing of practical tools that providers can use to strengthen their capacity to offer integrated services.

The FRONTIERS program developed and piloted the BCS+ in Kenya (2005 to 2007) and South Africa (2004 to 2006) because both countries have high rates of STIs, including HIV, and their contraceptive prevalence rates are relatively high for the region. This situation provides opportunities to reach a substantial proportion of the sexually active population (albeit predominantly female) that is seeking to prevent pregnancy and that also may be at risk of exposure to an STI/HIV. As in most countries, their family planning and STI/HIV programs are implemented separately, although both countries are actively seeking ways to integrate services. Thus, both Ministries of Health were keen to develop practical tools for increasing the quality of services and numbers of clients receiving integrated services.

The study findings are described more fully elsewhere (see Liambila et al. 2008; Mullick et al. 2008). Both studies showed that:

- Integrating STI/HIV prevention counseling and risk assessment with offering HCT during family planning consultations is feasible and acceptable to clients and providers. 
- The quality of care for both family planning and STI/HIV counseling improved significantly with the use of the BCS+ tools.

- Counseling on HCT increased substantially. In Kenya, more than 40 percent of clients were offered HCT services, with almost half of these deciding to be tested, either on site or through referral. In South Africa, those offered testing increased to 29 percent. Furthermore, an overall increase in testing was observed in the district with a doubling of individuals tested.

- Use of the BCS+ tools facilitated greater risk assessment for STIs and HIV. Also, decisions about contraceptive method choice were made with a better understanding of their relationship to infection prevention.

- Despite the concern that adding these services may have a negative impact on the family planning service, improved quality of counseling and no evidence of a decline in utilization showed that this concern was unfounded.

\section{THE BALANCED COUNSELING STRATEGY PLUS}

The BCS+ is divided into four counseling stages. Each stage contains a sequence of steps to follow. The BCS+ assumes that the motive of a client's visit is family planning but serves to also offer the client additional counseling and services in the same facility or through referral. The BCS+ integrates postpartum counseling messages to ensure health of the mother and the infant; an opportunity to discuss healthy timing and spacing of pregnancies; counseling on STI/HIV transmission and prevention; screening for reproductive cancers; violence prevention; post-abortion care; and male and adolescent services. Information on the cards instructs providers through conducting an STI/ HIV risk assessment, discussing dual protection and positive health, and discussing and offering the client HIV counseling and testing. The BCS+ process can be summarized as a decision-making algorithm, which is described on the next three pages. Below is a summary of the four counseling stages:

1. Pre-Choice Stage: During this stage, the provider creates the conditions that help a client select a family planning method. The provider cordially greets the client. The provider emphasizes to the client that, during the consultation, other reproductive health issues will be addressed depending on her/his individual circumstance. The provider reviews the client's fertility intentions and counsels her/him on healthy timing and spacing of pregnancy. Pregnancy is ruled out using the counseling card with the checklist of questions. If the client is not pregnant, the provider displays all the method cards and asks questions described in the algorithm. As the client responds to each question, the provider sets aside the cards of the methods that are not appropriate for the client. Setting aside these cards helps to avoid giving information on methods that are not relevant to the client's needs.

If pregnancy cannot be ruled out, the provider skips to steps 13 to 19 to discuss other relevant services the client may need. The client is given a back-up method, such as condoms, and asked to return when she has her menstruation.

2. Method Choice Stage: During this stage, the provider offers more extensive information about the methods that have not been set aside, including their effectiveness. This helps the client select a method suited to her/his reproductive needs. Following the steps in the BCS+ algorithm, the provider continues to narrow down the number of counseling method cards until a method is chosen.

3. Post-Choice Stage: During this stage, the provider uses the method brochure to give the client complete information about the method that $\mathrm{s} /$ he has chosen. If the client has conditions where the method is not advised or is not satisfied with the method, the provider returns to the Method Choice Stage to help the client select another method. The provider also encourages the client to involve her/his partner(s) in decisions about contraception, either through discussion or visit to the clinic.

4. Systematic Screening for Other Services Stage: During this stage, the provider uses information collected previously and targeted questions to determine additional health services and counseling that the family planning client may need. Using the remaining counseling 
cards, the provider may review important information for a postpartum mother or infant; may refer him/her to well-child services; discuss and offer cervical screening tests; discuss breast cancer; offer adolescent or male service counseling; discuss women's support and safety; offer post-abortion care as appropriate; discuss STI/HIV and Zika ${ }^{3}$ transmission and prevention; conduct a risk assessment; discuss dual protection and positive health; and offer the client HIV counseling and testing. The provider offers HIV testing to the client, following national protocols, and encourages the client to disclose her/his STI/HIV status to her/ his partner(s), letting the client know both the benefits and risks of disclosure. Upon completion of the counseling session, the provider gives follow-up instructions on the chosen contraceptive method, the method brochure, and a condom brochure. The provider and client also fix a date for a follow-up visit.

\section{WHAT IS INCLUDED IN THIS TOOLKIT?}

The BCS+ job aids and guides are intended for reproductive health programs interested in both strengthening the quality of family planning counseling and responding to the additional service and counseling needs of clients. In addition to adding further guidance on other integrated services, the second edition incorporated an additional job aid, the World Health Organization's Medical Eligibility Criteria Wheel, to complement existing provider tools and facilitate comprehensive family planning service provision. Below is a list of the toolkit components:

5. BCS+ User's Guide on how to implement the BCS+. It explains how to use the job aids and can be distributed during training on the BCS+ or used for self-teaching with the BCS+ job aids.

6. BCS+ job aids, including:

- The BCS+ algorithm that summarizes the 19 steps recommended to implement the BCS + during a family planning consultation. These steps are organized under four stages of the consultation: pre-choice needs assessment; method choice; post-choice actions; and systematic screening for other services. During each stage of the consultation, the provider is given step-by-step guidance on how to use the BCS+ job aids. Depending on the client's response to the issues discussed, the algorithm outlines which actions to take. The BCS + algorithm can be found on pages 7 to 8 as well as separately with the other job aids in the toolkit.

- Counseling cards that the provider uses during a counseling session. There are 34 counseling cards. The first card contains 6 questions that the service provider asks to rule out whether a client is pregnant (adopted from those developed by Stanback et al. 1999). There are 18 method-specific cards that contain information about each family planning method. Each method card has an illustration of the contraceptive method on the front side. The back of the card contains a list of key features of the method and describes the method's use, indications, risk factors, and level of effectiveness. These cards are used to first exclude those methods that are inappropriate for the client's reproductive intentions and then to narrow the choice to reach a final decision. Fifteen (15) counseling cards provide information on additional counseling and services that a family planning client may need. These are: healthy timing and spacing of pregnancies; promoting healthy postpartum period for the mother; post abortion care; promoting newborn and infant health; STI/HIV transmission and prevention; Zika transmission and prevention; STI/HIV risk assessment; positive health, dignity and prevention; dual protection; HIV counseling and testing; screening for cervical cancer; adolescent counseling; women's support and safety; male services; and breast cancer information and awareness. These cards are used during the fourth stage of the consultation-systematic screening for other services.

- Method brochures on each of the 18 contraceptive methods. They are designed to help the client better understand the method chosen. The provider gives the client the brochure for the selected method and a brochure with information on condoms to take

${ }^{3}$ and any other emergency infectious disease that may be transmitted sexually 
home. Providers should encourage low-literate or illiterate clients to take the brochure home so that their partner or other trusted friend can review the brochure with them again.

- WHO Medical Eligibility Criteria (MEC) Wheel (2015) which is a provider job aid based on the four eligibility categories for contraceptive use in relation to medical conditions described in the document Medical Eligibility Criteria for Contraceptive Use, Fifth edition, published by Department of Reproductive Health, World Health Organization. This tool guides providers through medical conditions and medications that may be contraindications to use of particular contraceptive methods. The job aid has been field-tested in three countries by $\mathrm{WHO}$, and is found to be very useful to providers who used it.

7. BCS+ Trainer's Guide that supervisors and others can use to train providers on how to use the BCS+. The guide includes exercises and activities to increase participants' comprehension and proper utilization of the BCS+ toolkit.

The BCS+ job aids, BCS+ Trainer's Guide, and BCS + User's Guide incorporate the latest international family planning and STI/HIV norms and guidance as recommended by the World Health Organization (WHO), including Medical Eligibility Criteria for Contraceptive Use (WHO 2015), Family Planning: A Global Handbook for Providers (WHO/RHR and JHU/CCP, INFO Project 2011 update), Contraceptive Technology (Hatcher et al. 2011), Sexually Transmitted and Other Reproductive Tract Infections: A Guide to Essential Practice (WHO 2005), and Guidelines for the Management of Sexually Transmitted Infections (WHO 2003).

These job aids can be revised depending on national and/or regional guidelines and protocols. Electronic copies of the BCS+ materials are available so that the job aids and instructional guides can be easily printed or adapted to meet local needs.

\section{HOW SHOULD THIS TOOLKIT BE USED?}

1. Read this entire BCS+ User's Guide on how to implement the Balanced Counseling Strategy Plus.

2. Refer to the BCS+ algorithm as a reminder of the 19 steps used to implement the BCS+. It is helpful to have a copy available on the provider's desk or on a wall in the consultation area so that the provider can refer to it easily.

3. Use the BCS + counseling cards and WHO MEC Wheel to help a client choose a method based on her/his reproductive intentions. Use the first counseling card to rule out whether the client is pregnant. If she is not, use the method cards to help the client choose a contraceptive method best suited to her/his reproductive health intentions by discarding those that are inappropriate. Emphasize dual protection throughout the counseling.

4. Once the client has chosen a contraceptive method, use the corresponding BCS+ method brochure to discuss contraindications to the chosen method. If there are none, review the rest of the brochure with the client to reinforce information about the method chosen and to respond to questions. This helps to ensure that the client understands the method. Give the brochure to the client. S/he can refer to it at home or use it to talk to her/his partner.

5. Use the counseling cards to discuss additional reproductive health services that the family planning client may need during and after s/he has selected a contraceptive method. These include counseling on postpartum health for the mother and infant, cervical cancer screening, breast cancer, adolescent needs, women's support and safety, post-abortion care, male services, STI/HIV transmission and prevention, Zika transmission and prevention, conducting a risk assessment, defining dual protection, and discussing and offering HIV counseling and testing.

6. For trainers, use the BCS + Trainer's Guide to familiarize health care staff with this new counseling approach and to build capacity to effectively use the BCS+. The exercises in the trainer's guide can be given all together in a workshop and/or used separately during staff meetings or on-the-job training during supervisory visits.

7. The four BCS+ job aids, BCS+User's Guide, and BCS+ Trainer's Guide are also available as electronic files on Population Council's website, at http://www.popcouncil.org/research/ 
the-balanced-counseling-strategy-plus-a-toolkit-for-family-planning-service. Adapt these materials for use in your region or country as needed.

\section{WHY IS TRAINING SERVICE PROVIDERS ON BCS+ IMPORTANT?}

\section{Poor provider compliance}

When the original BCS was developed in Peru, health care providers were given an initial two-day training (16 hours) and a one-day refresher course six months later. An assessment of the use of the BCS revealed that there were significant improvements in quality of care and improved client knowledge of certain methods when the providers used the job aids. Only 37 percent of the providers trained on how to use the BCS model and job aids actually used them to counsel clients. This was attributed to the shortness of the training and weaknesses in the implementation component of the BCS model (León et al. 2003b; León et al. 2001). Furthermore, the benefits for clients were less marked when the providers received less than the three-day training.

\section{Much improved provider compliance}

When the BCS was adapted for use in Guatemala, special emphasis was placed on the reinforcement of learning through supervision. The eight-hour training included at least three hours of role play and was followed by supervision and retraining. Eight weeks after the initial training, each provider was monitored at least twice a week while s/he counseled clients. The provider was observed during counseling and given feedback as soon as the client left. Three to four counseling sessions were observed during each visit to a provider. An assessment of the BCS in Guatemala showed that as a result of this more supportive training strategy, 70 percent of the service providers trained were using the job aids in their daily interactions with clients. Consequently, researchers found an improved quality of care among providers who used the BCS model (León et al. 2003a; León et al. 2003c).

\section{WHO SHOULD USE THE BCS+ TRAINER'S GUIDE?}

Midwives, supervisors, program managers, or anyone responsible for training health care providers can use this BCS+ Trainer's Guide. The trainer should be very familiar with using the BCS + User's Guide and BCS+ job aids.

\section{HOW SHOULD THE BCS+ TRAINING BE IMPLEMENTED?}

The BCS+ can be used as outlined in this manual or introduced in more extensive training on family planning. For example, in Kenya, training on the BCS+ was offered as part of a longer training session for family planning providers (degree nurses, registered nurses, and enrolled nurses). Any training on BCS+ should be followed up with periodic refresher training and/or on-the-job training during supervisory visits.

The BCS+ User's Guide is designed to reinforce training and serve as a reminder of the steps needed to implement the BCS+ model for counseling family planning clients. For optimal implementation of the BCS+ strategy in family planning services, providers should receive the entire training and subsequent refresher training.

The exercises in this BCS+ Trainer's Guide can be given all together in a workshop, used separately during staff meetings or on-the-job training during supervisory visits, or incorporated into a larger training program. Trainers are encouraged to adapt any of the exercises in this module and/or add other exercises that are helpful for enabling providers to effectively use the BCS + during family planning consultations. Be sure to allow for sufficient practice time. The importance of repetition for mastering any new skill or methodology cannot be emphasized enough. The success of the BCS + lies in the provider's ability to use the BCS+ job aids. Thus, practice should be a priority during any training or supervisory event. 


\section{Algorithm for Using the Balanced Counseling Strategy Plus}

\section{PRE-CHOICE STAGE}

(1) Establish and maintain a warm, cordial relationship.

(2) Inform client (and partner, if present) that there will be opportunities to address both health needs and family planning needs during this consultation.

(3) Ask client about current family size and current contraceptive practices. Counsel client on Healthy Timing and Spacing of Pregnancy using counseling card.

a) If client is currently using a family planning method or delaying pregnancy, ask about her/his satisfaction with it and interest in continuing or changing the method.

b) If partner is present, use the male services and support card.

(4) Rule out pregnancy using the Checklist to Make Reasonably Sure a Woman is not Pregnant card to be reasonably sure the woman is not pregnant.

5 Display all of the method cards. Ask client if she/he wants a particular method.

6) Ask all of the following questions. Set aside method cards based on the client's responses.

a) Do you wish to have children in the future?

If "Yes," set aside vasectomy and tubal ligation cards. Explain Why.

If "No," keep all cards and continue.

b) Have you given birth in the last 48 hours?

If "Yes," set aside combined oral contraceptives (the Pill) and combined injectables. Explain why.

If "No," continue with the next question.

c) Are you breastfeeding an infant less than 6 months old?

If "Yes," set aside the combined oral contraceptives (the Pill) and combined injectable cards. Explain why.

If "No," or she has begun her monthly bleeding again, set aside the lactational amenorrhea (LAM)

card. Explain why.

d) Does your partner support you in family planning?

If "Yes," continue with the next question

If "No," set aside the following cards: female condom, male condom, Standard Days Method(), Two

Days Method@, and withdrawal. Explain why.

e) Do you have any medical conditions? Are you taking any medications?

If "Yes," ask further about which conditions or medications. Refer to WHO Medical Eligibility Criteria

Wheel or current national guidelines and set aside all contraindicated method cards. Explain why.

If "No," keep all the cards and continue.

f) Are there any methods that you do not want to use or have not tolerated in the past?

If "Yes," set aside the cards the client does not want.

If "No," keep the rest of the cards.

\section{METHOD CHOICE STAGE}

(7) Briefly review the methods that have not been set aside and indicate their effectiveness.

a) Arrange the remaining cards in order of effectiveness (see back of each card).

b) In order of effectiveness (highly effective to not effective), briefly review the attributes on each method card.

(8) Ask the client to choose the method that is most convenient for her/him.

a) If client is adolescent use the counseling card to inform her that she can get any method

(9) Using the method-specific brochure, check whether the client has any condition for which the method is not advised.

a) Review "Method not advised if you..." section in the brochure

b) If the method is not advisable, ask the client to select another method from the cards that remain. Repeat the process from Step 8. 


\section{POST-CHOICE STAGE}

(10) Discuss the method chosen with the client, using the method-specific brochure as a counseling tool. Determine the client's comprehension and reinforce key information.

(11) Make sure the client has made a definite decision. Give her/him the method chosen, a referral, and a back-up method depending on the method selected.

(12) Encourage the client to involve partner(s) in decisions about/practice of contraception through discussion or a visit to the clinic.

\section{SYSTEMATIC SCREENING FOR OTHER SERVICES STAGE}

(13) Using information collected previously, determine client's need for postpartum, newborn, infant care, well-child services or post abortion care.

a) If client reported giving birth recently, review the Promoting Healthy Postpartum Period and Promoting Newborn and Infant Health card with client. Provide or refer for services, if needed.

b) For clients with children less than 5 years of age, ask if children have been taken to well-child services. Provide or refer for immunizations and growth monitoring services, if needed.

c) If client reported a recent abortion, review the Post Abortion Care card with the client. Provide or refer post abortion care services, if needed.

(14) Ask client when she had her last screening for cervical cancer (VIA/VILI or pap smear) or breast cancer.

a) If her last Cervical Cancer screening was more than 3 years ago (*6-12 months if she is HIV positive) or she doesn't know, ask if she would like to have a screening today. Review the Screening for Cervical Cancer card. Provide or refer for services.

b) If her last Cervical Cancer screening was less than 3 years ago continue with next question.

c) Review Breast Cancer Information and Awareness counseling card with client.

15. Discuss STI/HIV Transmission \& Prevention and Dual Protection counseling cards with client. Offer condoms and instructions on correct and consistent use.

a) In regions with active Zika virus, discuss Zika Transmission \& Prevention counseling card with client.

(16) Conduct STI and HIV risk assessment using the counseling card. If symptoms are identified, treat her/him syndromically.

(17) Ask client whether s/he knows her/his HIV status.

a) If client knows $\mathrm{s} /$ he is living with HIV,

- Review Positive Health, Dignity, \& Prevention counseling card with client.

- Refer client to center for wellness care and treatment.

b) If client knows $\mathrm{s} / \mathrm{he}$ is HIV negative,

- Discuss a time frame for repeat testing.

c) If client does not know her/his status,

- Discuss HIV Counseling and Testing (HCT) with client, using counseling card.

- Offer or initiate testing with client, according to national protocols.

- Counsel client on test results. If client is living with HIV, review Positive Health, Dignity, \& Prevention counseling card and refer client to center for wellness care and treatment.

d) Counsel client using Women's Support \& Safety Card.

- If client shows any major Intimate Partner Violence (IPV) triggers, refer her for specialized services.

(18) Give follow-up instructions, a condom brochure, and the brochure for the method chosen. Set a date for next visit.

(19) Thank her/him for the visit. Complete the counseling session. 


\section{Tips for Trainers}

1. Read this entire BCS + Trainer's Guide to prepare for the workshop. Flag pages to which you refer participants during the training.

2. Follow the detailed steps on how to conduct the training provided in this guide. Note that there are more than 3 hours of role plays and practice exercises. It is important to adhere to the suggested timing to ensure sufficient time for practice. Feel free to adapt the exercises to your local situation.

3. Practice using the BCS + job aids to counsel clients on family planning and other related services. Familiarity with the job aids will enhance your capability as a trainer of the BCS+.

4. Prior to the training, make enough copies of the BCS + User's Guide and BCS+ job aids to give to each participant in the training. (Note: If available, give participants the original, full-color copy of The Balanced Counseling Strategy Plus: A Toolkit for Family Planning Service Providers Working in High STI/HIV Prevalence Settings that contains the BCS+User's Guide, job aids, and BCS+ Trainer's Guide.)

5. Be sure there are enough BCS + method brochures for providers to use in their practice after the training.

6. The Balanced Counseling Strategy Plus: A Toolkit for Family Planning Service Providers Working in High STI/HIV Prevalence Settings is also available on the Population Council's website, at http:// www.popcouncil.org/research/the-balanced-counseling-strategy-plus-a-toolkit-for-family-planning-service. Please use it to print more materials, such as the BCS+ brochures or $B C S+$ User's Guide. You can also photocopy these materials if printing is not an option.

7. As you deliver the training, be sure to keep these facilitation skills in mind:

- Ask questions frequently. It is important to address any questions about how to use BCS + job aids as they come up.

- Use open-ended questions that begin with "how," "what," "when," and "why" to invite discussion and feedback.

- Handle difficult questions in the following way:

- Acknowledge the effort of the participant, regardless of the type of question. "That is a good question" is always a good response, no matter how difficult or inappropriate the question may be.

- Invite the group to answer the participant's question. This approach also engages the group in the learning process.

- Minimize potential embarrassment for wrong or inappropriate questions by waiting until the break to answer the question. For example, you could say, "That is a good question. Why don't we talk about it during the break?"

- Defer until the break prolonged discussions that are taking you away from the topic.

- Use good observation skills so that you know how well participants are understanding and receiving the training. As you observe how the training is being received, adjust the facilitation to meet participants' learning needs (see table on next page).

8. Remember: Effective training techniques keep participants engaged in the learning process, help trainers assess how the training is being received, and help trainers adjust the training process as needed. See table on next page for guidance. 


\begin{tabular}{|c|c|}
\hline If participants seem... & Try this... \\
\hline BORED & $\begin{array}{l}\text { - Speed up the pace of the training } \\
\text { - Take a break } \\
\text { - Stop talking and invite more participation, such as asking questions or } \\
\text { getting participants to practice } \\
\text { - Change your training style: use different training techniques, such as } \\
\text { turning off PowerPoint and just talking } \\
\text { - Conduct impromptu practice or small group work }\end{array}$ \\
\hline CONFUSED & $\begin{array}{l}\text { - Ask questions to clarify participant's understanding of the topic } \\
\text { - Give examples or demonstrate } \\
\text { - Have others in the group explain the topic } \\
\text { - Have participants practice. Provide hands-on assistance, if necessary }\end{array}$ \\
\hline SLEEPY & $\begin{array}{l}\text { - Make sure the room is not too warm or stuffy } \\
\text { - Make sure there is enough light } \\
\text { - Use a variety of training methods and aids } \\
\text { - Conduct impromptu icebreakers } \\
\text { - Take a break }\end{array}$ \\
\hline $\begin{array}{l}\text { INATTENTIVE } \\
\text { Talking, writing, looking } \\
\text { at their watches, shuf- } \\
\text { fling papers }\end{array}$ & $\begin{array}{l}\text { - Stop talking and ask questions } \\
\text { - Walk among the participants } \\
\text { - Have participants practice } \\
\text { - Ask others to explain the topic } \\
\text { - Speed up the pace } \\
\text { - Change your training technique }\end{array}$ \\
\hline ATTENTIVE & - Keep going \\
\hline
\end{tabular}




\section{Sample Agenda: BCS+ Training}

$\begin{array}{lll}\text { 8:00 am } & -8: 40 \mathrm{am} & \text { Welcome and Telephone Exercise } \\ \text { 8:40 am } & - \text { 9:30 am } & \text { Background on the Balanced Counseling Strategy Plus } \\ \text { 9:30 am } & -11: 00 \mathrm{am} & \text { Pre-Choice Stage } \\ \text { 11:00 am }-11: 15 \mathrm{am} & \text { Break } \\ \text { 11:15 am }-12: 00 \mathrm{pm} & \text { Method Choice Stage } \\ \text { 12:00 pm }-12: 45 \mathrm{pm} & \text { Post-Choice Stage } \\ \text { 12:45 pm }-2: 00 \mathrm{pm} & \text { Lunch } \\ \text { 2:00 pm }-4: 15 \mathrm{pm} & \text { Systematic Screening for Other Services Stage } \\ \text { 4:15 pm }-4: 45 \mathrm{pm} & \text { Role Play \#1 } \\ \text { 4:45 pm }-5: 00 \mathrm{pm} & \text { Break } \\ \text { 5:00 pm }-5: 30 \mathrm{pm} & \text { Role Play \#2 } \\ \text { 5:30 pm }-5: 45 \mathrm{pm} & \text { Next Steps and Closing }\end{array}$




\section{BCS+ Training for Family Planning Providers}

\section{Introduction}

Total Time: 90 minutes

By the end of this session, participants will:

- Know each other

- Be able to describe why and how the BCS+ was developed

\section{WELCOME}

Time: 20 minutes

\section{Materials and Advance Preparation}

- Have flipchart (newsprint) paper and markers available.

- Prepare a flipchart paper with the workshop objective ahead of time.

\section{Instructions}

1. Use the following exercise to help participants get to know each other. Feel free to use another icebreaker, if desired.

a. Divide participants into pairs.

b. Ask participants to tell their partner something interesting about her/himself that colleagues may not know about them.

c. Allow a couple of minutes for the first partner to tell her/his story.

d. After 5 minutes, have the pairs switch roles and ask the other partner to tell something about her/himself.

e. Allow a couple of minutes for the second partner to relate her/his story.

f. Once the group is finished (do not let them linger too long), ask each participant to: (1) introduce her/his partner by name and (2) tell one interesting thing about her $/ \mathrm{him}$.

g. You might begin by introducing yourself and telling the group something interesting about yourself.

8. Review the objective of the training:

3. Housekeeping: Review where the bathrooms are located, whether there will be refreshments, where lunch will be held, and any other housekeeping items.

\section{OBJECTIVE}

By the end of the training, participants will be able to use the BCS+ job aids to counsel a client on family planning and HIV counseling and testing (HCT).

4. Ground rules: Ask participants to suggest any ground rules that they think the group should abide by. Write the ground rules on flipchart paper. (Note: If not mentioned by participants, include a ground rule about use of cell phones.)

5. Begin the session with the telephone exercise that follows. This is a fun and participatory exercise to introduce the need for the BCS+. It also involves participants from the outset of the training. 


\section{TELEPHONE EXERCISE}

Time: 20 minutes

\section{Materials and Advance Preparation}

- Have flipchart (newsprint) paper and markers available.

- Have four to five blank sheets of paper available.

- Make a transparency or PowerPoint of Slide \#1 (found on page 14). If an overhead projector or computer and projector are not available, draw the graph from Slide \#1 on flipchart paper

\section{Instructions}

1. Ask everyone to stand up and form a semicircle. (Try to find a space in the room not interrupted by the tables and chairs.)

2. Give the first person in the semicircle a blank sheet of paper and a pen or marker. Then give every 4 th or 5 th person and the last person in the semicircle the same.

3. Mention that you are going to read something to the first person in the semicircle.

4. Explain that this person will repeat what $\mathrm{s} /$ he heard you say to the next person in the line. Subsequently, the next person repeats what s/he heard to the next person and so forth, until the information reaches the end of the line.

5. Cover these two rules:

1. Whisper the information to your partner so that others do not hear it.

2. You may only say the information once; you may not repeat it.

6. Ask the participants with the blank sheet of paper to write down exactly what they hear. Here are their rules:

1. They may not ask the person who gave them the information to repeat anything.

2. They must not let anyone see what they write.

7. Remind participants that when it is their turn, they may speak slowly, but they may not repeat the information.

8. Be aware that participants may begin to giggle. Smile and encourage them to be as quiet as possible so that their fellow participants can hear the sentence.

9. Quietly read the following information to the first person in the semicircle. Speak slowly and clearly. Take care that the person cannot see what you are reading.

\section{READ THIS}

People remember 25 percent of what they hear; 45 percent of what they hear and see; and 70 percent or more of what they see, hear, and experience on their own.

10. Tell the first person to repeat what $\mathrm{s} /$ he heard to the next person and so forth.

11. Remind the participants with the sheet of paper to write down exactly what they hear.

12. Encourage participants to be as quiet as possible so that the receiver of the information can hear what is being said.

13. Wait until the last person in the semicircle has heard the sentence and has written it down on her/his sheet of paper.

14. Read aloud exactly what you (the trainer) read to the first participant.

15. Ask the first person in the semicircle with the sheet of paper to read what $\mathrm{s} /$ he wrote on the paper.

16. Going along the semicircle ask the rest of the participants with a sheet of paper to read what they wrote, including the last person in the semicircle.

17. Expect the message to be substantially distorted by the time the last person has read what s/ he wrote down.

18. After participants have settled down, ask them to take a seat. 


\section{Instructions for Processing Exercise}

1. Ask why the message got so distorted.

2. Ask how we could have avoided such a distortion of the message. How could it have been improved so that more people would remember it?

3. Write participants' responses on flipchart paper. If not mentioned, suggest the following:

- The message could have been shorter.

- The message could have come with visual aids.

- The person could have been given printed material to read to remind her/him of the message.

4. Ask whether participants could remember the same message one week from now. (Expect them to say "no.")

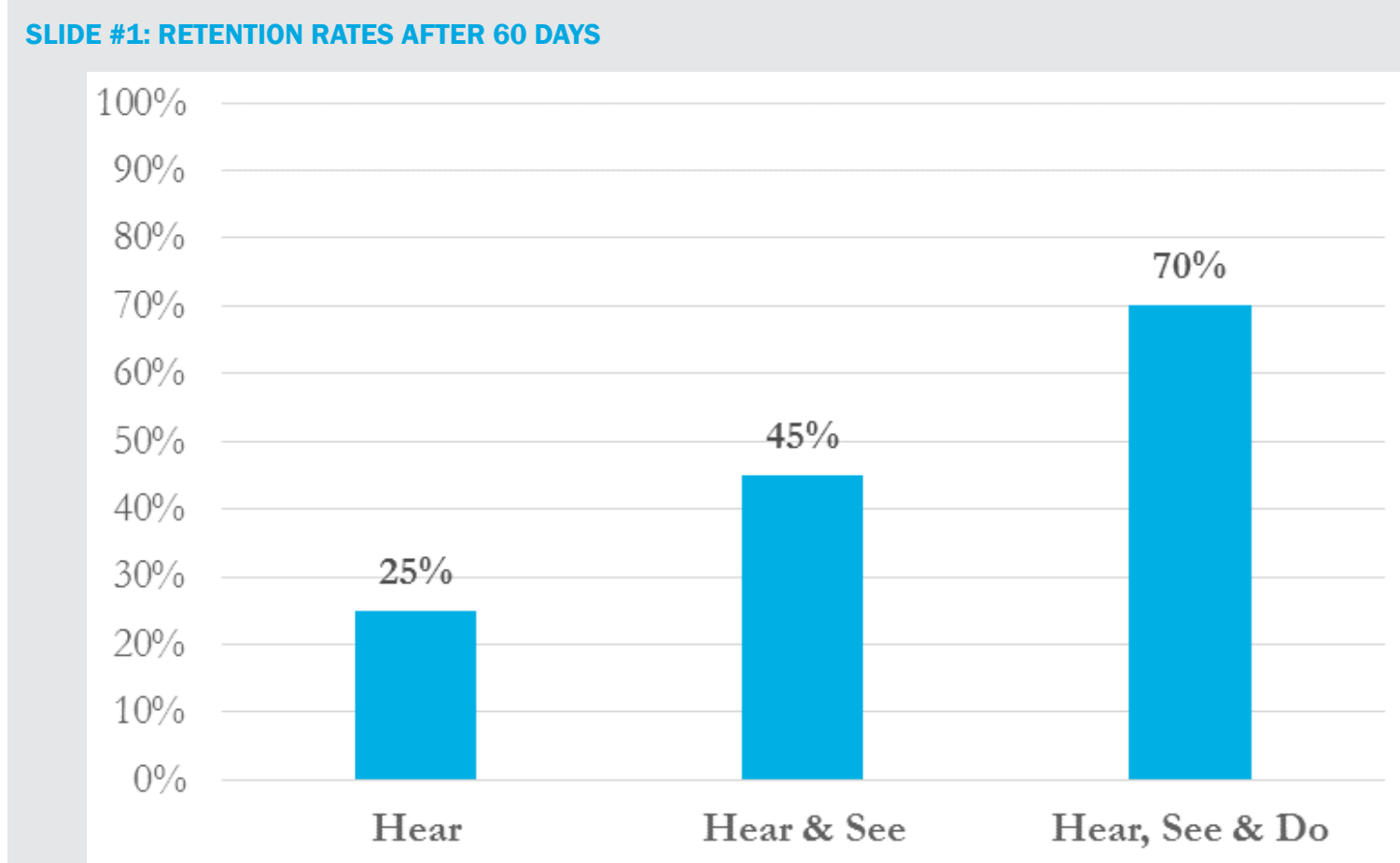

5. Show slide \#1 of retention rates and ask the following questions:

- What would it have been like if I (you the trainer) had told you the message using the slide?

- If you were given a copy of the slide to take home, could you remember the message a week from now?

6. Explain that the point of this exercise is for participants to:

- Reflect on how difficult it is to remember what one hears.

- Realize that less information enhances learning.

- Understand the need to reinforce verbal information with written materials.

7. Emphasize the fact that too much information is often given to clients when choosing a contraceptive method.

8. Ask how the inability to remember information could affect the client and his/her use of a contraceptive method. Write responses on the flipchart.

9. Mention that if the participants could not remember the simple message from the exercise we just played, how can we expect family planning clients to remember all the information we give them?

10. Mention that you are now going to discuss the link between the objectives of the telephone exercise and why the BCS+ was developed. 


\section{BACKGROUND ON THE BALANCED COUNSELING STRATEGY PLUS}

Time: 50 minutes

\section{Materials and Advance Preparation}

- Have flipchart (newsprint) paper and markers available.

- Prepare a flipchart paper with the workshop objective ahead of time.

- Have enough copies of the BCS+ Toolkit for each participant in the training. They will need it during the practice sessions and to take home with them to use in the clinic. (Note: If the entire toolkit is not available, at least make sure there are enough copies of the BCS+ User's Guide and the BCS+ job aids.)

- If you have not already done so, review the BCS+ User's Guide prior to the training and have a copy of the BCS+ Toolkit to use during the training.

- Have flipchart (newsprint) paper and markers available.

- Prepare a flipchart paper or PowerPoint with a summary of the three key findings mentioned in "Instructions for Balanced Counseling Strategy-The Beginning Explanation" point \#1 (page 15).

- Prepare a flipchart paper or PowerPoint with the definition of a job aid in the box labeled "clarify" under "Instructions for Balanced Counseling Strategy-The Beginning Explanation" point \#4 (page 16).

- Prepare a flipchart paper or PowerPoint of the operations research studies mentioned under "Instructions for Balanced Counseling Strategy Plus Explanation" point \#7 (page 16).

- Prepare a flipchart paper with the list of considerations to be taken into account when conducting client counseling with awareness and respect, mentioned in "Instructions for The Third Edition of the Balanced Counseling Strategy Plus Explanation" (page 17).

\section{Instructions for Balanced Counseling Strategy-The Beginning Explanation}

1. Explain that in the late 1990s, the FRONTIERS Program worked in collaboration with Ministries of Health in several Latin American countries to develop a practical, interactive, and client-friendly strategy for improving counseling within family planning consultations. This was in response to a study to assess providers' compliance with new national guidelines on family planning care. Three main findings emerged: (Note: As you discuss the findings, show the flipchart or PowerPoint prepared beforehand.)

- Providers failed to discuss the client's wishes.

- Providers mainly asked medical questions, such as the date of the client's last menstruation.

- Providers failed to ask the client basic questions about her reproductive intentionssuch as whether she wanted more children or whether her partner cooperated in contraceptive use.

- Information obtained from the client, such as blood pressure, often had limited practical use in the method selection process.

- Providers often gave excessive information.

- Providers furnished excessive detail on most of the contraceptive methods available at Ministry of Health clinics, regardless of whether the methods suited the client's needs.

- This overloaded clients with more information than they could remember, and they could not use much of it.

- Information provided about the chosen contraceptive method was sparse.

- Most of the counseling time was spent describing numerous method options. Important information for both provider and client - such as contraindications, side effects, and warning signs related to the chosen method—was neglected.

- Subsequently, clients interviewed after the consultation knew little about the method they had chosen. 
2. Mention that as a result of these findings, the Population Council and the Peruvian Ministry of Health developed and tested an interactive, client-friendly counseling strategy that sought to simplify decision-making and respond more appropriately to the client's needs and reproductive intentions.

3. Explain that this new family planning counseling approach was called the Balanced Counseling Strategy or BCS. Easy-to-use job aids are a key component of the BCS strategy.

4. Clarify what a job aid is. (Note: Refer to the flipchart paper prepared beforehand).

CLARIFY
A job aid is a storage place for information, other than long-term memory, which is ac-
cessed in real time on the job.
Characteristics of a job aid:
- More reliable than memory
- Describes the desired on-the-job behavior
- Minimizes trial and error and reduces the amount of recall necessary to perform on-
the-job tasks

\section{Instructions for Balanced Counseling Strategy Plus Explanation}

1. Mention that current efforts by family planning services to avoid STI/HIV have been mostly limited to education on risk reduction, STIs, encouraging use of condoms, and providing family planning choices to infected clients to avoid unwanted pregnancy.

2. Mention that HIV counseling and testing (HCT) in many African countries is often limited to antenatal care settings and a few stand-alone centers.

3. Explain that the large proportion of sexually active women using family planning offers an opportunity for providers to integrate information about other services.

4. Point out that in response to the need to incorporate counseling, screening, and services for STIs, including HIV, within routine family planning consultations in settings characterized by high prevalence of these infections, the original BCS was revised to integrate HIV prevention counseling, risk assessment, and HCT.

5. Mention that the FRONTIERS Program developed and piloted the BCS+ through operations research studies in Kenya (2005 to 2007) and South Africa (2004 to 2006). Both countries have high rates of STIs, including HIV, and their contraceptive prevalence rates are relatively high for the region.

6. Explain that the Ministries of Health in both countries were keen to develop practical tools for increasing the quality of services and numbers of clients receiving integrated services.

7. Point out the key findings of the operations research studies conducted in Kenya and South Africa on the use of the BCS+. (Note: Show overhead or flipchart of these findings as you discuss.)

- Integrating STI/HIV prevention counseling and risk assessment with offering HCT during family planning consultations is feasible and acceptable to clients and providers.

- The quality of care for both family planning and STI/HIV counseling improved significantly with the use of the BCS+ tools.

- Counseling on HCT increased substantially. In Kenya, more than 40 percent of clients were offered HCT services, with almost half of these deciding to be tested, either on site or through referral. In South Africa, those offered testing increased to 29 percent. Furthermore, an overall increase in testing was observed in the district, with a doubling of individuals tested.

- Use of the BCS+ tools facilitated greater risk assessment for STIs and HIV. Also, decisions about contraceptive method choice were made with a better understanding of their relationship to infection prevention. 
- Despite the concern that adding these services may have a negative impact on family planning services, improved quality of counseling and no evidence of a decline in utilization showed that this concern was unfounded.

\section{Instructions for The Third Edition of the Balanced Counseling Strategy Plus Explanation}

1. Explain that since its publication in 2008, many organizations and governments have used the BCS+ toolkit. Based on their experiences, some partners made modifications to the tool, added questions, or rephrased the toolkit according to the local context or a specific topic that their program was focused on. Others incorporated the toolkit into larger training activities and systems, including many governments and ministries of health that have adopted the toolkit as their family planning service provision tool for providers. An updated second edition of the BCS + was developed in 2011 to reflect some of these partner experiences and needs and updates on WHO Medical Eligibility Criteria (MEC) 2010.

2. Indicate that experiences with using the second edition of the BCS + toolkit in various settings and contexts, as well as the compilation of feedback and experiences from other organizations, new contraceptive technologies, and additional WHO updates to MEC in 2015 made it clear that the toolkit would benefit from another review and update. This update responded to several developments since its previous publication:

- Partners and colleagues implementing the tool mentioned a need and an interest in integrating additional services into the Balanced Counseling Strategy Plus algorithm and associated toolkit components. There is also widespread interest in integrating family planning into other services for which clients may have an unmet need in addition to those already covered in the BCS+. Such topics include breast cancer information, post-abortion care, women's support and safety, and male- and adolescent-specific counseling.

- The World Health Organization published the fifth edition of the Medical Eligibility Criteria for Contraceptive Use in 2015, updating guidance on the safety and efficacy of some methods.

- Two new contraceptive technologies were developed and approved for use in family planning services and were included in WHO MEC 2015: the Caya ${ }^{\circledR / S i l c s ~ D i a p h r a g m ~}$ and the Progesterone Vaginal Ring.

3. Mention that the previous two editions were tested in Kenya and are now part of national guidelines for family planning.

\section{Instructions for Counseling with Awareness and Respect Explanation}

1. Explain to participants that counseling family planning clients on other health issues entails asking questions that may be uncomfortable and different from those normally addressed in a family planning session.

2. Explain that it can be difficult to begin a conversation about these issues with a client because you will need to ask very personal questions.

3. Explain that beginning a consultation with questions about a woman's general health can set the scene for more sensitive questions about sexual practices and HIV.

4. Review the following list of questions that might be used when talking to a client and review them with participants. (Note: Have these questions prepared on flipchart beforehand. Feel free to adjust the questions as needed.)

- Have you ever talked to your partner about when you want to have children and how many you want to have?

- Have you ever talked to your partner about family planning?

- Have you ever talked to your partner about your sexual life in general?

- Do you have other sexual partners?

- How many sexual partners have you had in the past?

- Do you ever use condoms?

- Have you ever had a cervical cancer screening? 
- Have you ever used any form of contraception? Which ones? How often? How does your partner feel about it?

- Have you ever talked to your partner about STIs or HIV?

- Have you ever had an STI?

- Have you ever been tested for HIV?

- Has your partner ever been tested for HIV?

- How likely do you think it is that you may be at risk for STIs or HIV? How likely do you think it is that your partner could be at risk for STIs or HIV?

- Do you think you or your partner may have an STI now? Do you have any symptoms that worry you?

- Has anyone ever been violent with you and demanded sex?

- Has anyone ever forced you to have sex?

- Have you ever been depressed after having a baby?

- Have you ever talked to your partner about having sex after pregnancy?

5. Ask participants to pair up and ask each other some of the questions. Have them note which questions they feel uncomfortable asking or answering.

6. Remind participants that discussing these topics can be an uncomfortable experience, even for health professionals.

7. Point out that in order for clients to receive comprehensive health services, we must have these conversations and be confident doing so.

8. Mention that to reduce the stigma around these issues we must begin to talk more freely about these issues, sex, and women's and men's health in general.

\section{Instructions for The Balanced Counseling Strategy Plus Toolkit Explanation}

1. Ask participants to open their copy of The Balanced Counseling Strategy Plus: A Toolkit for Family Planning Service Providers Working in High STI/HIV Prevalence Settings. Allow them a minute or so to open the package and look at its contents.

2. Review the contents of the toolkit. If the entire toolkit is not available, review the BCS+ job aids and BCS+User's Guide and describe the following:

- BCS+ User's Guide on how to implement the BCS+. It is a detailed explanation of the 19-step BCS+ algorithm.

- BCS+ algorithm that summarizes the 19 steps recommended to implement the BCS+ during a family planning consultation. These steps are organized under four stages of the consultation: pre-choice needs assessment; method choice; post-choice actions; and systematic screening of other service needs. During each stage of the consultation, the provider is given step-by-step guidance on how to use the BCS+ job aids. Depending on the client's response to the issues discussed, the algorithm outlines which actions to take.

- Counseling cards that the provider uses during a counseling session. There are 34 counseling cards. The first card contains six questions that the service provider asks to rule out whether a client is pregnant (adopted from those developed by Stanback et al. 1999). There are 18 method-specific cards that contain information about each family planning method. Each method card has an illustration of the contraceptive method on the front side. The back of the card contains a list of key features of the method and describes the method's effectiveness. These cards are used to first exclude those methods that are inappropriate for the client's reproductive intentions and then to narrow the choice to reach a final decision. Fifteen counseling cards provide information on additional counseling and services that a family planning client may need. These include: healthy timing and spacing of pregnancies; healthy postpartum period for the mother and the newborn; cervical cancer screening; breast cancer; adolescent counseling; women's support and safety; male services; post-abortion care; STI/HIV transmission and prevention; Zika transmission and prevention, risk assessment; dual protection; positive health, dignity, and prevention; and HIV counseling and testing. 
- Method brochures on each of the 18 contraceptive methods. They are designed to help the client better understand the method chosen. The provider gives the client the brochure for the selected method and a brochure with information on condoms to take home. Providers should encourage low-literate or illiterate clients to take the brochure home so that their partner or other trusted friend can review the brochure with them again.

- WHO Medical Eligibility Wheel (2015) is a provider job aid based on the four eligibility categories for contraceptive use in relation to medical conditions described in the document Medical Eligibility Criteria for Contraceptive Use, fifth edition, published by the Department of Reproductive Health, World Health Organization. The job aid is an interactive tool to identify contraindicated methods for specific medical conditions. It has been field-tested in three countries and found to be very useful to providers who used it.

3. Point out that the BCS + job aids and BCS+ User's Guide incorporate the latest international norms and guidance as recommended by the WHO (2015).

4. Explain that participants should refer to the BCS+User's Guide when they need details on how to use the BCS+. The BCS+ User's Guide is more comprehensive than the BCS+ algorithm.

5. Ask whether there are any questions before proceeding.

6. Mention that participants are now going to learn how to implement the BCS+ using the BCS+ job aids. 


\section{Pre-Choice Stage}

Total time: 90 minutes

By the end of this session, participants will:

- Be able to counsel a family planning client on the BCS+ pre-choice stage

\section{VALUES CLARIFICATION}

Time: 20 minutes

\section{Materials and Advance Preparation}

- Have flipchart (newsprint) paper and markers available.

- Have list of value statements ready to read aloud to participants. Feel free to add to or subtract from the value statements under sentence \#5.

\section{Instructions}

1. Explain that our values form a fundamental part of our lives and, as such, have an effect on how we behave both personally and professionally.

2. Point out that it is important to be aware of our values regarding health and sexual health matters and avoid making value judgments that affect our work professionally.

3. Mention that you are going to read some statements and after each one vote whether you agree with it or not. Then we will discuss the statements as a group.

4. Point out that there are no "right" or "wrong" answers with respect to values.

5. Read the statements, one at a time, and have the group vote on them.

- It is acceptable for someone to have more than one sexual partner at a time.

- It is more acceptable for men to have multiple sexual partners than for women to have multiple sexual partners.

- People who don't use condoms can only blame themselves for getting HIV.

- Health care providers have the right to know the HIV status of their patients.

- A woman who knows she is infected with HIV should not have a baby.

- Oral sex should be encouraged to reduce risk of HIV.

- Children should be taught about HIV as early as possible.

- Teenage girls should be discouraged from using family planning.

- Educating parents about condoms will help protect teenagers from HIV.

- Most uneducated women are incapable of making their own decisions about their sexual and reproductive life.

6. Once you have discussed the above-mentioned statements and how they might affect their behavior with clients, encourage a discussion about how to respect the values of others despite one's own values. (Note: Write responses on flipchart.)

7. Point out that providers must be aware of their own beliefs and avoid imposing them on their clients.

\section{STEPS 1 TO 6}

Time: 45 minutes

\section{Materials and Advance Preparation}

- Have flipchart (newsprint) paper and markers available.

- Make sure all participants have a copy of the BCS+User's Guide and counseling cards. 


\section{Instructions}

STEP 1. ESTABLISH AND MAINTAIN A WARM, CORDIAL RELATIONSHIP.

1. Ask participants to open their BCS+ User's Guide and go to Step 1. Review the following actions that help to accomplish Step 1:

- Establish a formal but friendly manner.

- Call the client by her/his name.

- Demonstrate interest in what the client tells you.

- Establish eye contact with the client.

- Listen to and answer her/his questions.

- Show support and understanding without judgment.

- Ask questions to encourage participation in the discussion.

2. Ask participants whether there are other actions that are good for establishing a warm and cordial relationship. (Note: Write responses on flipchart.)

STEP 2. INFORM CLIENT (AND PARTNER, IF PRESENT) THAT THERE WILL BE AN OPPORTUNITY TO ADDRESS BOTH HEALTH NEEDS AND FAMILY PLANNING NEEDS DURING THIS CONSULTATION.

1. Explain that family planning clients may have questions about other health issues or a need for other health services. These questions and services may be addressed during the same consultation and are included in the Systematic Screening for Other Services Stage.

2. Ask participants to think about other services that are available in the facility where BCS+ will be implemented. Ask about those services a client may need that are available by referral.

3. Instruct participants to inform each client of these services and take note of any specific services that she/he requests so that you can address them after going through the BCS+ algorithm.

4. Explain that the primary goal of the BCS+ is to guide providers through family planning counseling and assist in the selection of an appropriate family planning method and, therefore, this issue will be addressed first.

\section{STEP 3. ASK CLIENT ABOUT CURRENT FAMILY SIZE, DESIRE TO HAVE MORE CHILDREN, AND CURRENT CONTRACEPTIVE PRACTICES. COUNSEL THE CLIENT ON HEALTHY TIMING AND SPACING OF PREGNANCY USING COUNSELING CARD.}

1. Explain that all couples and individuals have the right to decide freely and responsibly the number and spacing of their children and to have access to information and education about family planning.

2. Explain that data show higher rates of maternal and/or infant and perinatal death and illness when a pregnancy following a live birth is spaced less than two years or more than five years.

3. Explain that data show a similar negative effect on mother's and her baby's health when a pregnancy occurs less than six months after an induced or spontaneous abortion.

4. Explain that research clearly shows that young women who become pregnant before the age of 18 face a number of negative health and social outcomes, as do their children. Young women ages 15 to 19 are twice as likely to die of pregnancy-related complications as their peers over the age of 20 , and young women under the age of 15 are five times more likely to die.

5. Instruct participants to ask the following questions of their clients:

- How many children do you have?

- How many children do you (and your partner) want?

- Are you currently using contraception or delaying pregnancy?

- If yes, what method are you using? Are you happy with your current method or would you like to change your method? 
6. Review counseling points listed on the Healthy Timing and Spacing of Pregnancy counseling card with participants. Read the following points out loud with participants:

- For women who want to have more children after a live birth, advise:

- For the health of the mother and baby, wait at least 2 years (24 months) but not more than 5 years before trying to become pregnant again.

- Use of a family planning method of her choice allows a woman to plan for a healthy pregnancy.

- For women who decide to have a child after a miscarriage or abortion, advise:

- For the health of the mother and baby, wait at least 6 months before trying to become pregnant again.

- Use of a family planning method of her choice allows a woman to plan for a healthy pregnancy.

- For adolescents, advise:

- For the health of the mother and baby, wait until at least 18 years of age before trying to become pregnant.

- If sexually active, use of a family planning method of her choice allows a young woman to prevent unintended pregnancy.

7. If client's partner is present, counsel using the Male Services \& Support card.

8. Ask participants if they have any questions.

\section{STEP 4. RULE OUT PREGNANCY USING THE PREGNANCY CHECKLIST CARD WITH 6 QUESTIONS.}

1. Explain that it is important to rule out the possibility of the client being pregnant before proceeding with a family planning consultation. Pregnancy is a contraindication for most methods except barrier methods such as condoms.

2. Ask participants to take out their BCS + counseling cards and locate the pregnancy checklist card for ruling out pregnancy.

3. Review the 6 questions on the card:

- Did you have a baby less than 6 months ago? If so, are you fully or nearly fully breastfeeding? Have you had no monthly menstrual bleeding since giving birth?

- Have you abstained from unprotected sex (no method of family planning) since your last menstrual bleeding or delivery?

- Have you given birth during the last 4 weeks?

- Did your last menstrual bleeding start within the past 7 days (or within 12 days if you plan to use an intrauterine device (IUD)?

- Have you had a miscarriage or abortion in the last 7 days?

- Have you been using a reliable contraceptive method consistently and correctly?

4. Refer participants to the first table on the next page which also appears in the BCS+ User's Guide, and review which actions to take based on how a client answers each of the 6 questions. 


\begin{tabular}{|c|c|}
\hline If the client answers.. & Then... \\
\hline $\begin{array}{l}\text { "Yes" to any of the questions and is free of } \\
\text { signs and symptoms of pregnancy, } \\
\text { *Once the client has answered yes to one } \\
\text { of the questions, it is not necessary to } \\
\text { continue asking the remaining questions }\end{array}$ & $\begin{array}{l}\text { 1. Pregnancy is unlikely } \\
\text { 2. Continue to Step } 5\end{array}$ \\
\hline "No" to all of the questions & $\begin{array}{l}\text { 1. Pregnancy cannot be ruled out. } \\
\text { 2. Give client a pregnancy test if available, or refer her to an } \\
\text { antenatal clinic. } \\
\text { 3. Provide her with a back-up method, such as condoms, to } \\
\text { use until she has her menstrual bleeding. } \\
\text { 4. Provide in advance her preferred method (where possible) } \\
\text { to use on the 1st day of her menses OR request that she } \\
\text { return at that point to receive her preferred method. } \\
\text { 5. Go to Step } 13\end{array}$ \\
\hline
\end{tabular}

\section{STEP 5. DISPLAY ALL OF THE METHOD CARDS. ASK CLIENT IF SHE/HE WANTS A PARTICULAR METHOD.}

1. Display all of the method cards as shown in Figure 1 (see Appendix) of the BCS+ User's Guide.

2. Mention that before narrowing down a client's method choices, the provider should first ask whether a client has a method in mind.

3. Refer participants to the table below in the BCS+User's Guide and review what to do as the client responds to the question, "Do you have a particular method in mind?"

\begin{tabular}{l|l|}
\hline $\begin{array}{l}\text { If the client... } \\
\text { Answers "no" }\end{array}$ & Do this... \\
\hline $\begin{array}{l}\text { Continue to Step } 6 \\
\text { Answers "yes" }\end{array}$ & $\begin{array}{l}\text { 1. Ask which method s/he wants. } \\
\text { 2. Ask what the client knows about the method. } \\
\text { 3. If the information is correct, go to Step } 9 .\end{array}$ \\
\hline $\begin{array}{l}\text { Gives incomplete information about the } \\
\text { method s/he has chosen } \\
\begin{array}{l}\text { OR } \\
\text { Does not know other alternatives that } \\
\text { might be more convenient }\end{array}\end{array}$ & $\begin{array}{l}\text { 1. Correct any misinformation. } \\
\text { 2. If necessary, go to Step } 6 \text { to help the client choose a } \\
\text { method. }\end{array}$ \\
\hline
\end{tabular}

\section{STEP 6. ASK ALL OF THE FOLLOWING QUESTIONS. SET ASIDE METHOD CARDS BASED ON THE CLIENT'S RESPONSES.}

1. Point out that this step is the heart of the BCS+ model. Refer participants to Step 6 in the BCS+ User's Guide.

2. Explain that there are six key questions under Step 6. These questions help the provider identify a client's reproductive intentions. They also help the client choose the family planning method that best suits her/his intentions.

3. Mention that participants may want to begin the process by saying something like this to the client, "Now we are going to discuss your contraceptive needs. We will narrow down the number of methods that might be best for you. Then, I will discuss the key features of each method with you. This will help us to find the right method for your needs."

4. As you explain this step, demonstrate with a participant how to ask the questions and set aside the counseling cards. Select a participant from the group (or use a co-trainer) and give her/him the following script: 


\section{SCENARIO}

You are a 28-year-old woman who has three children. You gave birth to a baby 5 months ago. You are breastfeeding your baby and have a history of uterine fibroids. You are tired and do not want to have more children for a while. Your husband is not very cooperative when it comes to family planning. He does not want anything to interfere with having sex when he wants it. You have used spermicides in the past. Their failure resulted in pregnancy with your third child. You are interested in a method that you can use without your husband noticing.

5. Refer participants to the table under Step $\mathbf{6}$ in the BCS+ User's Guide and have them follow along.

6. Begin with the question: "Do you wish to have children in the future?"

7. Demonstrate keeping or setting aside the method cards per the instructions in the table below.

\begin{tabular}{|l|l|}
\hline If the client... & Do this... \\
\hline Answers "yes" & $\begin{array}{l}\text { 1. Set aside the vasectomy and tubal ligation cards. } \\
\text { 2. Explain that sterilization is permanent and not suitable for someone } \\
\text { who thinks s/he might want to have another child. }\end{array}$ \\
\hline Answers "no" & Keep all cards and continue \\
\hline
\end{tabular}

8. Ask the next question: "Have you given birth in the last $\mathbf{4 8}$ hours?"

9. Demonstrate keeping or setting aside the method cards per the instructions in the table below.

\begin{tabular}{|l|l|}
\hline If the client... & Do this... \\
\hline Answers "yes" & $\begin{array}{l}\text { 1. Set aside combined oral contraceptives (the Pill), monthly injectable, } \\
\text { implants, and tubal ligation cards. }\end{array}$ \\
\hline $\begin{array}{l}\text { 2. Explain that combined hormonal methods and tubal ligation are not } \\
\text { safe for women to use immediately after giving birth. }\end{array}$ \\
\hline Answers "no" & Keep all cards and continue \\
\hline
\end{tabular}

10. Ask next question: "Are you breastfeeding an infant less than $\mathbf{6}$ months old?"

11. Demonstrate keeping or setting aside the counseling cards per the instructions in the table below.

\begin{tabular}{|l|l|}
\hline If the client... & Do this... \\
\hline Answers "yes" & $\begin{array}{l}\text { 1. Set aside the combined oral contraceptives (the Pill) and combined } \\
\text { injectable contraceptive (CIC) cards. }\end{array}$ \\
\hline $\begin{array}{l}\text { 2. Explain that the hormones in these methods affect breastfeeding. } \\
\text { Answers "no" }\end{array}$ & $\begin{array}{l}\text { 2. Set aside the Lactational Amenorrhea Method (LAM) card and the pro- } \\
\text { gesterone vaginal ring (PVR) card aside. }\end{array}$ \\
\hline $\begin{array}{l}\text { 2. Explain that LAM and PVR are not suitable for women who are not } \\
\text { breastfeeding or are having menstrual bleeding again. }\end{array}$
\end{tabular}

12. Ask whether there are any questions so far.

13. Ask the next question: "Does your partner support you in family planning?"

14. Demonstrate keeping or setting aside the counseling cards per the instructions in the following table. 


\begin{tabular}{l|l}
\hline If the client... & Do this... \\
\hline Answers "yes" & Continue with the next question \\
\hline Answers "no" & $\begin{array}{l}\text { 1. Set aside female condom, male condom, Standard Days Method }{ }^{\circ}, \\
\text { TwoDay® Method, and withdrawal cards. } \\
\text { 2. Explain that these methods require partner cooperation. }\end{array}$
\end{tabular}

15. Explain to participants that they should invite the client to bring her/his partner to a counseling session to discuss family planning with a provider.

16. Point out that male and female condoms are important for protecting against STIs, including HIV and Zika, and also require partner cooperation.

17. Ask the next question: "Do you have any medical conditions? Are you taking any medications?"

18. Demonstrate use of the WHO Medical Eligibility Criteria Wheel to determine contraceptive methods that are contraindicated according to a condition the client has or a medication the client is taking. Follow instructions in the table below.

\begin{tabular}{l|l}
\hline If the client... & Do this... \\
\hline $\begin{array}{l}\text { 1. Ask further about which medical conditions the client has or medica- } \\
\text { tions she/he is taking. }\end{array}$ \\
$\begin{array}{l}\text { 2. Refer to the WHO Medical Eligibility Criteria Wheel (included), or current } \\
\text { national guidelines, to identify contraindicated methods. } \\
\text { Answers "yes" }\end{array}$ \\
$\begin{array}{l}\text { 3. Set aside all contraindicated method cards. } \\
\text { 4. Explain to client the reason for setting aside method cards, according to } \\
\text { information provided in guidelines. }\end{array}$ \\
\hline Answers "no" & Continue with next question
\end{tabular}

19. Read out loud the following note about the WHO Medical Eligibility Criteria Wheel:

- The WHO Medical Eligibility Criteria (MEC) Wheel which is a provider job aid based on the four eligibility categories for contraceptive use in relation to medical conditions described in the document Medical Eligibility Criteria for contraceptive use, Fifth edition, published by Department of Reproductive Health, World Health Organization. This tool guides providers through medical conditions and medications that may be contraindications to use of particular contraceptive methods. The job aid has been field-tested in three countries by WHO, and is found to be very useful to providers who used it.

20. Ask participants if they have any questions about the WHO Medical Eligibility Criteria, the WHO MEC Wheel, or their national guidelines concerning contraindications.

21. Ask the last question: "Are there any methods that you do not want to use or have not tolerated in the past?"

22. Demonstrate keeping or setting aside the counseling cards per the instructions in the table below.

\begin{tabular}{l|l|l|l|l}
\hline If the client... & Do this... \\
\hline Answers "yes" & $\begin{array}{l}\text { 1. Ask which methods s/he has used and her/his experience with each. } \\
\text { 2. Set aside the cards for the methods the client does not want. }\end{array}$ \\
\hline $\begin{array}{l}\text { Answers "no" } \\
\text { The client has eliminated a } \\
\text { method because of rumors } \\
\text { or false information. }\end{array}$ & $\begin{array}{l}\text { 1. Provide the correct information. } \\
\text { 2. Do not set aside the card for that method. }\end{array}$ \\
\hline
\end{tabular}




\section{PRACTICE}

Time: 25 minutes

\section{Instructions}

1. Have participants conduct a short role play to practice the BCS + pre-choice stage using Steps 1 to 6 .

a. Ask participants to pick a partner, preferably someone sitting next to them.

b. Have one person in the pair play the "service provider" and the other person play the "client."

c. Ask the person playing the provider to use the counseling cards to go through the BCS+ pre-choice stage.

d. Ask the person playing the "client" to think of a family planning client they counseled recently and to play that role when their partner asks the pre-choice questions.

e. Ask the person playing the "client" to think of a contraceptive method s/he plans to use and whether or not $\mathrm{s} /$ he will have a condition for which it is not advised.

f. If the "client" decides to have a contraindication to the first method chosen, be sure to have another method in mind to allow the service provider to discover what that method is.

g. Tell the person playing the provider that after Step $6 \mathrm{~s} /$ he should hold on to the remaining method cards that have not been set aside during the role play. (Note: As participants conduct the role play, walk around to observe and gently correct, if needed.)

h. Remind the "provider" to use good counseling skills.

i. Allow about 15 minutes for this role play.

j. After 15 minutes, ask participants to switch roles. Allow about 15 minutes for the second role play.

k. Be sure to ask the participant playing the provider to hold onto any remaining method cards that have not been set aside.

2. Ask whether participants have any questions. Address all comments and questions before proceeding.

3. Remind participants that the BCS+ was developed in response to the finding that providers were giving clients too much information on all the methods. They did so regardless of whether the method was relevant to the client's needs or reproductive intentions.

4. Mention that the method cards remaining from their role play are an example of how to narrow down contraceptive methods that are more suitable to a client's needs and intentions.

5. Explain that this helps to reduce the amount of information we give clients. It also helps improve retention and recall of information. Remind participants of the telephone game. 


\section{Method Choice Stage}

Total time: 45 minutes

By the end of this session, participants will:

- Be able to counsel a family planning client on the BCS+ method choice stage

\section{STEPS 7 TO 9}

Time: 30 minutes

\section{Materials and Advance Preparation}

- Make sure participants have their BCS+ method brochures.

\section{Instructions}

1. Ask participants to look at the back of the method cards that were not set aside during their role play.

2. Review the section on method effectiveness, pointing out:

- The written description of the method's effectiveness

- The percentage on the left-hand side of the card that also represents the effectiveness

3. Explain that method effectiveness is measured as the number of pregnancies among 100 women in the first year of using the method.

4. Point out that the higher the percentage, the more effective the method. A higher percentage means that there are fewer pregnancies occurring among 100 women using that method per year.

5. Point to the method effectiveness information on the Tubal Ligation and TwoDay Method counseling cards as examples. Refer participants to Figure 3 in the BCS+User's Guide.

FIGURE 3. EXAMPLES OF METHOD CARDS SHOWING EFFECTIVENESS FOR PREVENTING PREGNANCY

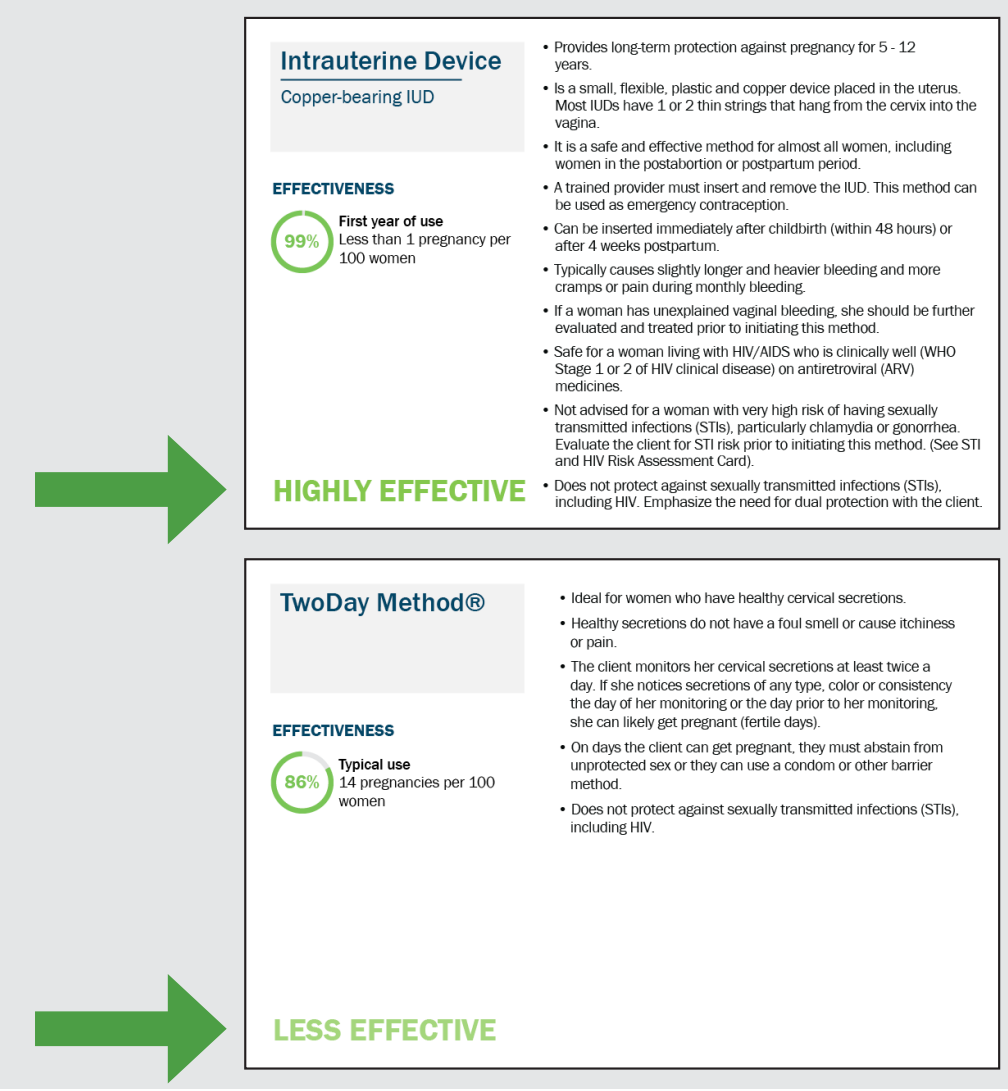




\section{STEP 7. BRIEFLY REVIEW THE METHODS THAT HAVE NOT BEEN SET ASIDE AND INDICATE THEIR EFFECTIVENESS.}

1. Point out the features of the method located to the right of the information on method effectiveness.

2. Ask participants to arrange the remaining method cards in order of their level of effectiveness. The cards should go from the most effective (highest percentage) to the least effective (lowest percentage).

3. Demonstrate how to display the cards with the highest percentage of effectiveness first and the lowest percentages last.

4. Explain that beginning with the card with the highest percentage (most effective), the provider reviews with the client the features of each of the remaining method cards.

5. Explain that in this way, the provider is giving information only on family planning methods that are relevant to the client's needs and reproductive intentions.

6. Point out that by beginning with the card with the highest percentage the provider discusses the most effective method first.

7. Emphasize that condoms (male or female) are the only method that offers dual protection: protection against pregnancy and STIs, including HIV and Zika. Emphasize the following:

- Male and female condoms significantly reduce the risk of infection with STIs, including HIV and Zika, when used correctly and consistently with every act of sex.

- When used correctly and consistently, condom use prevents 80 percent to 95 percent of HIV transmission that would have occurred without the use of condoms.

- Condoms reduce the risk of becoming infected with many STIs when used consistently and correctly:

- Protect best against spread of STIs by discharge, such as HIV, Zika, gonorrhea, and chlamydia.

- Also protect against spread of STIs from skin-to-skin contact, such as herpes and human papillomavirus.

\section{STEP 8. ASK THE CLIENT TO CHOOSE THE METHOD THAT IS MOST CONVENIENT FOR HER/HIM.}

1. Explain that if the client is an adolescent, the provider should use the Adolescent Counseling card to inform her that she can get any method.

2. Mention that, at this point, the provider asks whether the client has any questions, doubts, or comments about the methods discussed.

3. Explain that after answering any questions, the provider asks the client to choose a method from the method cards that have been discussed.

4. Emphasize that once the method is chosen a provider should not take the method cards off the table. S/he may need them again if there are conditions where the method is not advised for the client, or the client may change her/his mind.

5. Mention that if the client does not like any of the methods discussed or cannot make up her/his mind, give the client a method to use until s/he decides and go to Step 13.

6. Point out the importance of not letting a client leave empty-handed. Condoms can provide dual protection until the client has selected another method.

7. Ask whether participants have any questions or comments. Be sure to answer all questions before proceeding to Step 9.

\section{STEP 9. USING THE METHOD-SPECIFIC BROCHURE, CHECK WHETHER THE CLIENT HAS ANY CONDITIONS FOR WHICH THE METHOD IS NOT ADVISED.}

1. Explain that contraindications to a method were initially reviewed in Step 6, and this step is intended to confirm that the client does not have any contraindications.

2. Explain that the provider selects the brochure for the method chosen by the client. Let's pretend that it is the Pill. 
3. Point out that the provider should review the "Method not advised if you" section of the brochure. For the Pill, it would be:

- Are breastfeeding an infant less than 6 months old.

- If you are within 21 days of giving birth, regardless of breastfeeding status.

- Smoke cigarettes and are 35 years old or older.

- Have high blood pressure, 140/90 or higher.

- Have certain uncommon serious diseases of the heart or blood vessels. Discuss with your provider.

- Have severe liver conditions.

- Have blood clots, deep vein thrombosis, or pulmonary embolism, or are on anticoagulant therapy. Discuss with your provider.

- Have lupus.

- Have gall bladder disease, even if medically-treated. Discuss with your provider.

- Have breast cancer or a history of breast cancer.

- Have migraine headaches (a severe headache that does not go away with paracetamol) and are 35 years old or older.

- Have migraine aura (sometimes seeing a growing bright spot in one eye)

- Take medicine for seizures or take rifampicin (for tuberculosis or other infections).

- Take ritonavir-boosted protease inhibitors as part of HAART.

4. Explain that if the client has a condition for which the method chosen is not advised, there is no need to give further information available in the brochure and the client will need to select another method.

5. Refer participants to the table below and in the BCS+User's Guide and review how the provider decides whether to provide the method or return to a previous step.

\begin{tabular}{|l|l|}
\hline If the client... & Do this... \\
\hline Has no conditions & Go to Step 10. \\
\hline Has any condition & $\begin{array}{l}\text { 1. Explain the need to choose another method. } \\
\text { 2. Return to Step 7. }\end{array}$ \\
\hline $\begin{array}{l}\text { Has any condition and reached this step from } \\
\text { Step } 5 \text { (already had the method in mind) }\end{array}$ & $\begin{array}{l}\text { 1. Explain the need to choose another method. } \\
\text { 2. Return to Step } 6 .\end{array}$ \\
\hline
\end{tabular}

\section{PRACTICE}

Time: 15 minutes

1. Ask participants to turn to their partner and explain Steps 7 to 9. They do not need to roleplay, just explain the process.

2. After about 7 to 8 minutes, ask them to reverse roles and have the listener explain Steps 7 to 9. 


\section{Post-Choice Stage}

Total time: 45 minutes

By the end of this session, participants will:

- Be able to counsel a family planning client on the BCS+ post-choice stage

STEPS 10 TO 12

Time: 20 minutes

Materials and Advance Preparation

- None

Instructions

STEP 10. DISCUSS THE METHOD CHOSEN WITH THE CLIENT, USING THE METHOD BROCHURE AS A COUNSELING TOOL. DETERMINE THE CLIENT'S COMPREHENSION AND REINFORCE KEY INFORMATION

1. Explain that at this point, the client has selected a method and is now ready to hear more about the method chosen.

2. Explain that it is important to make sure the client understands the method s/he has chosen. Comprehension is key to effective use of the method and maintaining the client's health.

3. Mention ways to begin the conversation, such as, "Mrs./Mr. \{name\}, this brochure is for you to take home. Before you go, I would like to review the information with you."

4. Use the BCS+ method brochure on the Pill to demonstrate how a provider reviews the following information in the method brochure with a client:

- General information (This is the same information as on the BCS+ counseling card.)

- How method works

- Important facts (about the method)

- Method not advised if you

- Side effects

- Health benefits (if applicable)

- How to use

- Follow-up (if applicable)

- When to return to the health care facility

5. Explain that after the provider discusses the information in the method brochure, $\mathrm{s} /$ he gives the brochure to the client. S/he encourages the client to review the brochure again at home and when s/he needs to remember anything about the method.

6. Mention that a provider can validate the client's understanding of the method by asking her/ him to answer the following questions in her/his own words. The client may refer to the brochure.

- How do you use the method you have chosen?

- What side effects might you experience with the method?

- Can the method protect you against getting an STI, including HIV and Zika?

- What are the signs indicating when you should return to the health care facility?

7. The provider should assure the client that it is fine if $\mathrm{s} /$ he cannot remember all the details of the method. Make sure the client can find the information in the brochure.

8. Remember to ask the client whether s/he has any questions. Reinforce the basic information on the method chosen, as needed. 


\section{What if methods are not available?}

1. Ask participants what they would do if methods such as the IUD, tubal ligation, and/or vasectomy were not offered in your health care facility.

2. Review the following, if not mentioned by participants:

- Still talk to the client about these methods (if they meet the client's reproductive intentions).

- Give the client the brochure for the method chosen.

- Refer the client to a facility or commercial outlet where s/he can obtain the method.

- Provide the client with an alternative, suitable method until s/he can obtain the method of choice.

3. Reinforce the importance of never letting a client go away empty-handed. This may be her/ his first and/or only consultation. It is important to respond to a client's needs even if you do not have the method on hand.

4. Review what to do if a client selects a method that is temporarily unavailable (out of stock).

- Give the client a brochure for the method chosen.

- Refer the client to another facility or commercial outlet for the method.

- Provide the client with a back-up method until s/he can obtain the method of choice.

- Ask client to return to the facility when the method is in stock.

5. Ask whether there are any questions or comments.

\section{STEP 11. MAKE SURE THE CLIENT HAS MADE A DEFINITE DECISION. GIVE HER/HIM THE METHOD CHOSEN, A REFERRAL, AND A BACK-UP METHOD DEPENDING ON THE METHOD SELECTED.}

1. Explain that providers should ask the client if her/his choice is a definite one. Make sure the client is happy with the method.

2. Refer participants to the table below and in the BCS + User's Guide and review what to do based on the client's responses.

\begin{tabular}{|c|c|}
\hline If the client is... & Do this... \\
\hline Happy with the method chosen & $\begin{array}{l}\text { 1. Give her/him the method and brochure. } \\
\text { 2. If IUD, implant, tubal ligation, or vasectomy is chosen and } \\
\text { not available on site, give a referral for the procedure, if } \\
\text { needed. } \\
\text { 3. If the client cannot immediately use the chosen method, } \\
\text { provide a back-up method (e.g. condoms). Give the BCS+ } \\
\text { brochure on condoms. } \\
\text { 4. Suggest that s/he may also abstain from sex until s/he } \\
\text { obtains the method of choice. }\end{array}$ \\
\hline $\begin{array}{l}\text { Not happy with the method chosen and } \\
\text { wishes to consider other options }\end{array}$ & $\begin{array}{l}\text { 1. Assure the client that it is fine to change her/his mind. } \\
\text { The client has a right to informed choice. } \\
\text { 2. Return to Step } 7 \text {. }\end{array}$ \\
\hline
\end{tabular}

3. Emphasize the importance of not letting the client leave empty-handed. If a method is not available, make sure the client has a back-up method, a referral, and the BCS+ brochure on condoms.

\section{STEP 12. ENCOURAGE THE CLIENT TO INVOLVE PARTNER(S) IN DECISIONS ABOUT/PRACTICE OF CONTRACEPTION THROUGH DISCUSSION OR A VISIT TO THE CLINIC.}

1. Ask participants the ways in which a client can involve her/his partner in contraception.

2. If not mentioned by participants, review the following:

- Your partner can remind you of the time to take your method, if taking a method regularly, and follow-up dates. 
- You can negotiate condom use to prevent STI, including HIV and Zika.

- You can discuss your plans to have children, regardless of whether you are HIV positive or negative.

- You can let your partner know that prevention of mother-to-child transmission (PMTCT) during pregnancy can reduce transmission of HIV and Zika to infants.

- Your partner can support you if you need wellness or HIV services (antiretroviral therapy $[$ ART] and wellness sites).

3. Encourage participants to adapt this list based on what works for them and their clients.

\section{PRACTICE}

Time: 25 minutes

1. Ask participants to pair up with same partner.

2. Have one person in the pair play the "service provider" and the other person play the "client."

3. Explain that the provider will help the client to select a method following Steps $\mathbf{7}$ to $\mathbf{1 2}$ and using the method cards and method brochures.

4. Explain that the person playing the "service provider" may refer to Steps $\mathbf{7}$ to $\mathbf{1 2}$ in the BCS+ algorithm as support. Remind him/her to use good counseling skills. (Note: As participants conduct the role play, walk around to observe and gently correct, if needed.)

5. Allow about 10 minutes for this role play. Then, ask the pairs to switch roles and repeat the process.

6. Allow about 10 minutes for the second role play.

7. After the second role play, ask participants for comments and questions. Address them all before proceeding. 


\section{Systematic Screening for Other Services Stage}

\section{Total time: 135 minutes}

By the end of this session, participants will be able to:

- Identify clients' need for postpartum, newborn, infant, child health, or post abortion care counseling or services.

- Counsel clients on appropriate and necessary services

- Identify need for cervical or breast cancer screening. Provide or refer for services

- Identify the level of HIV risk associated with various behaviors

- Provide HIV counseling and testing

- Counsel clients on HIV prevention, risk reduction, dual protection, and positive health, dignity. and prevention, where appropriate.

- Counsel clients on Zika prevention, risk reduction, and dual protection where appropriate.

- Counsel clients on women's support and safety.

- Identify need for adolescent services counseling

- Provide counseling for male services

- Counsel clients on appropriate and necessary services or provide referral.

\section{POSTNATAL CARE EXERCISE ${ }^{2}$}

\section{Time: 25 minutes}

\section{Materials and Advance Preparation}

- In large letters, print each of the following titles on cards (or pieces of paper), one title per card: First visit (24 to 48 hours); Second visit (3 to 7 days); Third visit (4 to 6 weeks); Fourth visit (4 to 6 months).

- Tape the signs high on the wall with room for participants to gather around.

- Prepare four markers for distribution.

\section{Instructions}

1. Inform participants that they will complete an activity that looks at the services that are entailed in postnatal care.

2. Define targeted postnatal care to the participants and explain the rationale for postnatal care services.

3. Refer to national guidelines for specific information and services to be included in postnatal care and to be emphasized among the group of providers being trained.

\section{NOTE}

The postnatal period is the time beginning immediately after the birth of a baby and extending for about six weeks thereafter. Postpartum period and puerperium are other terms used for the same period. Targeted postnatal care is a set of postnatal care services delivered to both the mother and the baby in a minimum of four visits spread throughout the first six months. The recommended schedule is as follows:

- Within 48 hours

- 3 to 7 days

- 4 to 6 weeks

- 4 to 6 months

Postnatal care meets the needs of both the mother and the baby, reduces the risk of morbidity and mortality, and promotes health and wellbeing.

\footnotetext{
${ }^{2}$ This exercise was adapted from the curriculum titled: Community Based Maternal and Newborn Care (Ministry of Public Health and Sanitation and Ministry of Medical Services, Kenya, 2008).
} 
4. Ask participants to count off, one at a time, 1, 2, 3 and 4. Let all participants who counted to 1 come together, then 2, 3 and 4, to make four individual groups. Each group will stand in front of the print chart corresponding to their number. Give a marker to each group.

5. Ask participants to take 5 minutes to brainstorm on the services for mother and baby that should be included in the visit to which their group corresponds.

6. Ask one of the participants from each group to divide the print chart in two equal parts. Using the marker, write Mother on one side and Baby on the other side.

7. Referring to what the group has brainstormed, have each group write the services for mother and baby on each side.

8. Once the four groups are done, ask each group to review what other groups have written.

9. To begin discussion and feedback, ask each group to report if there are listed services that they disagree with, that they do not understand, or that they have difficulty with.

10. Discuss the services listed for each visit. Refer to national guidelines for postnatal care services or the WHO guidelines on postpartum and postnatal care to see the full list of key elements and correct timing for postnatal care for mother and baby.

11. Once participants have reviewed key elements and timing of postnatal care services, briefly discuss major danger signs during the postnatal period.

12. Explain that danger signs are conditions about which providers should counsel the woman and her family at each visit. Providers should advise the woman to go to the health center immediately, day or night, if she or her baby experiences these danger signs.

13. Read out the following list with participants:

14. Ask participants if they have any questions about the above danger signs. Answer any questions before proceeding.

- Vaginal bleeding

- Fits

- Fast or difficult breathing

- Fever and too weak to get out of bed

- Severe abdominal pain

- Severe headaches with blurred vision
- Difficulty breathing

- Convulsions (fits)

- Fever

- Feels cold

- Bleeding

- Stops feeding

- Diarrhea and vomiting

\section{HIV RISK ASSESSMENT EXERCISE}

Time: 20 minutes

\section{Materials and Advance Preparation}

- In large letters, print each of the following titles on cards (or pieces of paper), one title per card: Higher Risk, Medium Risk, Low Risk, and No Risk.

- Tape the signs (Higher Risk, Medium Risk, Low Risk, and No Risk) on the wall.

- In clear, large letters, print each of the following sexual behaviors (or other behaviors applicable to your area or client population) on index cards, post-its, or pieces of paper, one behavior per card:

- Abstinence

- Masturbation

- Vaginal sex without a condom

- Vaginal sex with a condom 
- Hugging a person with HIV

- Kissing

- Dry sex without a condom

- Massage

- Performing oral sex on a man without a condom

- Performing oral sex on a man with a condom

- Performing oral sex on a woman without a dental dam

- Performing oral sex on a woman with a dental dam

- Infant breastfeeding by an HIV-infected mother

- Anal sex without a condom

- Anal sex with a condom

\section{Instructions}

1. Inform participants that they will complete an activity that looks at the behaviors that carry risk for contracting HIV.

2. Place the sexual behavior cards face down in a stack. Ask participants to pick a card and place it on the wall under the appropriate risk category (Higher Risk, Medium Risk, Low Risk, or No Risk) with respect to HIV transmission. (Note: Give participants some tape to affix the card on the wall under the appropriate sign.)

3. Once all the cards are on the wall, ask participants to review where the cards have been placed. Then ask participants to state whether they:

- Disagree with the placement of any of the cards

- Do not understand the placement of any of the cards

- Had difficulty placing any of the cards

4. Begin by asking participants why they think the card was placed in a certain category. Discuss the placement of selected cards, particularly those that are not clear-cut in terms of risk, or cards that are clearly misplaced. Consult the correct answers on the next page if you are unsure about where a certain behavior belongs.

5. Ask participants to look at the behaviors in the Low Risk and No Risk categories. Ask the group to identify other behaviors that could fit in these categories. Point out that some pleasurable sexual behaviors involve low or no risk.

6. Conclude by emphasizing that risk depends on the context of the behavior and other factors, such as:

- Gender

- Whether or not the partner is infected

- Whether or not the partner is the "giver" or "receiver" of the sexual behavior

- The difficulty of knowing whether or not one's partner is infected

7. Remind participants that they need to consider their values when talking about STI/HIV so that they do not impose their own values on others.

\section{Correct Answers}

NO RISK

- Abstinence

- Masturbation

- Hugging a person with HIV

- Kissing

- Massage

\section{LOW RISK}

- Vaginal sex with a condom 
- Performing oral sex on a man with a condom

- Performing oral sex on a woman with a dental dam

\section{MEDIUM RISK}

- Performing oral sex on a man without a condom

- Performing oral sex on a woman without a dental dam

- Infant breastfeeding by an HIV-infected mother who is taking ARV medicines

- Anal sex with a condom

\section{HIGHER RISK}

- Vaginal sex without a condom

- Anal sex without a condom

- Dry sex without a condom

- Infant breastfeeding by an HIV-infected mother who is NOT taking ARV medicines

\section{STEPS 13 TO 19}

\section{Time: 90 minutes}

\section{Materials and Advance Preparation \\ - None}

\section{Instructions}

\section{STEP 13. USING INFORMATION COLLECTED PREVIOUSLY, DETERMINE CLIENT'S NEED FOR NATAL, NEWBORN, AND INFANT CARE OR WELL-CHILD SERVICES.}

1. Explain that this step is the integration of postnatal, newborn, and infant care, and well-child services into the family planning session.

2. Refer to Step $\mathbf{1 3}$ on the algorithm with the participants.

3. Instruct participants to consider information that the client has provided previously during the counseling session, including her/his responses to questions in Step 3 and Step 4, to determine the client's needs for these services.

4. Instruct participants that if information was not revealed already, they should ask the following two questions of the family planning client:

- Have you given birth recently?

- Do you have any children less than 5 years of age?

\begin{tabular}{|c|c|}
\hline If the client has... & Do this... \\
\hline Given birth recently & $\begin{array}{l}\text { 1. Review Promoting a Healthy Postpartum Period for the } \\
\text { Mother counseling card with client. } \\
\text { 2. Review Newborn and Infant Health counseling card with } \\
\text { client. }\end{array}$ \\
\hline Children less than 5 years of age & $\begin{array}{l}\text { 1. Ask if children have been taken to well-child services. } \\
\text { 2. Ask if children have received all immunizations. } \\
\text { 3. Ask if children have had their height and weight moni- } \\
\text { tored. } \\
\text { 4. Refer to well-child services if needed. }\end{array}$ \\
\hline
\end{tabular}

5. Refer participants to the BCS + User's Guide and the table below to review what to do based on the client's responses.

6. Refer to the counseling card on Promoting a Healthy Postpartum Period. Review the following points that providers can use to discuss postpartum health with the client, if she has 
given birth recently:

- Ensure that the mother has support for the first few days after birth; encourage rest and sleep.

- Recommend a nutritious diet for the mother that includes plenty of fluids and micronutrients (including Vitamin A and iron).

- Discuss normal postpartum bleeding and lochia (postpartum vaginal discharge). Counsel on maternal danger signs, such as bleeding or vaginal discharge that has a foul smell.

- Discuss the need for four postnatal care visits: at 24 to 48 hours, 3 to 7 days, 4 to 6 weeks, and 4 to 6 months.

- Advise on maintaining personal hygiene, including care of perineum and breasts.

- Counsel on return to sexual activity, which should be whenever the mother feels ready and usually after lochia stops. Advise that she can become pregnant again even before her menses returns, if she is not using contraceptives.

- Counsel on postnatal depression, which may entail: crying easily; feeling tired, agitated, or irritable; lacking motivation; having difficulty sleeping; rejecting the baby.

7. Instruct providers that if they are unable to counsel or provide postpartum services, they should refer the client to the appropriate facility where the client can receive these services.

8. Refer to the counseling card on Promoting Newborn and Infant Health and provide instructed counseling and services. Review the following points that providers can use to discuss newborn and infant health with the client, if she has given birth recently:

- Discuss careful hand washing to prevent infection prior to handling the baby and after changing diapers.

- Counsel the mother on newborn danger signs and when to seek care immediately. Danger signs include: difficulty feeding and/or breathing; feeling too hot or too cold; being irritable for extended period of time.

- Discuss the importance of providing good ventilation and keeping the baby warm.

- Encourage exclusive breastfeeding for 6 months. Nothing else is necessary, not even water. Introduce complementary foods at 6 months and continue to breastfeed.

- For infants exposed to HIV:

- Advise mother to give infant anti-retroviral drugs (ARVs) daily while breastfeeding and continue for one week after cessation of breastfeeding (around one year) and advise mother to continue ARV per national protocols.

- Recommend that HIV-exposed infants be tested for HIV at 6 weeks and start co-trimoxazole prophylaxis (CTX).

- Link mother and infant to HIV clinic.

- Explain immunization schedule for infants using national or global guidelines, and include recommendation for Vitamin A at 6 months.

- Discuss the need to attend child-welfare clinic (including key activities such as growth monitoring).

9. Instruct providers that if they are unable to counsel or provide infant or newborn services, they should refer the client to the appropriate facility where she can receive this counseling and services.

10. Explain to participants the types of services that are included in well-child services and the importance of receiving timely care and monitoring during the first five years of a child's life. Read them the list of services that may be included in well-child services, below:

- Immunizations

- Growth monitoring

- Infant feeding support

- Vitamin A provision at 6 months

- Sick child services (including Integrated Management of Childhood Illnesses, IMCI) 
11. Instruct providers that if the client has a child under 5 years of age, they should ask her/ him if the child has been taken to well-child services, and provide or refer client for these services, if needed.

12. If client reported a recent abortion, review the Post Abortion Care card with the client. Provide or refer for post abortion care services, if needed.

13. Ask participants if there are any questions about postpartum,well-child, or post abortion care services.

STEP 14. ASK CLIENT WHEN SHE HAD HER LAST SCREENING FOR CERVICAL CANCER (VIA/VILI OR PAP SMEAR) OR BREAST CANCER.

1. Referring to User's Manual, explain to participants that cervical cancer:

- Results from uncontrolled, untreated growth of abnormal cells in the cervix.

- Is caused by a sexually-transmitted infection, the human papillomavirus (HPV).

- Takes 10 to 20 years to develop, so there is a long period of opportunity to detect and treat changes and growths before they cause cancer.

2. Referring to User's Manual, explain to participants that screening for cervical cancer:

- Helps to detect any changes and precancerous growths before they become cancer.

- Is simple, quick, and generally not painful.

3. Instruct providers that after informing client about cervical cancer, they should ask her when she had her last screening for cervical cancer.

4. Refer participants to the BCS+User's Guide and the table below to review what to do based on the client's responses.

\begin{tabular}{l|l} 
If the client has... & Do this... \\
\hline $\begin{array}{ll}\text { Had her last screening more than } 3 \text { years } \\
\text { ago }\end{array}$ & $\begin{array}{l}\text { Provide Pap smear or VIA/VILI screening test. } \\
\text { OR }\end{array}$ \\
$\begin{array}{ll}\text { OR } \\
\text { Does not know when her last screening } \\
\text { was }\end{array}$ & $\begin{array}{l}\text { Refer for Pap smear or VIA/VILI screening test at appropriate } \\
\text { facility when test available. }\end{array}$ \\
$\begin{array}{ll}\text { Had her last screening less than 3 years } \\
\text { ago }\end{array}$ & Advise client when to seek next screening \\
\hline
\end{tabular}

5. Ask participants if they have any questions about cervical cancer screening.

6. Review Breast Cancer Information and Awareness counseling card with client.

7. Ask participants if they have questions about breast cancer information and awareness.

\section{STEP 15. DISCUSS STI/HIV TRANSIMISSION \& PREVENTION AND DUAL PROTECTION WITH THE CLIENT USING THE COUNSELING CARD. OFFER CONDOMS AND INSTRUCT HER/HIM IN CORRECT AND CONSISTENT USE. ${ }^{3}$}

1. Explain that this is the first part of integrating STI/HIV counseling and testing into the family planning session.

2. Refer to the counseling card on STI/HIV Transmission \& Prevention. Review the following points that providers can use to discuss STIs/HIV with the client:

- A person can become infected with STIs, including HIV and Zika, through unsafe or unprotected sexual activity.

- STIs are common and Zika is common in some areas.

- A person living with STIs (including HIV) may have no symptoms, may look healthy, and may not be aware that $\mathrm{s} /$ he is infected.

- Common STI symptoms include vaginal discharge, discharge from the penis, sores in the genital area, burning on urination for men, lower abdominal pain for women.

In regions with active Zika transmission/travelers to active Zika regions, also use Zika counseling card 
- Some STIs can be treated. To avoid re-infection, both partners must be treated.

- Risk of infection can be reduced by using a condom, limiting the number of sex partners, and delaying sex (adolescents).

- HIV is a sexually transmitted infection. HIV is transmitted through an exchange of bodily fluids such as semen, blood, breast milk, and during delivery.

- Knowing your HIV status protects you, your partner, and your family.

- Although HIV cannot be cured, early identification and treatment can allow a person to live a long, productive life and prevent his/her partner from becoming infected.

- Male circumcision reduces the risk of heterosexually acquired HIV infection in men by approximately $60 \%$ and should be one element of a comprehensive HIV-prevention package.

- Maternal transmission of HIV to the child can be substantially reduced by identifying women living with HIV and providing treatment or prophylactic ARV medicines during pregnancy.

3. Instruct participants that after discussing HIV transmission and prevention, s/he should ask the client whether s/he has any questions.

4. Explain to the participants that dual protection is the simultaneous prevention of STIs and pregnancy.

5. Refer to counseling card on Dual Protection. Review the following points that providers can use to discuss Dual Protection with the client:

- Dual protection is the use of condoms consistently and correctly in combination with another family planning method. This provides added protection against pregnancy in case of condom failure.

- Use a male or female condom correctly and consistently with every act of sex. This one method protects against STIs and pregnancy.

- Only engage in safer sexual intimacy that prevents semen and vaginal fluids from coming in contact with partner's genitals or other vulnerable areas, such as the mouth and anus.

- Delay or avoid sexual activity, especially with a partner whose STI/HIV status is not known.

6. Instruct providers to ask client if she/he has any questions.

7. Instruct providers to offer condoms, if available, to clients. If not available, providers should tell clients where to get them.

8. Point out that providers should also show the client how to properly use a condom.

9. Demonstrate how to use a condom in front of the class. If participants are comfortable with condoms, have one of them demonstrate how to use it.

STEP 16A. CONDUCT STI AND HIV RISK ASSESSMENT USING THE COUNSELING CARD. IF SYMPTOMS ARE IDENTIFIED, TREAT HER/HIM SYNDROMICALLY.

1. Explain that at this stage, the provider should explore what the client knows about STIs, HIV, and AIDS in order to correct any misinformation, fill in gaps, and answer questions.

2. Ask participants to refer to the BCS+ counseling card on STI and HIV Risk Assessment. It contains the following points that a provider discusses with clients to help them perceive their risk of STI/HIV:

- HIV status and HIV status of partner(s). If partner is positive, whether s/he is taking ARV medicines.

- Number of sexual partners, both current and in the past.

- Knowledge of partner's sexual practices and past partners.

- Knowledge of male partner's circumcision status.

- Past and present condom use (including perception of partner's attitude) and whether s/he is aware that condoms protect against both STIs/HIV and pregnancy. 
- Type of sex or sexual activities and behaviors (for example, mutual monogamy, whether partner has other sexual partners, oral sex, anal sex, dry sex, or use of detergents and/or spermicides).

- Home-life situation (for example, partner violence and social support).

- Use of PMTCT services during pregnancy, delivery, and breastfeeding.

3. Ask participants whether they have any questions about the STI and HIV risk assessment or the above-mentioned points.

4. Explain that at this point the provider has an opportunity to correct misinformation, fill in the gaps, and answer any questions the client may have about STIs and HIV.

5. Mention that once the provider has a clearer picture of the client's sexual risks and social context, $\mathrm{s} /$ he can help the client make a plan to reduce risk using any of the following strategies:

- Reducing the number of sexual partners.

- Using condoms (male or female) correctly and consistently with every act of sex. Condoms are the only method that protects against STIs, including HIV.

- Making condoms available to her/his partner and encourage their use correctly and consistently.

- Avoiding the use of unclean skin-cutting instruments and/or injection needles.

- Having any STI or cervical infection detected and treated immediately.

- Undergoing any procedures involving the genital tract in an aseptic environment.

- Practicing dual protection.

- Knowing your HIV status.

6. Inform providers that they have a responsibility to help the client reduce her/his risk of acquiring HIV and STIs.

7. Instruct participants that, if client has STI, they should treat her/him syndromically according to national guidelines or refer her/him for tests, if available.

8. Refer participants to guidelines for STIs or national guidelines for STI management.

\section{STEP 16B. IN REGIONS WITH ACTIVE TRANSMISSION/TRAVELERS TO ZIKA REGIONS, CONDUCT ZIKA RISK ASSESSMENT USING COUNSELLING CARD.}

\section{STEP 17. ASK CLIENT WHETHER SHE/HE KNOWS HER/HIS HIV STATUS.}

1. Instruct participants to gently inquire whether the client knows her/his HIV status.

2. Inform the client that you will not share her/his status without consent.

3. Review the following table in User Manual with participants and walk through instructions on appropriate HIV counseling and testing according to client's knowledge of HIV status and testing status.

\begin{tabular}{|l|l|}
\hline If the client has: & Do this: \\
\hline Knows HIV status and is living with HIV & $\begin{array}{l}\text { 1. Review Positive Health, Dignity, \& Prevention counseling } \\
\text { card with client. }\end{array}$ \\
$\begin{array}{ll}\text { 2. Ask when the client last attended a health facility for her/ } \\
\text { his monitoring visit. } \\
\text { 3. Refer client to center for wellness care and treatment, if } \\
\text { necessary. }\end{array}$ \\
\hline Knows HIV status and is negative & Discuss time frame for repeat testing
\end{tabular}

If client knows her/his HIV status and is living with HIV:

- Review counseling points listed on the Positive Health, Dignity, \& Prevention counseling card with participants. Read the following points out loud to participants: 
- People living with HIV should always use a condom correctly and consistently with their sexual partners.

- If a woman with HIV wants to get pregnant, the risk of her passing HIV to her newborn may be greatly reduced by taking antiretroviral (ARV) medicines and having a safe delivery. It is important to receive care at an antenatal care clinic and an HIV treatment center.

- People living with HIV need regular health checkups to see if they need ARV medicine, to evaluate how they are doing on ARV medicines, and to rule out other infections or illnesses.

- If a client is taking ARV medicine, s/he should attend follow-up clinic visits as recommended by the provider. Visits may be more frequent when ARV medicines are initiated.

- The client should do her/his best to adhere to the medication regimen prescribed and should not share medications.

- Partners should get tested as well. The client can bring her/his partner in for counseling, to talk together, if this will help.

- If currently taking medications for tuberculosis, $\mathrm{s} /$ he should follow up with provider.

- Positive health results from taking care of oneself and being alert to health concerns that warrant attention, which may include physical and mental health issues as well as social support.

- Instruct participants that they should give support to clients and encourage them to disclose their status with their partners. Explain to participants that there are benefits to disclosing one's status. Read the following benefits out loud, and explain that disclosing one's HIV status will help the client:

- Get support from their spouse, family, and health center.

- Better plan and make appropriate decisions about HIV care and support and family matters.

- Get early access to medicine and support that keeps them healthy.

- Save an HIV-negative partner's and unborn child's life by not infecting them.

- Better negotiate condom use with their partner to prevent them from being infected.

- Avoid exposure to repeated infections that will compromise their health.

- Read the following risks of disclosing one's HIV status and explain that there may be risks associated with disclosing one's status as well:

- Stigmatization and discrimination from family, friends, and community.

- Abuse from spouse.

- Divorce from spouse.

- Inform participants that they should be sensitive and receptive to all concerns and questions clients may have.

- Explain that they should be prepared to offer resources, if available, to people living with HIV who face abuse or difficult family situations because of their status.

- Point out that as providers, they should be able to inform clients about the importance of being healthy, answer questions, and refer clients to appropriate facility for comprehensive care.

- Instruct participants to become aware of HIV health and wellness centers and services available. Explain that they should refer clients to the appropriate services when needed.

If client know her/his HIV status and is negative:

- Instruct participants to discuss HIV retesting with a client who knows her/his HIV status and is HIV negative. The provider should consider the client's risk assessment and sexual behaviors to decide the most appropriate frequency for HIV testing.

- Explain HIV retesting to participants, including the fact that global recommendations on HIV retesting, including frequency of testing, vary depending on client's risk behaviors and sexual practices.

- Instruct providers to refer to their national guidelines and protocol to determine the appropriate time frame and recommendations for HIV retesting. 
- Explain that providers should emphasize that prevention, early detection, and prompt management of STIs, including HIV, are beneficial to clients, their partner and family, and the community at large.

\section{If client does not know her/his HIV status:}

- Mention that the provider should use the HIV Counseling and Testing (HCT) card to guide the discussion about HIV testing. Below are the key points providers should cover with the client:

- Knowing your HIV status can help you make decisions about protecting yourself and your sexual partner(s).

- Testing permits people living with HIV to seek treatment so that they can live a full life. The test involves taking a small sample of blood. The test is free and available at clinics, hospitals, and HIV counseling and testing sites.

- Test results are kept confidential.

- When a person is first infected with HIV, it can take 3 or more months or the test to detect the infection. This is called the "window period" and is the reason why repeat testing is important.

- A positive test result means the person is infected with HIV and can transmit the virus to others.

- A negative test result can mean the person is not infected or that $\mathrm{s} /$ he is in the "window period." Another test should be taken within 3 months. If the second test is still negative, the person is currently not living with HIV but can still become infected with HIV.

- HIV is a sexually transmitted infection (STI). It is important to ask your sexual partner(s) to be tested too.

- Instruct providers to emphasize to the client that prevention, early detection, and prompt management of STIs, including HIV, are beneficial to them, their partner and family, and the community at large.

- Explain to participants that testing for HIV is often a very frightening event for individuals. Many people who know they should be tested do not do so out of fear and other reasons.

- Point out that as providers, they should be able to respond to the fears, excuses, and arguments that clients offer as to why they will not or cannot be tested.

- Refer to User's Manual and briefly discuss WHO's policy on provider-initiated HIV testing and counseling (PITC).

- Instruct providers to offer or initiate HIV testing, according to national protocols, in the family planning clinic. If testing services are not provided, explain to providers that they should refer the client to specialized HTC services.

- Explain that participants should be prepared to counsel client on the results of the HIV test.

- Point out that if the client's test is positive, participants should review the Positive Health, Dignity, \& Prevention card with the client and should refer client to a center for wellness care and treatment to receive necessary HIV-related services.

Counsel client using Women's Support and Safety Card

- If client shows any major Intimate Partner Violence (IPV) triggers, refer her for specialized services.

\section{STEP 18. GIVE FOLLOW-UP INSTRUCTIONS, A CONDOM BROCHURE, AND THE BROCHURE FOR THE} METHOD CHOSEN. SET A DATE FOR NEXT VISIT.

1. Remind participants that the provider should summarize the key points mentioned during the consultation.

2. Explain that the provider then gives the client follow-up instructions for the method chosen along with the corresponding method brochure.

3. Mention that the provider also gives the client a brochure on condoms, reiterating the fact that only condoms provide dual protection against both STIs and unintended pregnancy. 
4. Mention that providers may need to give the client a follow-up appointment, depending on the method provided.

5. Review some of the reasons why a client should return to the clinic, for example:

- Check on how the client is using the method.

- Provide a new supply of the method.

- Provide information and support needed for the client to continue using the method correctly and consistently, or to select another method.

- Bring the partner for further counseling on family planning and/or STI/HIV.

- Have an HIV test.

6. Explain that it is important to encourage the client to return to the health care facility any time s/he has a question or wishes to change methods.

\section{STEP 19. THANK HER/HIM FOR THE VISIT. COMPLETE THE COUNSELING SESSION.}

1. Mention that the provider should be warm and cordial when ending the session. This attitude will encourage the client to feel welcome to return.

2. Remind participants that a client has the right to change her/his reproductive goals and to stop using the family planning method if $\mathrm{s} /$ he wishes.

\section{PRACTICE SESSION ROLE PLAYS}

\section{Total Time: 90 minutes}

By the end of this session, participants will be able to:

- Counsel clients using the BCS+ job aids

\section{Materials and Advance Preparation}

- Divide the number of participants expected for the workshop by two. This is the number of role-play scripts you will need.

- Make enough copies of the role-play scripts (found at the end of this exercise) to accommodate the number of participants who will need a script. It is okay if a couple of participants are playing the same role of client. (Note: There are two role plays. You can use the same role-play scripts, just make sure participants get a different script for the second role play.)

- Feel free to make up your own scripts or roles.

- Cut along the lines so that you can give each participant playing the role of client a script to use.

- Note that the ideal method for each role is written in parentheses at the end of each script.

\section{ROLE PLAY \#1}

Time: 30 minutes

\section{Instructions for Role Play \#1}

1. Ask the participants to stand up. Have them count off "1," " 2, ," "1," "2," etc.

2. Explain that all of the " $1 \mathrm{~s}$ " will play the "family planning providers," and all of the " $2 \mathrm{~s}$ " will be "family planning clients."

3. Ask all of the " $2 \mathrm{~s}$ " to raise their hands.

4. Ask the " $1 \mathrm{~s}$ " to find a participant to work with.

5. Once participants have found partners, give each participant playing the "client" a script.

\section{Conducting the Role Play \#1}

1. Tell participants to find a place in the room where they will conduct their counseling session. (Note: Do not let them sit down yet.) 
2. Ask participants to begin the role play standing so that they can greet the client. After greeting the client, they may sit down and begin the counseling session.

3. Allow about 30 minutes for the role play.

4. After 25 minutes, tell participants that they have 5 minutes to conclude their counseling session. (Note: During the role play, walk around and observe how participants are doing. Note anything you see that is not being done well and recount that information when you evaluate the role play.)

\section{Evaluating the Role Play}

1. When the time is up, ask the participants who played the providers what it was like going through the entire BCS+ process, using the algorithm and job aids.

2. Ask whether they have any questions or comments about using the BCS+ algorithm, counseling cards, WHO MEC wheel, or method brochures to counsel their client.

3. Answer all questions and address all comments before proceeding. (Note: It is important that you be familiar with using the BCS+ job aids to counsel family planning clients. This experience will help you better answer participants' questions and comments.)

4. Ask the participants who played the clients the following questions:

- What was it like to be counseled using the BCS+ approach?

- Was anything confusing to you? If so, what?

- Do you have any tips for the participants who played the provider? (Note: Write the tips on newsprint or flipchart paper.)

5. Provide any positive reinforcement and input based on your observations during the role plays.

\section{ROLE PLAY \#2}

Time: 30 minutes

\section{Instructions for Role Play \#2}

1. Tell participants that they are going to reverse roles. The person who was the client is going to play the provider, and the provider will now be the client.

2. Give each client a script with a role on it. (See scripts for role play \#2 at the end of this section.)

\section{Conducting the Role Play}

1. Ask participants to begin the role play by greeting each other as in the previous role play.

2. Allow about 30 minutes for the second role play.

3. During the role play, walk around and observe how participants are doing. Note anything you see that is not being done well and recount that information for when you evaluate the role play.

\section{Evaluating the Role Play}

1. When the time is up, ask the participants who played the providers what it was like to use the BCS+ algorithm and job aids.

2. Ask whether they have any questions about how to use the BCS+ algorithm, counseling cards, WHO MEC Wheel, or method brochures. Answer all questions before proceeding.

3. Ask the participants who played the clients the following questions:

- What was it like to be counseled using the BCS+ approach?

- Was anything confusing to you? If so, what?

- Do you have any tips for the participants who played the provider? (Note: Write the tips on newsprint or flipchart paper.)

4. Mention your comments based on your observations during the role plays.

5. Address all questions and comments before proceeding to the next step. 


\section{Client Scripts for Practice Session Role Plays}

You are a 23 -year-old married woman who has two young children. You want to wait 2 to 3 years before getting pregnant again. Your husband is not interested in family planning. You have not used modern contraceptive methods before. Your last child is 5 months old, and you are breastfeeding. You are very worried about using the IUD and refuse it if offered. You are not sure of your HIV status, but think your husband had many partners before marriage. You have never been screened for cervical cancer.

(Combined Injectable Contraceptive [CIC])

You are a 26-year-old woman who gave birth a week ago. You mix feed because you are at work during the day and do not have enough milk to express. You previously used a 3-month injectable but now want to change to a different method since you are tired of an injection. You are on anti-hypertensive medication and your blood pressure is controlled.

(Progestin-only oral contraceptive-Minipill)

You are a 40-year-old woman who has tested HIV positive a month ago. Your CD4 count is $<200$ and you have uncontrolled high blood pressure. The doctor has initiated you on ARVs. You would like to continue using a 3-month injectable which has never given you problems since you were a teenager.

(Progestin-only injectable)

You are an 18-year-old girl. You started your menstrual bleeding 10 days ago. You are sexually active and have a boyfriend. You want to avoid getting pregnant and want the Pill, because you heard the Pill prevents pregnancy. Neither you nor your boyfriend wants to use condoms. Later on in the consultation you reveal that you had unprotected sex 2 days ago. You have a slight vaginal discharge.

(Emergency Contraceptive Pills [ECPs] and the Pill)

You are 25 years old and have multiple sexual partners. You slowly reveal that you are a sex worker trying to earn enough money to support your two children. Your (paying) partners do not like to use condoms. You have heard of sexually transmitted diseases and are afraid of getting one. You also cannot afford to get pregnant again.

(Female condom)

You are an adolescent boy who has come to the clinic with an STI but not HIV. You are concerned about getting an STI again. You have had several girlfriends. Your current girlfriend wants to get pregnant to show you that she loves you, but you are not so happy about the idea. If the "provider" offers you condoms, agree. Before you leave, ask the provider how your girlfriend can avoid getting pregnant.

(Male condom and the provider should encourage the girlfriend to come in.) 
You are a 30-year-old married woman who does not want to have any more children. You already have four (your latest child is 3 months old) and are tired and fed up with being pregnant. Your partner is interested in more children. Your husband likes having sex frequently and does not like using condoms. You are afraid of injections. You have had mild seizures in the past and sometimes take medicine for them. If offered the minipill, explain that you are afraid you will forget to take the pill every day. Your husband travels occasionally and you are not sure if he is faithful.

(IUD)

You are a 20-year-old woman with a 4-month-old child that you are breastfeeding. Your husband is working on a farm as a migrant laborer and is gone 22 days of the month. You have never used family planning but want to control your fertility. You are about to start your menstruation. It is Monday, and your husband is coming home this weekend. He does not like to use condoms and is not supportive of family planning. If offered the IUD, explain that you cannot afford to go to the hospital, which is 100 miles away.

(Progestin-only oral contraceptive-Minipill)

You are a 35-year-old married woman with 3 children. The youngest child is 6 weeks old. You are not ready to have another child. Your husband does not cooperate with family planning. You live fairly far from the health center. You have heard negative things about the IUD and refuse it if offered. If offered implants, explain that your husband would notice and be angry. You had an extramarital affair several years ago.

(Progestin-only injectable — DMPA only requires client to return every 3 months)

You are 18 years old and single. You have a boyfriend and do not want to get pregnant. You and your boyfriend go to school. You are about to begin your menstruation. If offered the IUD or Norplant, reveal that you do not want something foreign in your body. If offered injectables, scream and say you hate needles. If offered the minipill, explain that you have come to the clinic before for the minipill, but they are always out of stock. You have no conditions that prevent you from taking the Pill. Besides, there is a pharmacy in your community that carries the most popular Pill. You have had several boyfriends in the past.

(Combined oral contraceptives)

You are 29 years old and have been fully breastfeeding your child and using LAM as a birth control method. You are beginning to give your infant food. You want to make sure that using LAM is still effective. You have chosen LAM because you want to breastfeed your baby, and you are very religious. You and your husband do not believe in modern contraceptive methods. Your husband supports you in wanting to space your children. If TwoDay Method is offered, you do not want to touch your genitals. Both you and your husband are monogamously faithful.

(Standard Days Method) 
You are a 22-year-old woman with a 1-year-old child. You are in a stable marriage, and your husband supports family planning. You do not like modern contraceptive methods. Sometimes he will use a condom but not consistently because it reduces feeling for him. You do not like the side effects of hormonal methods. You are religious and would not like a modern method. If the provider offers you a fertility awareness method, such as Standard Days Method or TwoDay Method, appear to be interested. Then, reveal that your monthly menstruation cycles are very irregular.

(Female condom)

You are 39 years old and have 6 children. You are tired and do not want any more children. Your husband cooperates with family planning but will not use a condom. You have tried hormonal methods in the past but do not like the side effects. Furthermore, you were not good at remembering to take the pill, which resulted in your fifth pregnancy. You are afraid of the IUD and you have heard that women can get pregnant with it. You live far away from the hospital, but with planning could go there. Despite your dislike of the side effects of the Pill, you would be open to a monthly injectable until you get a tubal ligation at the hospital. You suspect your husband has not been faithful.

(Combined Injectable Contraceptive [CIC] until client can get a tubal ligation at the hospital)

You are a 38-year-old man who has come to the clinic with his wife who wants family planning. You cannot afford to have any more children-you have 5 children now. Your wife has used several methods, but she has still had 5 pregnancies. You both feel you have enough children. If tubal ligation is offered, mention that your wife just discovered she is pregnant. Toward the end of the consultation, also reveal that you are HIV positive. You confess that you have had many women in the past.

(Vasectomy) 


\section{Next Steps and Closing}

Total Time: 15 minutes

By the end of this exercise, participants will have:

- Made a plan to incorporate the BCS+ in their counseling work in their health care facility

\section{Materials and Advance Preparation}

- Have flipchart (newsprint) paper and markers available.

- If certificates of completion will be given to participants, have them made, signed, and ready to distribute at the end of the workshop.

\section{Instructions}

1. Ask participants how they like using the BCS+ and job aids.

2. Remind participants that the 19-step BCS+ algorithm is a summary of the BCS+User's Guide and is easier to refer to when on the job.

3. Encourage participants to review sections of the BCS+User's Guide to remind them exactly how to conduct each of the 19 steps.

4. Ask participants what steps they will take to implement the BCS+ model at work. In other words, how will they do things differently when they go back to the clinic?

5. Write their responses on newsprint or flipchart paper.

6. Ask participants what they can do to promote the use of the BCS+ in their health care facilities. (Note: Write responses on newsprint or flipchart paper.)

7. Ask whether there are any comments or questions before closing the workshop.

8. Remind participants that the BCS+ Toolkit is also available electronically. The job aids (algorithm, counseling cards, and method brochures) can be easily adapted or revised to support national and/or regional protocols. Guidelines for adapting these job aids are provided in the BCS + User's Guide.

9. Thank participants for their participation.

10. Conduct any closing activities and distribute certificates of completion, if available. 


\section{$\prod_{\text {Appendix }}$}

FIGURE 1. BCS+ METHOD CARDS

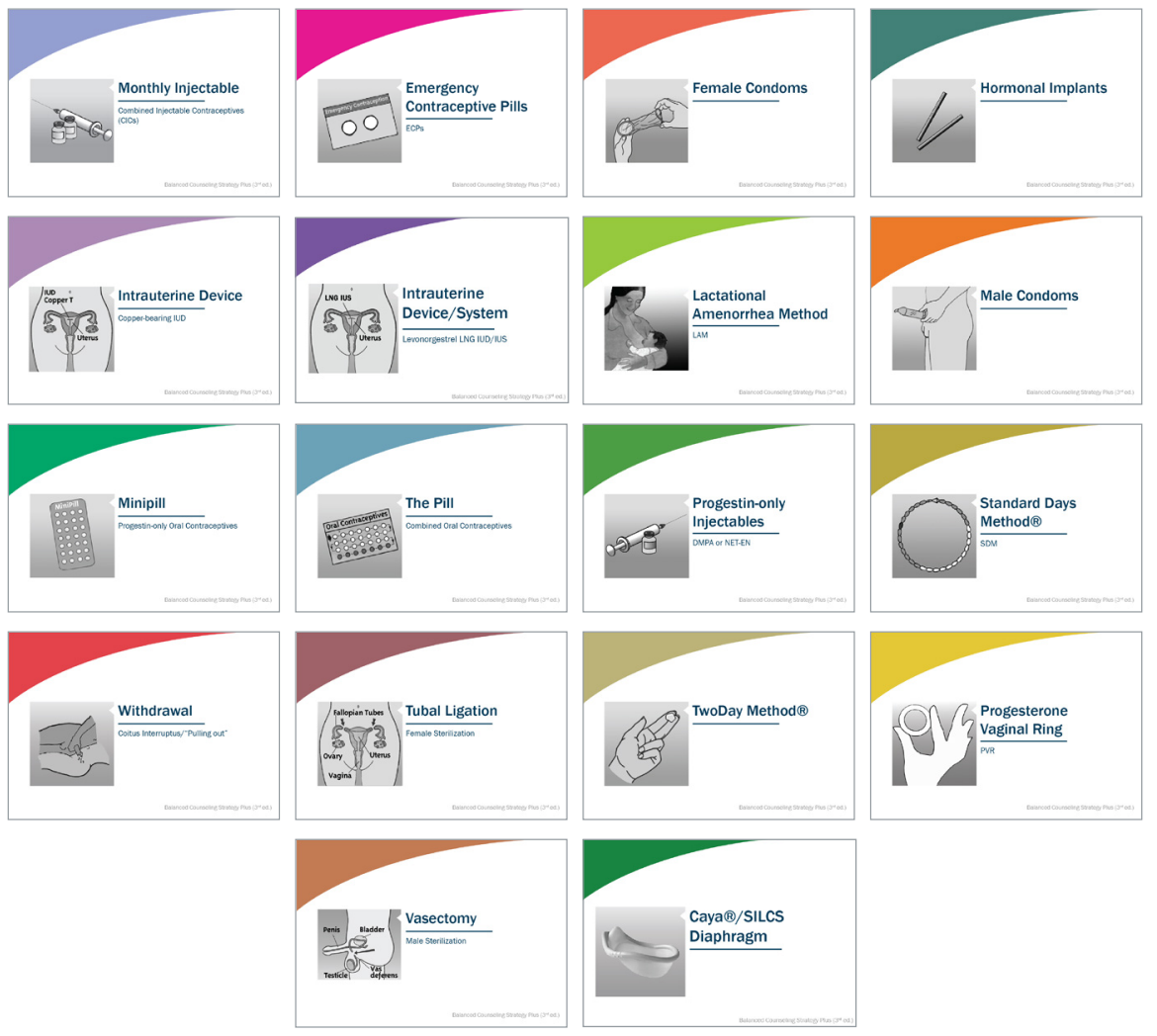

FIGURE 2. METHOD CARDS ARRANGED ACCORDING TO EFFECTIVENESS

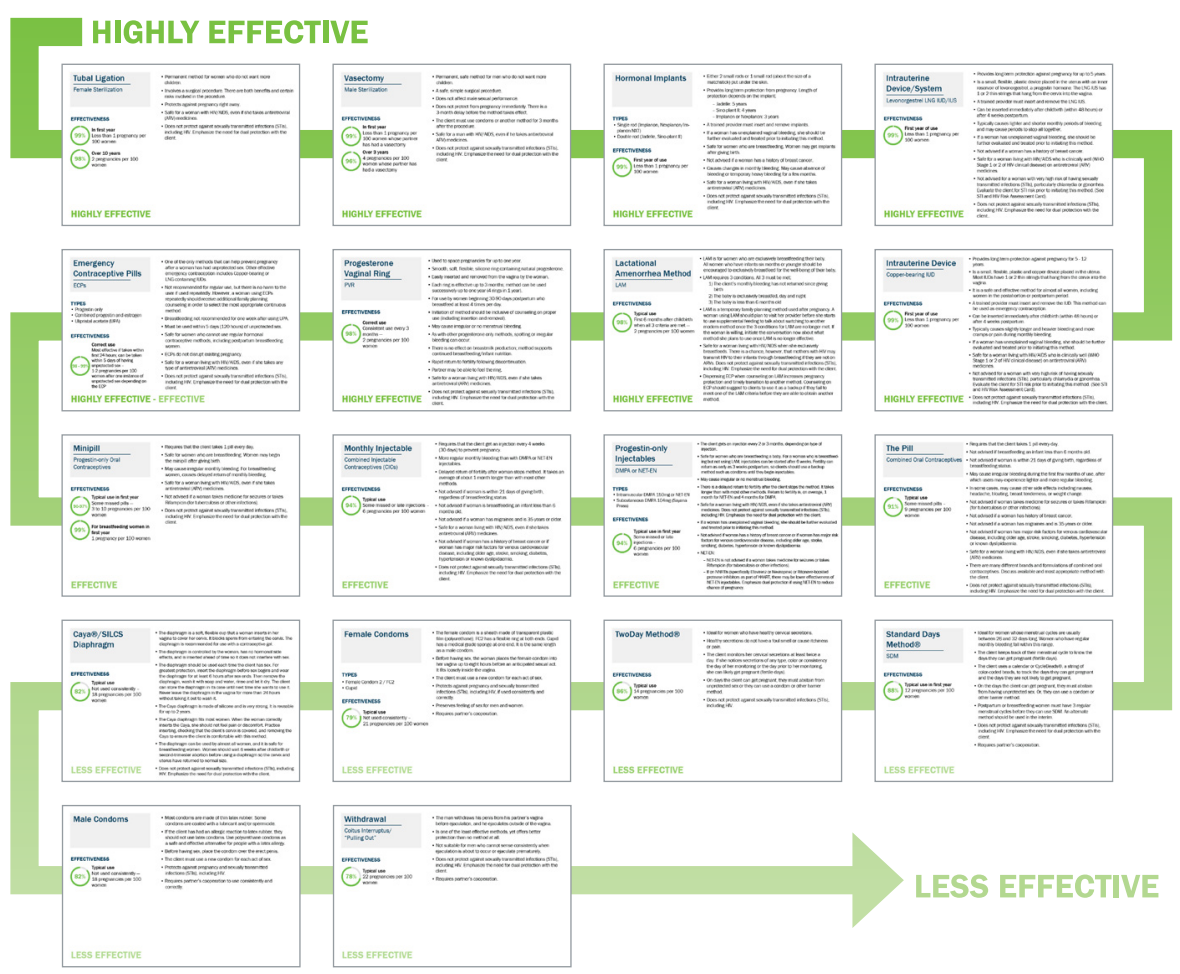




\section{ҐF For Additional Reference}

\section{FRONTIERS}

Journal Article: Liambila, W., Askew, I., Mwangi, J., Ayisi, R., Kibaru, J., \& Mullick, S. (2009). Feasibility and effectiveness of integrating provider-initiated testing and counseling within family planning services in Kenya. AIDS (London, England), 23 Suppl 1, S115-21.

Report: Feasibility, Acceptability, Effect and Cost of Integrating Counseling and Testing for HIV within Family Planning Counseling and Testing for HIV within Family Planning Services in Kenya http://pdf.usaid.gov/pdf docs/Pnadn569.pdf

Video: Using the Balanced Counseling Strategy Plus in South Africa http://www.popcouncil.org/ research/using-bcs-in-south-africa

\section{INTEGRA INITIATIVE}

Journal Article: Ndwiga, C., Abuya, T., Mutemwa, R., Kimani, J. K., Colombini, M., Mayhew, S., ... Warren, C. E. (2014). Exploring experiences in peer mentoring as a strategy for capacity building in sexual reproductive health and HIV service integration in Kenya. BMC Health Services Research, $14,98$.

Policy Brief: http://www.integrainitiative.org/wp/wp-content/uploads/2015/09/Integra-Steps02-peer-mentoring.pdf

Website: http://www.integrainitiative.org/projects/integrainitiative/overview-and-objectives/ 
Askew, Ian. 2007. "Achieving synergies in prevention through linking sexual and reproductive Health and HIV services," in Donta, Balaiah et al. (eds.), Proceedings of the International Conference on Actions to Strengthen Linkages between Sexual and Reproductive Health and HIV/AIDS. Mumbai: Indian Society for the Study of Reproduction and Fertility and World Health Organization.

Central Bureau of Statistics (CBS) [Kenya], Ministry of Health (MOH) [Kenya], and ORC Macro. 2004. Kenya Demographic and Health Survey 2003. Calverton, Maryland: CBS, MOH, and ORC Macro.

Engenderhealth and Planned Parenthood Association of South Africa. 2001. Curriculum entitled: Men As Partners: A Program for Supplementing the Training of Life Skills Educators, 2nd Edition. New York: Engenderhealth and Planned Parenthood of South Africa. 2002.

Hatcher, R.A. et al. 2011. Contraceptive Technology. Twentieth Revised Edition. New York: Ardent Media.

León, Federico R. 1999. "Peru: Providers' compliance with quality of care norms," FRONTIERS Final Report. Washington, DC: Population Council.

León, Federico R. et al. 2001. "Length of counseling sessions and the amount of relevant information exchanged: A study in Peruvian clinics," International Family Planning Perspectives 27(1):28-33, 46.

León, Federico R. et al. 2003a. "Effects of IGSS's job aids-assisted balanced counseling algorithms on quality of care and client outcomes (Guatemala)," FRONTIERS Final Report. Washington, DC: Population Council.

León, Federico R. et al. 2003b. "Enhancing quality for clients: The Balanced Counseling Strategy," FRONTIERS Program Brief No. 3. Washington, DC: Population Council.

León, Federico R. et al. 2003c. "Testing balanced counseling to improve provider-client interaction in Guatemala's MOH clinics,” FRONTIERS Final Report. Washington, DC: Population Council.

León, Federico R. et al. 2004. "One-year client impacts of quality of care improvements achieved in Peru,” FRONTIERS Final Report. Washington, DC: Population Council.

León, Federico, Ricardo Vernon, Antonieta Martin, and Linda Bruce. 2008. The Balanced Counseling Strategy: A Toolkit for Family Planning Service Providers. Washington, DC: Population Council.

Liambila, Wilson et al. 2008. "Feasibility, effectiveness and cost of models of integrating counseling and testing for HIV within family planning services in Kenya," FRONTIERS Final Report. Washington, DC: Population Council.

Mullick, Saiqa, Mantshi Menziwa, Doctor Khoza, and Edwin Maroga. 2008. "Feasibility, effectiveness and cost of models of integrating counseling and testing for HIV within family planning services in North West Province, South Africa," FRONTIERS Final Report. Washington, DC: Population Council.

Stanback, J. et al. 1999. "Checklist for ruling out pregnancy among family-planning clients in primary care," Lancet 354(9178):566.

World Health Organization. 2003. Guidelines for the Management of Sexually Transmitted Infections. Geneva: WHO.

—. 2004. Medical Eligibility Criteria for Contraceptive Use, 3rd ed. Geneva: WHO. 
— . 2005. Sexually Transmitted and Other Reproductive Tract Infections: A Guide to Essential Practice. Geneva: WHO.

— . 2015. Medical Eligibility Criteria for Contraceptive Use. 5th ed. Geneva: WHO.

— . 2010. WHO Technical Consultation on Postpartum and Postnatal Care. Geneva: WHO.

— . 2016. Prevention and Transmission of Zika Virus: Interim Guidance. WHO /ZIKV /MOC/16. 1 Rev. 3

World Health Organization, Department of Reproductive Health and Research (WHO/RHR) and Johns Hopkins Bloomberg School of Public Health/Center for Communication Programs (JHU/CCP) INFO Project. 2011. Family Planning: A Global Handbook for Providers. Baltimore and Geneva: $\mathrm{JHU} / \mathrm{CCP}$ and WHO.

World Health Organization and Joint United Nations Programme on HIV/AIDS (UNAIDS). Guidance on Provider-Initiated HIV Testing and Counseling in Health Facilities. Geneva: WHO. 


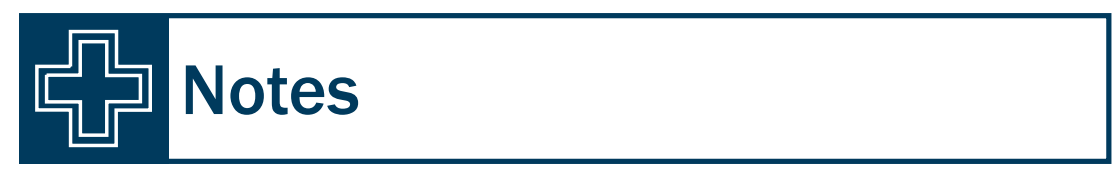




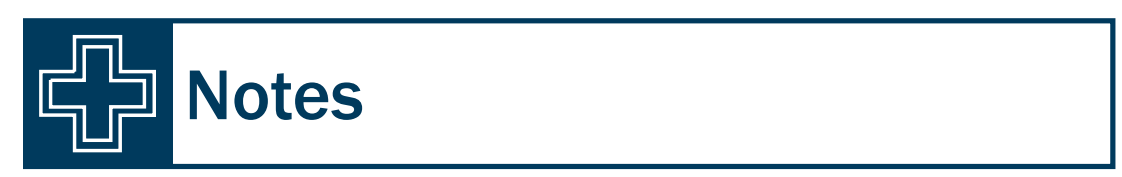




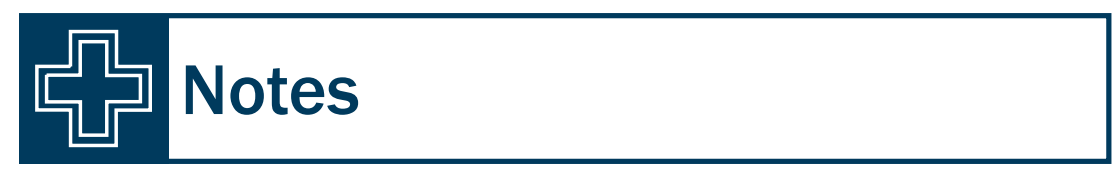


The Population Council confronts critical health and development issues-from stopping the spread of HIV to improving reproductive health and ensuring that young people lead full and productive lives. Through biomedical, social science, and public health research in 50 countries, we work with our partners to deliver solutions that lead to more effective policies, programs, and technologies that improve lives around the world. Established in 1952 and headquartered in New York, the Council is a nongovernmental, nonprofit organization governed by an international board of trustees.

For additional information please contact:

Population Council

4301 Connecticut Ave., NW, Suite 280

Washington, DC 20008 USA

Telephone: (202) 237-9400

Facsimile: (202) 237-8410

E-mail: publications@popcouncil.org

www.popcouncil.org 


\section{Algorithm for Using the Balanced Counseling Strategy Plus \\ THIRD EDITION, 2015}

\section{PRE-CHOICE STAGE}

(1) Establish and maintain a warm, cordial relationship.

(2) Inform client (and partner, if present) that there will be opportunities to address both health needs and family planning needs during this consultation.

(3) Ask client about current family size and current contraceptive practices. Counsel client on Healthy Timing and Spacing of Pregnancy using counseling card.

a) If client is currently using a family planning method or delaying pregnancy, ask about her/his satisfaction with it and interest in continuing or changing the method.

b) If partner is present, use the male services and support card.

(4) Rule out pregnancy using the Checklist to Make Reasonably Sure a Woman is Not Pregnant card to be reasonably sure the woman is not pregnant.

5 Display all of the method cards. Ask client if she/he wants a particular method.

6) Ask all of the following questions. Set aside method cards based on the client's responses.

a) Do you wish to have children in the future?

If "Yes," set aside vasectomy and tubal ligation cards. Explain why.

If "No," keep all cards and continue.

b) Have you given birth in the last 48 hours?

If "Yes," set aside combined oral contraceptives (the pill) and combined injectables. Explain why.

If "No," continue with the next question.

c) Are you breastfeeding an infant less than 6 months old?

If "Yes," set aside the combined oral contraceptives (the pill) and combined injectable cards. Explain why.

If "No," or she has begun her monthly bleeding again, set aside the lactational amenorrhea (LAM) card. Explain why.

d) Does your partner support you in family planning?

If "Yes," continue with the next question.

If "No," set aside the following cards: female condom, male condom, Standard Days Method@, Two Days Method@, and withdrawal. Explain why.

e) Do you have any medical conditions? Are you taking any medications?

If "Yes," ask further about which conditions or medications. Refer to WHO Medical Eligibility Criteria Wheel or current national guidelines and set aside all

contraindicated method cards. Explain why.

If "No," keep all the cards and continue.

f) Are there any methods that you do not want to use or have not tolerated in the past?

If "Yes," set aside the cards the client does not want

If "No," keep the rest of the cards.

\section{METHOD CHOICE STAGE}

(7) Briefly review the methods that have not been set aside and indicate their effectiveness.

a) Arrange the remaining cards in order of effectiveness (see back of each card).

b) In order of effectiveness (highly effective to not effective), briefly review the attributes on each method card.

(8) Ask the client to choose the method that is most convenient for her/him.

a) If the client is an adolescent use the counseling card to inform her that she can get any method

9) Using the method-specific brochure, check whether the client has any condition for which the method is not advised.

a) Review "Method not advised if you..." section in the brochure.

b) If the method is not advisable, ask the client to select another method from the cards that remain. Repeat the process from Step 8.

\section{POST-CHOICE STAGE}

(10) Discuss the method chosen with the client, using the method-specific brochure as a counseling tool. Determine the client's comprehension and reinforce key information.

11. Make sure the client has made a definite decision. Give her/him the method chosen, a referral, and a back-up method depending on the method selected.

(12) Encourage the client to involve partner(s) in decisions about/practice of contraception through discussion or a visit to the clinic.

\section{SYSTEMATIC SCREENING FOR OTHER SERVICES STAGE}

13. Using information collected previously, determine client's need for postpartum, newborn, infant care, well-child services or post abortion care.

a) If client reported giving birth recently, review the Promoting Healthy Postpartum Period and Promoting Newborn and Infant Health cards with client. Provide or refer for services, if needed.

b) For clients with children less than 5 years of age, ask if children have been taken to well-child services. Provide or refer for immunizations and growth monitoring services, if needed.

c) If client reported a recent abortion, review the Post Abortion Care card with the client. Provide or refer post abortion care services, if needed.

(14) Ask client when she had her last screening for cervical cancer (VIA/VILI or pap smear) or breast cancer.

a) If her last cervical cancer screening was more than 3 years ago ( ${ }^{*} 6-12$ months if she is HIV positive) or she doesn't know, ask if she would like to have a screening.

today. Review the Screening for Cervical Cancer card. Provide or refer for services.

b) If her last cervical cancer screening was less than 3 years ago continue with next question.

c) Review Breast Cancer Information and Awareness counseling card with client.

15) Discuss STI/HIV Transmission \& Prevention and Dual Protection with client using counseling cards. Offer condoms and instructions on correct and consistent use.

a) In regions with active Zika virius, discuss Zika Transmission \& Prevention counseling card with client.

16. Conduct STI and HIV Risk Assessment using the counseling card. If symptoms are identified, treat her/him syndromically.

(17) Ask client whether s/he knows her/his HIV status.

a) If client knows $\mathrm{s} /$ he is living with HIV,

- Review Positive Health, Dignity \& Prevention counseling card with client.

- Refer client to center for wellness care and treatment.

b) If client knows s/he is HIV negative,

- Discuss a time frame for repeat testing.

c) If client does not know her/his status,

- Discuss HIV Counseling and Testing (HCT) with client, using counseling card.

- Offer or initiate testing with client, according to national protocols.

- Counsel client on test results. If client is living with HIV, review Positive Health, Dignity \& Prevention counseling card and refer client to center for wellness care and treatment.

d) Counsel client using Women's Support \& Safety Card.

- If client shows any major intimate partner violence (IPV) triggers, refer her for specialized services.

(18) Give follow-up instructions, a condom brochure, and the brochure for the method chosen. Set a date for next visit.

(19) Thank her/him for the visit. Complete the counseling session. 


\section{Monthly Injectable}

Combined Injectable Contraceptives (CICs) 


\section{Monthly Injectable}

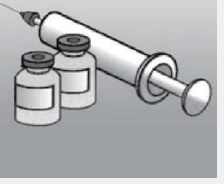

Combined Injectable Contraceptives (CICs)

\section{EFFECTIVENESS}

\section{Typical use}

Some missed or late injections:

6 pregnancies per 100 women

\section{GENERAL INFORMATION}

- Requires that you get an injection every 4 weeks (30 days) to prevent pregnancy.

- More regular monthly bleeding than with DMPA or NET-EN injectables.

- Delayed return of fertility after woman stops method. It takes an average of about 1 month longer than with most other methods.

- Safe for a woman living with HIV/AIDS, even if she takes antiretroviral (ARV) medicines.

- Does not protect against sexually transmitted infections (STIs), including HIV and Zika.

\section{HOW THE METHOD WORKS}

- The injection contains two hormones, progestin and estrogen.

- These hormones stop the release of eggs from the ovaries (ovulation). They also make cervical mucus thick. This stops sperm from meeting an egg.

- You get an injection every 4 weeks (30 days).

\section{IMPORTANT FACTS}

- Method does not require daily action by user.

- Private. No one else can tell you are using an injectable.

- Does not interfere with sex.

- Return of fertility is about 1 month longer than with most other methods.

- Use condoms (male or female) if you feel at risk of STIs or HIV (dual protection). 


\section{METHOD NOT ADVISED IF YOU...}

- Are within 21 days of giving birth (regardless of breastfeeding status).

- Breastfeed an infant less than 6 months old.

- Smoke cigarettes and are 35 years old or older.

- Have high blood pressure, 140/90 or higher

- Have a combination of cardiovascular risk factors such as diabetes, hypertension, older age and/or are a smoker. Discuss with your provider.

- Have severe liver disease.

- Have breast cancer or risk factors of heart disease: older age, stroke, smoking, diabetes, high blood pressure, or high cholesterol levels.

- Have migraine headaches (a severe headache that does not go away with paracetamol) and are 35 years old or older.

- Have migraine aura (sometimes seeing a growing bright spot in one eye) at any age.

- Have a history of blood clot, called thrombosis, or major surgery with prolonged immobilization.

- Have lupus.

- HIV positive and are on ritonavir-boosted protease inhibitors as part of HAART.

\section{SIDE EFFECTS}

- Common side effects include:

- Lighter bleeding and fewer days of bleeding

- Irregular bleeding

- Infrequent or prolonged bleeding

- No monthly bleeding

- Changes in monthly bleeding are normal. These changes usually lessen or stop within 3 months of starting injections.

- After stopping the injections, changes in monthly bleeding do not stop until the injection wears off (2-3 months or more).

- Some women may have weight gain, headaches, dizziness, or breast tenderness.

- These are not signs of illness.

- Not all women have these side effects. 


\section{HOW TO USE}

- A provider will give you the injection.

- You return every 4 weeks (30 days) to get another injection.

- Even if you are late, come back. You may still be able to get your injection.

- If you switch to another brand of injectable, get instructions on how to use it.

\section{FOLLOW-UP}

- Return every 4 weeks (30 days) to get your next injection.

- Try to come on time. You make come up to 7 days early or 7 days late and still get an injection. No matter how late you are, come back for your next injection.

- If you are more than 7 days late, abstain from sex or use condoms until you can get an injection.

\section{RETURN TO THE HEALTH CARE FACILITY ANY TIME IF...}

- You have any questions or problems.

- You need another injection.

- You develop any health problems.

- You are late for your injection, had sex in the past 5 days, and want to avoid pregnancy. You can take emergency contraceptive pills (ECPs).

- You think you may be pregnant 


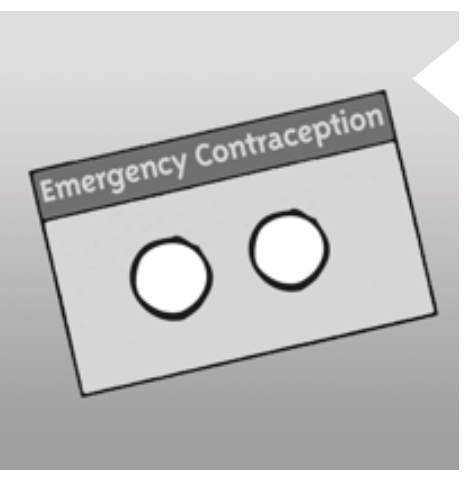

\section{Emergency}

\section{Contraceptive Pills}

\section{ECPs}




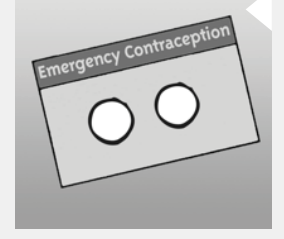

\section{Emergency Contraceptive Pills}

\section{ECPs}

\section{EFFECTIVENESS}

$98-99 \%$

\section{Correct use}

Most effective if taken within first 24 hours; can be taken within 5 days of having unprotected sex:

1-2 pregnancies per 100 women after one instance of unprotected sex depending on the ECP

\section{GENERAL INFORMATION}

- One of the only methods that can help prevent pregnancy after a woman has had unprotected sex.

- Not recommended for regular use. A woman using ECP repeatedly should receive additional family planning counseling in order to select the most appropriate continuous method.

- Must be used within 5 days (120 hours) of unprotected sex.

- Safe for women who cannot use regular hormonal contraceptive methods including postpartum breastfeeding women.

- Breastfeeding not recommended for 1 week after using ulipristal acetate (UPA)

- ECPs do not disrupt existing pregnancy.

- Safe for a woman living with HIV/AIDS, even if she takes antiretroviral (ARV) medicines.

- Does not protect against sexually transmitted infections (STIs), including HIV and Zika.

\section{HOW THE METHOD WORKS}

- ECPs contain the same hormones as combined or progestin-only oral contraceptive pills, but in higher doses.

- These hormones prevent the release of eggs from your ovaries (ovulation). 


\section{IMPORTANT FACTS}

- All women can use EC pills safely and effectively, including women who cannot use ongoing hormonal contraceptive methods.

- You can use ECPs for any act of unprotected sex, including forced sex (rape).

- You can also use them if there have been contraceptive mistakes or failures, such as:

- Condom broke, slipped, or was not used correctly

- You missed 3 or more combined oral contraceptive pills

- You started a new packet of pills 3 or more days late

- You are more than 7 days or 2 weeks late for a repeat injection of injectable contraceptive (depending on type of injection)

- Your IUD has come out of place

- You used TwoDay or Standard Days Method incorrectly. For example, you failed to abstain from sex or use condoms during the days you can get pregnant

- ECPs reduce the need to seek abortion.

- Dedicated ECP products, combined oral contraceptives (the pill), or progestinonly oral contraceptives (minipill) can all be used as ECPs.

- Have an ECP method on hand in case of an emergency (unprotected sex).

- They should not be used in place of an ongoing contraception method.

- You can become pregnant immediately after taking CPs if you have unprotected sex (even 1 day after taking ECPs).

- Use another method of contraception at once to continue to protect against pregnancy.

- Use condoms (male or female) if you feel at risk of STIs, including HIV and Zika.

\section{METHOD NOT ADVISED IF YOU...}

- Are on medicine for seizures or you take rifampicin.

\section{SIDE EFFECTS}

- You may have light vaginal bleeding for 1-2 days after taking ECPs.

- In the week after taking ECPs, you may have nausea, abdominal pain, fatigue, headache, breast tenderness, dizziness, or vomiting.

- Your monthly bleeding may start earlier or later than expected. 


\section{HOW TO USE}

- Take the ECPs as soon as possible within 5 days (120 hours) of having unprotected sex. The sooner you take them, the better. The effectiveness of ECPs decreases over time.

- Take the pills as directed by your provider.

Important: Dosage varies according to brand. Your provider will give you dosage information according to the brand or type of pill.

- If you vomit within 2 hours of taking ECPs, take another dose. If you vomit 2 hours after taking ECPs, you do not need to take another does.

- Start another method of contraception at once. ECPs are not effective as an ongoing method of contraception.

- Take a packet of ECPs (or oral contraceptive pills, with instructions on how to use them as ECPs) home to use when you need them.

\section{RETURN TO THE HEALTH CARE FACILITY ANY TIME IF...}

- You have questions or problems.

- You think you might be pregnant. 


\section{Female Condoms}

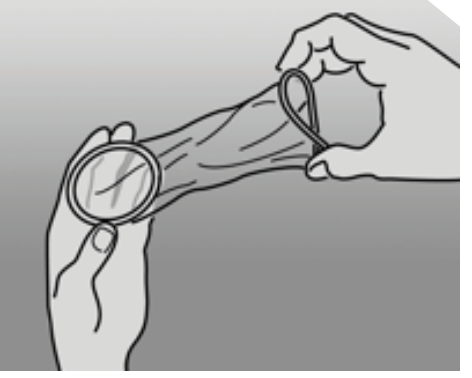




\section{Female Condoms}

\section{TYPES}

- Female Condom 2 / FC2

- Cupid

\section{EFFECTIVENESS}

\section{Typical Use}

79\% Not used consistently:

21 pregnancies per 100 women

\section{GENERAL INFORMATION}

- The female condom is a sheath made of a transparent latex with flexible rings at both ends. It is the same length as a male condom.

- Before having sex, place the female condom into your vagina. It fits loosely inside the vagina.

- You must use a new condom for each act of sex.

- Protects against pregnancy and sexually transmitted infections (STIs), including HIV and Zika.

- Preserves feeling of sex for men and women.

- Requires partner's cooperation.

\section{HOW THE METHOD WORKS}

- Before having sex, place the female condom into your vagina.

- The condom forms a barrier that keeps sperm out of the vagina during sex. This prevents pregnancy.

- The condom covers the cervix inside the vagina. The cervix is a closed space, so the female condom cannot disappear inside the body.

- It also protects you from getting or giving STIs including HIV. 


\section{IMPORTANT FACTS}

- Can be used as a temporary or backup method.

- Can be used without seeing a health provider.

- Can be initiated by the woman.

- Must not be used if the partner is using a male condom. The friction between the two condoms may cause one or both to break.

- May be relatively expensive and hard to find.

- Require you to touch your genitals.

- May make noises during intercourse; adding lubricant can help.

- Can be used during pregnancy to protect mother and fetus against STIs.

\section{HOW TO USE}

1. Use a new female condom for each act of sex.

2. Check th condom package. Do not use if torn or damaged. Avoid using a condom past the expiration date. Do so only if newer condoms are not available.

3. Insert up to 8 hours before sex. For the most protection, insert the condom before the penis comes into contact with the vagina.

4. Rub the sides of the female condom together to spread the lubricant evenly and insert:

- Hold the condom with the larger, open end hanging down.

- Choose a position that is comfortable for insertion. You can squat, raise one leg, sit, or lie down.

- Grasp the inner ring at the closed end. Squeeze it so that it becomes long and narrow.

- Find the opening of the vagina and separate outer lips (labia). With the other hand gently push the inner ring into the vagina as far up as it will go.

- Insert a finger into the condom to push it into place. Allow up 2 to $3 \mathrm{~cm}$ of the condom and outer ring to remain outside the vagina.

5. When you are ready for sex, guide the penis into the condom. Make sure it does not slip outside. If the penis goes outside the condom, withdraw the penis. Help guide it in again.

6. If the outer ring is pushed into the vagina or the condom is pulled out of the vagina during sex, put the condom back into place.

7. After having sex, remove the condom before standing to prevent leakage of semen. To remove the female condom, grasp the outer ring, twist it to seal in the fluid and gently pull it out of the vagina.

8. Place the condom in a tissue or in the empty package. Throw it into the rubbish or latrine. Do not put it into a flush toilet. This can cause problems with plumbing. 


\section{SIDE EFFECTS}

None

\section{RETURN TO THE HEALTH CARE FACILITY ANY TIME IF...}

- You have any questions or problems.

- You had unprotected sex in the past 5 days and want to avoid pregnancy. You can take emergency contraceptive pills (ECPs).

Important: If you did not use a condom for an act of sex, try to use one the next time. A mistake once or twice does not mean that it is too late to use condoms in the future. 


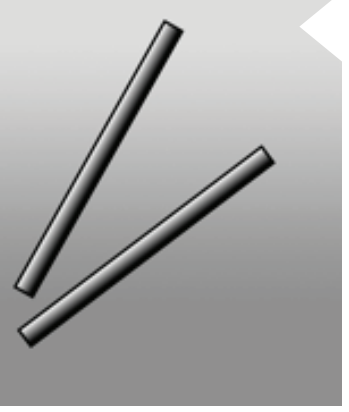

Hormonal Implants 


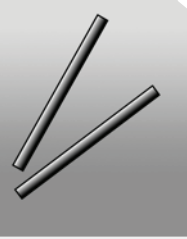

\section{Hormonal Implants}

\section{TYPES}

- Single Rod (Implanon, Nexplanon/Implanon NXT)

- Double Rod (Jadelle, Sino-plan II)

\section{EFFECTIVENESS}

Less than 1 pregnancy per 100 women

\section{GENERAL INFORMATION}

- Are small rods or capsules (about the size of a matchstick) put under the skin.

- Provide long-term protection from pregnancy for 3 to 5 years. Length of protection depends on the implant.

- A trained provider must insert and remove implants.

- Safe for women who are breastfeeding. You may get implants after giving birth.

- Often cause changes in monthly bleeding. May cause absence of bleeding or temporary heavy bleeding for a few months.

- Safe for women living with HIV/AIDS, even if she takes antiretroviral (ARV) medicines.

- Do not protect against sexually transmitted infections (STIs), including HIV and Zika.

\section{HOW THE METHOD WORKS}

- A trained provider inserts the implant(s) under the skin, usually on the inside of your upper arm.

- The implant(s) slowly release a hormone (progestin). Progestin makes the mucus around the cervix thick. This stops sperm from meeting an egg.

- This hormone also prevents the release of eggs from your ovaries (ovulation). 


\section{IMPORTANT FACTS}

- One of the most effective and long-last methods.

- Must be inserted and removed by a trained provider.

- Can help reduce anemia.

- Do not interfere with sex.

- May be difficult to obtain locally.

- Use condoms (male or female) to protect against STIs, including HIV and Zika.

\section{METHOD NOT ADVISED IF YOU...}

- Have unexpected vaginal bleeding.

- Have breast cancer or history of breast cancer in last 5 years.

- Take medicine for seizures or take reifampicin (as it may reduce effectiveness of contraceptive).

- Currently have blood clots.

- Have lupus.

- Have history of severe liver disease.

\section{SIDE EFFECTS}

- During the first several months, common side effects include:

- Lighter monthly bleeding and fewer days of bleeding

- Irregular monthly bleeding that lasts more than 8 days

- Infrequent monthly bleeding or no bleeding (amenorrhea)

- After about 1 year, common side effects include:

- Lighter monthly bleeding and fewer days of bleeding

- Irregular monthly bleeding or infrequent bleeding

- Implanon causes less irregular prolonged monthly bleeding than Jadelle. But, Implanon is more likely to cause infrequent monthly bleeding or no bleeding at all.

- May cause headaches, abdominal pain, breast tenderness, or other side effects.

- These are common and not signs of illness. 


\section{HOW TO USE}

- A trained provider gives you an anesthetic in the arm to prevent pain. $\mathrm{S} / \mathrm{he}$ inserts the implants just under the skin.

- The procedure takes only a few minutes. You are fully awake during the procedure. You may feel some tugging, pressure, or slight pain when the provider inserts the implants.

- After the procedure, get the following information from your provider:

- Type of implant

- Date of insertion

- Month and year when they need to be removed or replaced

\section{FOLLOW-UP}

- Keep the insertion area dry for 4 days.

- Your arm may be sore for a few days. You may also have swelling and bruising at the insertion site.

- This is normal. It will go away without treatment.

\section{RETURN TO THE HEALTH CARE FACILITY ANY TIME IF...}

- You have any inflammation, pus, or redness at the insertion site that gets worse or does not go away.

- You see an implant coming out.

- You have any questions or problems.

- It is time to replace the implant(s).

- You want to have the implant(s) removed.

- You have gained a lot of weight. Implants may not protect you from pregnancy as well if you weigh more than 70 kilos.

- You develop any health problems.

- You think you may be pregnant. 


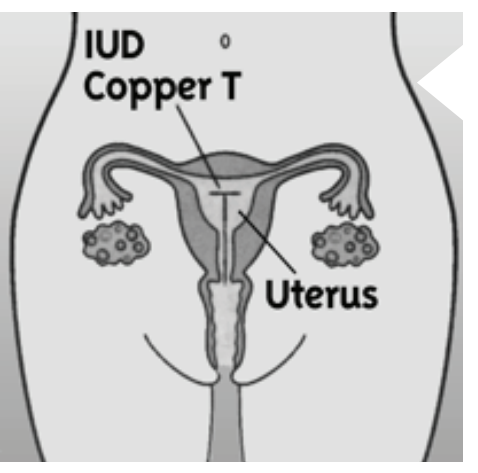

\section{Intrauterine Device}

Copper-bearing IUD 


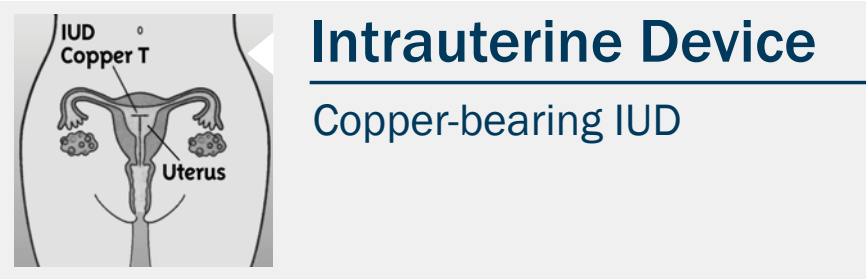

\section{EFFECTIVENESS}

First year of use

Less than 1 pregnancy per 100 women

\section{GENERAL INFORMATION}

- Provides long-term protection against pregnancy for 5 - 12 years.

- Is a small, flexible, plastic and copper device place din the uterus. Most IUDs have 1 or 2 thin strings that hang from the cervix into the vagina.

- It is a safe and effective method for almost all women. Including women in the postabortion or postpartum period.

- A trained provider must insert and remove the IUD.

- Can be inserted immediately after childbirth (within 48 hours) or after 4 weeks postpartum.

- Typically causes longer and heavier bleeding and more cramps or pain during monthly bleeding.

- Safe for a woman living with HIV or with AIDS who is clinically well on antiretroviral (ARV) therapy.

- Not advised for a woman at very high risk of having a sexually transmitted infection (STI).

- Does not protect against sexually transmitted infections (STIs), including HIV and Zika.

\section{HOW THE METHOD WORKS}

- A trained provider inserts the IUD into your uterus, where it stays.

- The plastic and copper device prevents the sperm and egg from meeting. 


\section{IMPORTANT FACTS}

- One of the most effective and long-lasting methods.

- Must be inserted and removed by a trained provider.

- Immediate return to fertility after IUD is removed.

- Does not interfere with sex.

- Does not require you to do anything once the IUD is inserted.

- Can be used as emergency contraception, if inserted within five day of unprotected intercourse or five days after estimated time of ovulation.

- Use condoms (male or female) if you feel at risk of STIs, including HIV and Zika.

\section{METHOD NOT ADVISED IF YOU...}

- Are pregnant or think you might be pregnant.

- Have unusual vaginal bleeding. Seek further assessment from provider.

- Have gonorrhea or Chlamydia.

- Are living with HIV and are not doing well clinically.

- Are at very high risk of having an STI.

\section{SIDE EFFECTS}

- Some bleeding or spotting after insertion. This may continue for 3 to 6 months.

- Cramping and some pain for a few days after insertion.

- Changes in bleeding patterns. They include prolonged and heavy monthly bleeding, irregular bleeding, or more cramps and pain during monthly bleeding. These are normal, especially in the first 3 to 6 months after insertion.

- These are not signs of illness.

- Side effects usually lessen after the first several months.

\section{HEALTH BENEFITS}

- May help protect against cancer of the uterus. 


\section{HOW TO USE}

- Have a pelvic exam to rule out genital infections.

- Take ibuprofen, paracetamol, or other pain reliever 30 minutes before insertion to reduce cramping and pain.

- A trained provider inserts the IUD in a place with the necessary supplies and equipment.

- The provider inserts the IUD into your uterus through your vagina and cervix. $\mathrm{S} /$ he cuts the strings on the IUD, leaving about $3 \mathrm{~cm}$ hanging out of the cervix.

- You will feel some discomfort or cramping during the procedure. This is normal.

- After the procedure get the following information from your provider:

- Type of IUD you have

- Date of insertion

- Date when IUD will need to be removed or replaced

\section{RETURN TO THE HEALTH CARE FACILITY ANY TIME IF...}

- You have questions or problems.

- You have any of the following, especially in the first 20 days after insertion:

- increasing or severe pain in the lower abdomen

- pain during sex

- unusual vaginal discharge

- fever, chills, nausea, or vomiting

- Your provider scheduled a post-insertion visit 3 to 6 weeks after insertion of the IUD.

- You think the IUD may have slipped out of place (you do not feel the strings or you feel the hard plastic of an IUD that has partially come out of the uterus).

- You miss your menstrual period or think you may be pregnant.

- You want to remove the IUD for any reason. 


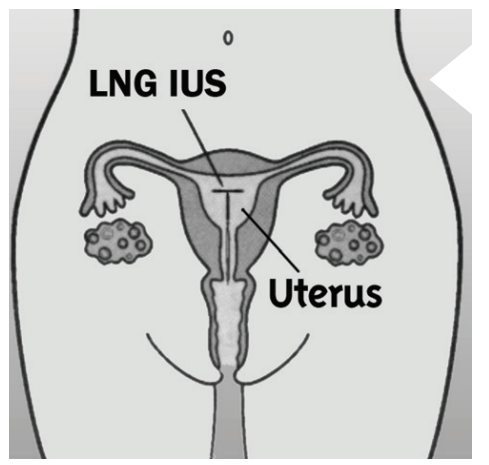

Intrauterine

\section{Device/System}

LNG IUD/IUS 


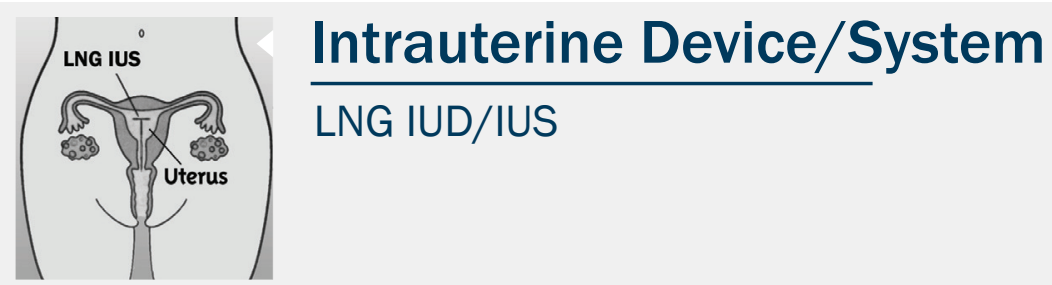

\section{EFFECTIVENESS}

\section{$99 \%$}

First year of use

Less than 1 pregnancy per 100 women

\section{GENERAL INFORMATION}

- Provides long-term protection against pregnancy for up to 5 years.

- Is a small, flexible, platic and device in the uterus with an inner reservoir of levonorgestrel, a progestin hormone. The LNG IUD/IUS has 1 or 2 thin strings that hang from the cervix into the vagina.

- A trained provider must insert and remove the LNG IUD/IUS.

- Causes lighter and shorter monthly periods of bleeding and may cause periods to stop all together.

- Safe for a woman living with HIV or with AIDS who is clinically well on antiretroviral (ARV) therapy.

- Not advised for a woman at very high risk of having a sexually transmitted infection (STI).

- Does not protect against sexually transmitted infections (STIs), including HIV and Zika.

- Can be inserted immediately after childbirth (within 48 hours) or after 4 weeks postpartum.

\section{HOW THE METHOD WORKS}

- A trained provider inserts the LNG IUD/IUS into your uterus, where it stays.

- The levonorgestrel (progesterone hormone) is released into uterus and inhibits fertilization of the egg by thickening the cervical mucus, inhibitin sperm movement, and hindering sperm and egg transport. 


\section{IMPORTANT FACTS}

- One of the most effective and long-lasting methods.

- Must be inserted and removed by a trained provider.

- Immediate return to fertility after LNG IUD/IUS is removed.

- Does not interfere with sex.

- Does not require you to do anything once LNG IUD/IUS is inserted.

- Use condoms (male or female) if you feel at risk of STIs, including HIV.

\section{METHOD NOT ADVISED IF YOU...}

- Are pregnant or think you might be pregnant.

- Have unusual vaginal bleeding. Seek further assessment from health provider.

- Have gonorrhea or Chlamydia.

- Have AIDS and are not taking ARV medicine or are not doing well clinically.

- Are at very high risk of having an STI.

- Have history of breast cancer.

\section{SIDE EFFECTS}

- Some bleeding or spotting after insertion. This may continue for 3 to 6 months.

- Cramping and some pain for a few days after insertion.

- Changes in bleeding patterns. They include prolonged and heavy monthly bleeding, irregular bleeding, or more cramps and pain during monthly bleeding. These are normal, especially in the first 3 to 6 months after insertion.

- Symptoms associated with hormones, including headaches, breast tenderness or weight gain.

- These are not signs of illness.

- Side effects usually lessen after the first several months.

\section{HEALTH BENEFITS}

- May help protect against cancer of the uterus.

- There are many additional health benefits to LNG IUD/IUS including its role as treatment for heavy or prolonged bleeding, as treatment for menstruation and endometrium disorders such as endometriosis, adenomyosis or dysmenorrheal, as an alternative for hysterectomy. 


\section{HOW TO USE}

- Have a pelvic exam to rule out genital infections.

- Take ibuprofen, paracetamol, or other pain reliever 30 minutes before insertion to reduce cramping and pain.

- A trained provider inserts the IUD/IUS in a place with the necessary supplies and equipment.

- The provider inserts the IUD/IUS into your uterus through your vagina and cervix. S/he cuts the strings on the IUD/IUS, leaving about $3 \mathrm{~cm}$ hanging out of the cervix.

- You will feel some discomfort or cramping during the procedure. This is normal.

- After the procedure get the following information from your provider:

- Type of IUD/IUS you have

- Date of insertion

- Date when IUD/IUS will need to be removed or replaced

\section{RETURN TO THE HEALTH CARE FACILITY ANY TIME IF...}

- You have questions or problems.

- You have any of the following, especially in the first 20 days after insertion:

- increasing or severe pain in the lower abdomen

- pain during sex

- unusual vaginal discharge

- fever, chills, nausea, or vomiting

- Your provider scheduled a post-insertion visit 3 to 6 weeks after insertion of the LNG IUD/IUS.

- You think the LNG IUD/IUS may have slipped out of place (you do not feel the strings or you feel the hard plastic of an IUD/IUS that has partially come out of the uterus).

- You want to remove the IUD/IUS for any reason. 


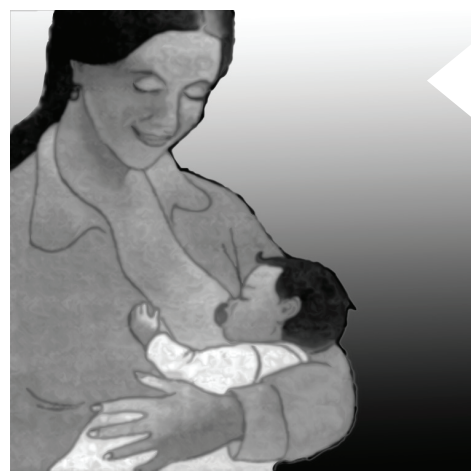

Lactational Amenorrhea Method

LAM 


\section{Lactational Amenorrhea Method}

LAM

\section{EFFECTIVENESS}

\section{Typical use}

98\% First 6 months after childbirth when all 3 criteria are met:

2 pregnancies per 100 women

\section{GENERAL INFORMATION}

- LAM is the use of fully breastfeeding after having a baby to delay the woman's return to fertility.

- LAM requires 3 conditions. All 3 must be met:

1. Your monthly bleeding has not returned since giving birth

2. The baby is fully exclusively breastfed, day and night

3. The baby is less than 6 months old

- LAM is a temporary family planning method to use after pregnancy, when women can think about which method to use after LAM no longer protects you from pregnancy.

- Safe for a woman living with HIV/AIDS. There is a chance, however, that mothers with HIV will transmit HIV to their infants through breastfeeding.

- Does not protect against sexually transmitted infections (STIs), including HIV and Zika.

\section{HOW THE METHOD WORKS}

- Fully breastfeeding stops the release of hormones that cause a woman to release eggs from her ovaries (ovulate). 


\section{IMPORTANT FACTS}

- Does not interfere with sex.

- No costs and no supplies needed.

- Effectiveness after 6 months postpartum is not certain.

- Fully and exclusively breastfeeding may be inconvenient or difficult for some women.

- Use condoms (male or female) if you feel at risk of STIs, including HIV and Zika.

- Once you begin feeding your baby food or liquids other than your breast milk, LAM no longer protects you from pregnancy. Contact your provider to begin using another method of contraception immediately.

- Have ECP method on hand in case you have unprotected sex when all 3 criteria are no longer met or you have not gone to facility.

- Before you start to use supplemental feeding talk to your provider about switching to another modern method.

\section{METHOD NOT ADVISED IF YOU...}

- You last gave birth over 6 months ago.

- Your monthly bleeding has returned.

- You are offering your baby any foods or liquids other than breast milk.

\section{SIDE EFFECTS}

None

\section{USE CAUTION WHEN LIVING WITH HIV/AIDS:}

- Mothers living with HIV should:

- Exclusively breastfeed for 6 months and continue breastfeeding, with complementary food, up to 12 months

- Upon decision to stop breastfeeding, stop gradually within one month. Stopping breastfeeding abruptly is not advised and you must have a reliable safe alternative to breast milk

- Giving anti-retroviral drugs (ARVs) to mother living with HIV or HIV-exposed infant during breastfeeding can significantly reduce the risk of HIVtransmission through breastfeeding.

- Mothers or infants who have been receiving ARV prophylaxis should continue prophylaxis for one week after breastfeeding is fully stopped. 


\section{HEALTH BENEFITS OF BREASTFEEDING}

- Provides the healthiest food for the baby.

- Protects the baby from diarrhea.

- Reduces bleeding after childbirth.

- Passes on the mother's immunities to the baby. This helps protect the baby from diseases such as measles and pneumonia. These diseases can kill babies.

- Helps develop a close bond between the mother and baby.

\section{HOW TO USE}

- Start breastfeeding as soon as possible after the baby is born. Breast feeding initiated within one hour of birth will allow baby the full benefit of colostrums.

- Breastfeed your baby exclusively for the first six months.

- Feed only breast milk day and night. You are protected against pregnancy if all 3 conditions are present:

1. Your menstrual bleeding has not returned

2. Your baby is fully breastfed. You must breastfeed both day and night.

3. Your baby is less than 6 months old.

- If and when any of these conditions are not present, you should:

- Use another method for effective family planning that will not interfere with breastfeeding.

- Keep breastfeeding your baby. Breastfeed even while feeding your baby other food or liquids.

- Complementary foods must be introduced to six months, however breastfeeding should also continue up to 2 years and longer. Women should discuss infant feeding with their health care provider.

\section{RETURN TO THE HEALTH CARE FACILITY ANY TIME IF...}

- You have any questions or problems.

- Any 1 of the 3 conditions needed for LAM changes, and you need another method.

- Before your baby is 6 months old so you can choose another method. 


\section{Male Condoms}
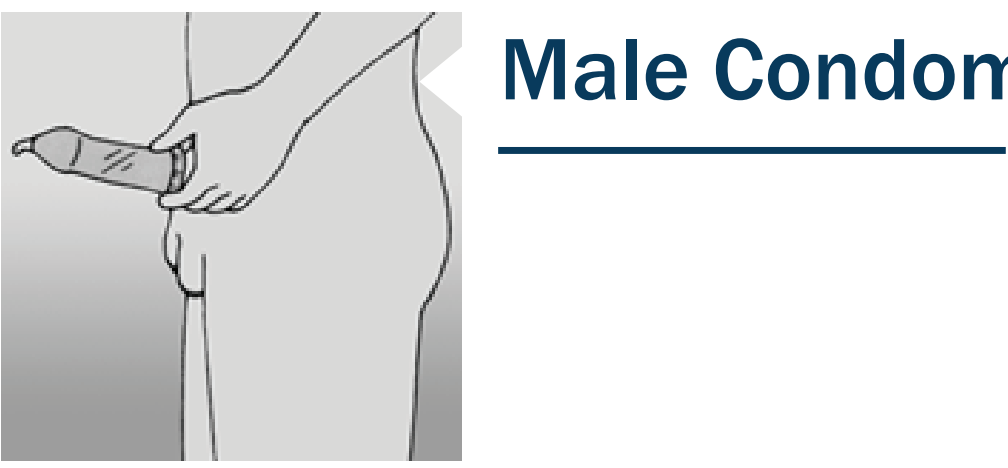


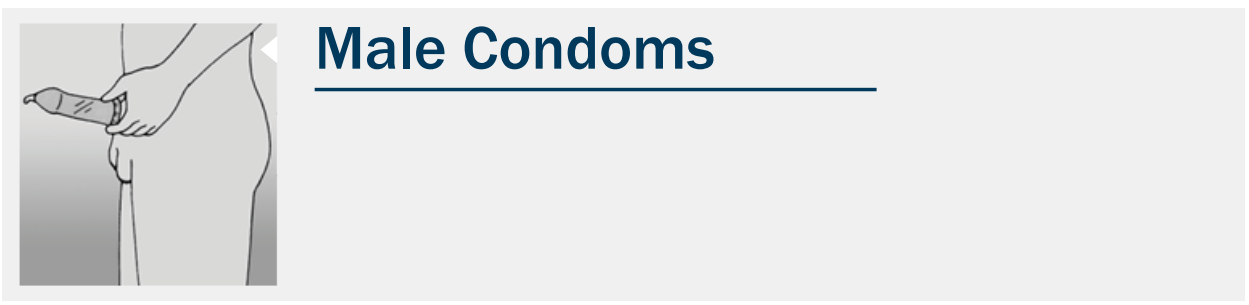

\section{EFFECTIVENESS}

\section{Typical use}

Not used consistently:

18 pregnancies per 100 women

\section{GENERAL INFORMATION}

- Most condoms are made of thin latex rubber. Some condoms are coated with a lubricant and/or spermicide.

- If you have had an allergic reaction to latex rubber, you should not use latex condoms.

- Before having sex, place the condom over the erect penis.

- You must use a new condom for each act of sex.

- Protects against pregnancy and sexually transmitted infections (STIs), including HIV and Zika.

- Requires partner's cooperation to use consistently and correctly.

\section{HOW THE METHOD WORKS}

- Before having sex, place the condom on the erect penis.

- The condom forms a barrier that keeps sperm out of the vagina during sex. This prevents pregnancy.

\section{IMPORTANT FACTS}

- Can be used without seeing a health provider.

- Can be used as a temporary or backup method.

- Condoms both male and female are the only method that prevents from STIs and HIV.

- May decrease sensation, making sex less enjoyable for either partner.

- You must take time to put the condom on the erect penis before the penis touches the woman's genitals.

- Increase male participation in family planning. 


\section{METHOD NOT ADVISED IF YOUR PARTNER...}

- Has had an allergic reaction to latex rubber. Some people may just be allergic to a specific brand of condoms. If it is not a latex allergy, switch to another brand.

\section{SIDE EFFECTS}

None

\section{HOW TO USE:}

1. Use a new condom for each act of sex.

2. Check the condom package. Do not use if torn or damaged. Avoid using a condom past the expiration date. Do so only if newer condoms are not available.

3. Open the package carefully. Do not use fingernails, teeth, or anything that could damage the condom.

4. Before any vaginal contact, place the condom on the tip of the erect penis. The rolled side should be on the outside.

5. Unroll the condom all the way to the base of the erect penis. If the condom does not unroll, it may be on backwards, damaged, or too old. Throw it away. Use a new condom. If the condom is on backwards and another is not available, turn it over and unroll onto the penis.

6. If desired, use water or a water-based lubricant on the outside of the condom. This helps prevent breaks. Do not use creams, oils, or petroleum jelly.

7. Immediately after ejaculation, hold the rim of the condom in place. Withdraw the penis will it is still erect. Be careful not to spill semen when withdrawing the penis or taking off the condom.

8. Place the condom in a tissue or in the empty package. Throw it into the rubbish. Do not put it into a flush toilet. This may cause problems with plumbing.

9. Store condoms in a dark, cool, dry place if possible.

Important: If you did not use a condom for an act of sex, try to use one the next time. A mistake once or twice does not mean that it is too late to use condoms in the future.

\section{RETURN TO THE HEALTH CARE FACILITY ANY TIME IF...}

- You have any questions or problems.

- You had unprotected sex in the past 5 days and want to avoid pregnancy. The woman can take emergency contraceptive pills (ECPs). 
POPULATION

COUNCIL

Ideas. Evidence. Impact. 
Progestin-only Oral

Contraceptives 
Progestin-only Oral Contraceptives

\section{EFFECTIVENESS}

Typical use in first year

$90-97 \%$ Some missed pills:

3 to 10 pregnancies per 100 women

$99 \%$

For breastfeeding women in first year

1 pregnancy per 100 women

\section{GENERAL INFORMATION}

- Requires that you take 1 pill every day.

- Safe for women who are breastfeeding.

- You may begin the minipill after giving birth.

- May cause irregular monthly bleeding. For breastfeeding women, causes delayed return of monthly bleeding.

- Safe for a woman living with HIV/AIDS, even if she takes antiretroviral (ARV) medicines.

- Does not protect against sexually transmitted infections (STIs), including HIV and Zika.

\section{HOW THE METHOD WORKS}

- You take 1 pill every day. The minipill is most effective when you take the pill at the same time every day.

- The minipill has small amounts of progestin. Progestin makes the mucus around the cervix thick. This stops sperm from meeting an egg.

- This hormone also prevents the release of eggs from the ovaries (ovulation). 


\section{IMPORTANT FACTS}

- Can be stopped at any time without a provider's help.

- You control the method.

- Does not interfere with sex.

- Can cause irregular monthly bleeding.

- You have to remember to take a pill once a day, every day.

- All of the pills have the hormone progestin in them; there are no placebos or sugar pills.

- Use condoms (male or female) if you feel at risk of STIs, including HIV and Zika.

\section{SIDE EFFECTS}

- May cause frequent or irregular monthly bleeding for the first several months or the entire time you use the minipill.

- May cause headaches, dizziness, breast tenderness, mood changes, or othe rpossible side effects.

- For breastfeeding women, it takes longer for monthly bleeding to return after giving birth.

- These are normal and not signs of illness.

- Not all women have these side effects.

\section{HOW TO USE}

- Begin with the firs tpill in the packet as directed by your provider.

- Take 1 pill every day until you finish the packet.

- Take the pill at the same time every day. Do not miss any pills.

- Have a new packet of pills on hand before you finish your packet.

- If you get your pills from a pharmacy, you can use the instructions in this brochure.

- If you miss taking your pills, follow the guidelines on the next page. 


\begin{tabular}{|l|l|}
\hline If you: & Do this: \\
\hline - Are 3 or more & - Take a pill as soon as possible. \\
hours late in & - Keep taking the pill every day at the same time. (This \\
OR & means that you may end up taking 2 pills at the \\
- Miss taking 1 pill & $\begin{array}{l}\text { - Use a backup method (condoms) or avoid sex for the } \\
\text { next 2 days. }\end{array}$ \\
& $\begin{array}{l}\text { - If you have unprotected sex in the past } 5 \text { days, } \\
\text { consider taking emergency contraception pills } \\
\text { (ECPs). }\end{array}$ \\
\hline $\begin{array}{l}\text { - Vomit within 2 } \\
\text { hours of taking a } \\
\text { pill }\end{array}$ & $\begin{array}{l}\text { - Take another pill from your packet as soon as } \\
\text { - }\end{array}$ \\
\hline
\end{tabular}

\section{RETURN TO THE HEALTH CARE FACILITY ANY TIME IF...}

- You have any questions or problems.

- You need more pills.

- You develop any health problems.

- You were late or missed a pill, had sex in the past 5 days, and want to avoid pregnancy. You can take emergency contraceptive pills (ECPs).

- You think you may be pregnant. 


\section{The Pill}

Combined Oral Contraceptives 


\section{The Pill}

\section{Combined Oral Contraceptives}

\section{EFFECTIVENESS}

\section{Typical use in first year}

Some missed pills:

9 pregnancies per 100 women

\section{GENERAL INFORMATION}

- Requires that you take 1 pill every day.

- May cause irregular bleeding during the first few months of use.

- Safe for a woman with HIV/AIDS, even if she takes antiretroviral (ARV) medicines.

- There are many different brands and regimens of combined oral contraceptives. Discuss available and most appropriate method with provider.

- Does not protect against sexually transmitted infections (STIs), including HIV and Zika.

\section{HOW THE METHOD WORKS}

- You take 1 pill every day. The pill is most effective when you take the pill at the same time every day.

- The pill contains small amounts of the hormones estrogen and progestin.

- These hormones make the mucus around the cervix thick. This stops sperm from meeting an egg.

- They also prevent the release of eggs from the ovaries (ovulation).

\section{IMPORTANT FACTS}

- You control the method.

- Can be stopped at any time without a provider's help.

- Does not interfere with sex.

- You have to remember to take a pill once a day, every day.

- Use condoms (male or female) if you feel at risk of STIs and Zika. 


\section{METHOD NOT ADVISED IF YOU...}

- Are breastfeeding an infant less than 6 months old.

- Smoke cigarettes and are 35 years old or older.

- If you are at risk of heart disease, stroke, smoking, diabetes, high blood pressure, or high cholesterol.

- Have certain uncommon series diseases of the heart or blood vessels. Discus with your provider.

- Have blood clots, deep vein thrombosis, or pulmonary embolism, or are on an anticoagulant therapy. Discuss with your provider.

- Have lupus or severe liver disease or gall bladder disease, even if medicallytreated. Discuss with your provider.

- Have breast cancer or a history of breast cancer.

- Have migraine aura

\section{SIDE EFFECTS}

- Irregular bleeding during the first few months of use

- Amenorrhea (absence of period) and intermittent spotting

- Headache and dizziness

- Change in mood

- Weight change

- Tenderness of the breasts

- Nausea

\section{HOW TO USE}

- Begin with the first pill in the packet as directed by your provider.

- Take 1 pill every day until you finish the packet.

- Take the pill at the same time every day. Do not miss any pills.

- Have a new packet of pills on hand before you finish your packet.

- If you get your pills from a pharmacy, you can use the instructions in this brochure.

- If you miss taking your pills, follow the guidelines on the next page. 


\begin{tabular}{|l|l|}
\hline If you: & Do this: \\
\hline - Are 3 or more & - Take a pill as soon as possible. \\
hours late in & - Keep taking the pill every day at the same time. (This \\
taking the pill & means that you may end up taking 2 pills at the \\
OR & same time or on the same day). \\
- Miss taking 1 pill & $\begin{array}{l}\text { - Use a backup method (condoms) or avoid sex for the } \\
\text { next 2 days. }\end{array}$ \\
& $\begin{array}{l}\text { - If you have unprotected sex in the past 5 days, } \\
\text { consider taking emergency contraception pills } \\
\text { (ECPs). }\end{array}$ \\
\hline $\begin{array}{l}\text { - Vomit within 2 } \\
\text { hours of taking a } \\
\text { pill }\end{array}$ & $\begin{array}{l}\text { - Take another pill from your packet as soon as } \\
\text { - }\end{array}$ \\
\hline
\end{tabular}

\section{RETURN TO THE HEALTH CARE FACILITY ANY TIME IF...}

- You have any questions or problems.

- You need more pills.

- You develop any health problems.

- You were late or missed a pill, had sex in the past 5 days, and want to avoid pregnancy. You can take emergency contraceptive pills (ECPs).

- You think you may be pregnant. 


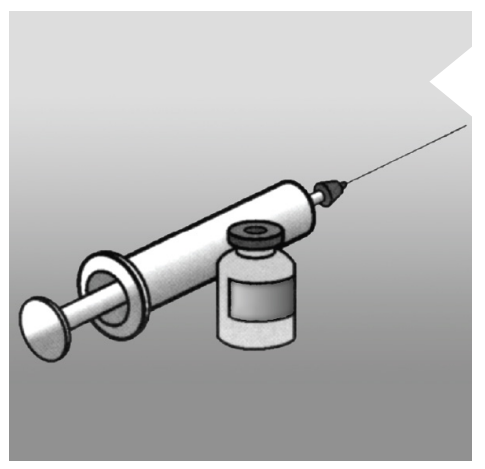

\section{Progestin-only} Injectables

DMPA or NET-EN 


\section{Progestin-only Injectables}

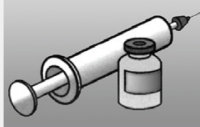

\section{DMPA or NET-EN}

\section{EFFECTIVENESS}

\section{Typical use in first year}

Some missed or late injections:

6 pregnancies per 100 women

\section{GENERAL INFORMATION}

- You get an injection very 2 or 3 months, depending on type of injectable.

- Fertility can return as early as 3 weeks postpartum so you should use a backup method such as condoms until you begin the injection.

- Safe for women who are breastfeeding. You may begin the method 6 weeks after giving birth.

- May cause irregular or no menstrual bleeding.

- There is a delayed return to fertility after you stop the method. It takes longer than with most other methods to conceive (1 months for NET-EN, 4 months for DMPA, up to 1 year for Sayana Press $\left.{ }^{\circledR}\right)$.

- Safe for a woman living with HIV/AIDS, even if she takes antiretroviral (ARV) medicines.

- Does not protect against sexually transmitted infections (STIs), including HIV and Zika.

\section{HOW THE METHOD WORKS}

- Progestin-only injectables contain the hormone progestin. Progestin makes the mucus around the cervix thick. This stops the sperm from meeting the egg.

- This hormone also stops the release of eggs from the ovaries (ovulation).

- DMPA, NET-EN, and Sayana Press are different types of injectables.

- If using DMPA, you get an injection once every 3 months (90 days).

- If using NET-EN, you get an injection once every 2 months (60 days).

- If using Sayana Press ${ }^{\circledR}$, you get an injection every 3 months (90 days). 


\section{IMPORTANT FACTS}

- Method is reversible.

- Can be stopped at any time, either to switch to another method or to get pregnant.

- Private. No one can tell you are using an injectable.

- Do not interfere with sex.

- Use condoms (male or female) if you feel at risk of getting STIs, including HIV and Zika.

\section{METHOD NOT ADVISED IF YOU...}

- Are breastfeeding an infant less than 6 weeks of age.

- Have very high blood pressure, over 160/100.

- Have major cardiovascular risk factors such as hypertension, obesity, older age, stroke, smoking, diabetes, high cholesterol, or certain uncommon diseases of the heart or blood vessels. Discuss with your provider.

- Have or have history of breast cancer.

- Have unexplained vaginal bleeding.

- Take medications for seizures or take rifampicin.

- Have lupus or take Ritonavir-boosted protease inhibitors as part of HAART (Efavirenz or Neviripine) may cause lower effectiveness of NET-EN.

- History of severe liver disease.

\section{SIDE EFFECTS}

- In the beginning, you may have irregular bleeding, prolonged bleeding, or frequent bleeding. Later on there is no monthly bleeding.

- Menstrual changes do not stop until the injection wears off (2-3 months or more).

- Some women have weight gain, headaches, dizziness, and other side effects. These are not signs of illness.

- Not all women have these side effects.

\section{HEALTH BENEFITS}

- Help prevent cancer of the lining of the uterus. Also help prevent uterine fibroids.

- May help protect against pelvic inflammatory disease (PID).

- May help prevent iron deficiency anemia.

- Reduce symptoms of endometriosis (pelvic pain, irregular bleeding). 


\section{HOW TO USE}

- Go to a provider to get an injection.

- Get your injections every 3 months (DMPA), 2 months (NET-EN), or self administer according to instructions every 3 months (Sayana Press). If you do not get your injection, you can get pregnant if you have sex.

- Even if you are late, come back. You may still be able to get your injection.

- If you switch to another brand of injectable, use this brochure on how to use the method.

\section{FOLLOW-UP}

For DMPA users:

- Return every 3 months or 13 weeks to get the next injection.

- Try to come on tie. You may come up to 2 weeks early or 4 weeks late and get an injection. No matter how late you are, come back for your next injection.

- If you are more than 4 weeks late, abstain from sex or use condoms until you can get an injection.

For NET-EN users:

- Return every 2 months or 9 weeks to get the next injection.

- Try to come on time. You may come up to 2 weeks early or 2 weeks late and get an injection. No matter how late you are, come back for your next injection.

- If you are more than 2 weeks late, abstain from sex or use condoms until you get an injection.

For Sayana Press ${ }^{\circledR}$ users:

- Return for periodic re-evaluation and to receive new injections.

\section{RETURN TO THE HEALTH CARE FACILITY ANY TIME IF...}

- You have any questions or problems.

- You need another injection.

- You develop any health problems.

- You are late for your injection, had sex in the past 5 days, and want to avoid pregnancy. You can take emergency contraceptive pills (ECPs).

- You think you may be pregnant. 


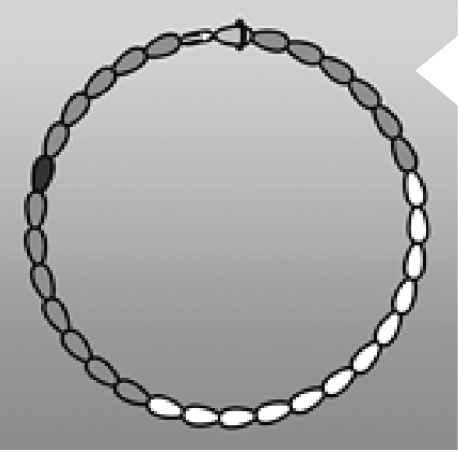

Standard Days Method $\AA$

SDM 


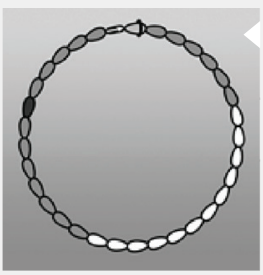

\section{Standard Days Method $\circledast$}

\section{SDM}

\section{EFFECTIVENESS}

Typical use in first year

12 pregnancies per 100 women

\section{GENERAL INFORMATION}

- Ideal for women whose menstrual cycles are usually between 26-32 days long. Women who have their regular monthly bleeding fall within this range.

- You use a calendar or CycleBeads $₫$, a string of color-coded beads, to track the days you can get pregnant and the days you are not likely to get pregnant.

- On the days you can get pregnant, you must not have sex or you must use a condo or other barrier method.

- Postpartum or breastfeeding women must have 3 regular menstrual cycles before they can use SDM. Use an alternative method during this period.

- Does not protect against sexually transmitted infections (STIs), including HIV and Zika.

- Requires partner's cooperation.

\section{HOW THE METHOD WORKS}

- Make a calendar or use CycleBeads ${ }^{\circledR}$ to track the days when you can get pregnant. You also track the days when you are not likely to get pregnant.

- The days you can get pregnant are days 8 to 19 of your menstrual cycle.

- On those days you must not have sex or you must use condoms to avoid getting pregnant.

\section{SIDE EFFECTS}

None 


\section{IMPORTANT FACTS}

- There are no costs needed, and no supplies if you choose to use calendar to track the days.

- There are 12 days during the month when you can get pregnant. On those days, you must abstain from sex or use a barrier method. This may be difficult for some couples.

- You will need counseling on how to use the method correctly.

- Use condoms (male or female) if you feel at risk of STIs, including HIV and Zika.

\section{METHOD NOT ADVISED IF YOU...}

- Do not have regular monthly bleeding, that means, if your cycles are not between 26-32 days long.

- Are not willing or able to abstain from sex or use a condom or other barrier method during the days you can get pregnant.

- Cannot keep track of the days of your menstrual cycle.

- Have not had at least 3 consecutive menstrual cycles since giving birth.

- Do not have regular monthly bleeding after discontinuing a hormonal method.

\section{HEALTH BENEFITS}

- It is natural, there are no hormones, devices or medical procedures required.

- Promotes male involvement and couple communication.

- No delay in return to fertility.

\section{HOW TO USE}

To use SDM with CycleBeads ${ }^{\circ}$ :

Each bead represents a day of your menstrual cycle. The RED bead marks the first day of your monthly bleeding. All BROWN beads mark the days when you are not likely to get pregnant. All WHITE beads mark the days you can get pregnant.

1. On the first day of your monthly bleeding, move the ring to the RED bead. Also mark that day on

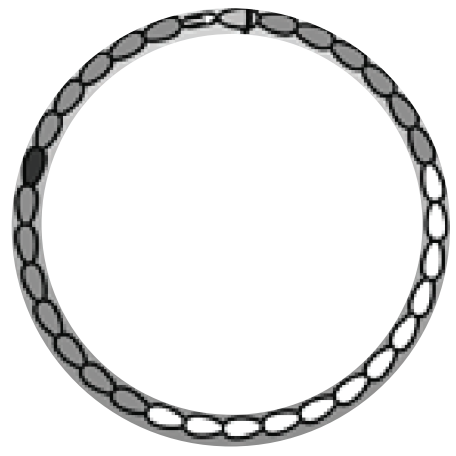
a calendar. This will help you remember where to put the ring if one day you forget to move it.

2. Move the ring to the next bead each day. Always move the ring in the direction of the arrow.

3. Move the ring even on the days that you have your monthly bleeding.

4. When the ring is on a BROWN bead you are not likely to get pregnant. You can have unprotected sex. 
5. When the ring is on a WHITE bead, you can get pregnant. Abstain from vaginal sex or use a condom or other barrier method.

6. On the day your monthly bleeding begins again, move the ring to the RED bead to start a new cycle. Skip over any beads that are left.

7. There is one DARK BROWN bead. If your monthly bleeding begins before you reach the DARK BROWN bead, it is too soon. This means that your menstrual cycle is shorter than 26 days.

8. If your monthly bleeding does not start the day after you reach the last BROWN bead, it is too long. This means that your menstrual cycle is longer than 32 days.

9. If more than once in a year you have a cycle that is too short or too long, you should use another method.

\section{IF USING A CALENDAR:}

1. On the first day of your monthly bleeding, mark that day on the calendar. This is day 1 of your cycle.

2. Days 1 to 7 of your cycle are days when you are not likely to get pregnant. You can have unprotected sex.

3. Days 8 to 19 of your cycle are days when you can get pregnant if you have unprotected sex. Abstain from vaginal sex or use a condom or other barrier method.

4. From day 20 until your monthly bleeding begins again are days when you are not likely to get pregnant. You can have unprotected sex.

5. To know if the method works for you, always check if you get your monthly bleeding every 26 to 32 days.

\section{RETURN TO THE HEALTH CARE FACILITY ANY TIME IF...}

- You have any questions or problems

- You have difficulty abstaining from sex or using a condom or other barrier method during the days you can get pregnant. You may want to choose another method.

- You get your monthly bleeding before you reach the DARK BROWN bead.

- You do not get your monthly bleeding by the day after you reach the BROWN bead.

- You have sex on a day when you can get pregnant (WHITE bead days or days 8 to 19 on calendar) and want to avoid pregnancy. You can take emergency contraceptive pills (ECPs).

- You think you may be pregnant. 


\section{Withdrawal}

Coitus Interruptus/"Pulling Out" 


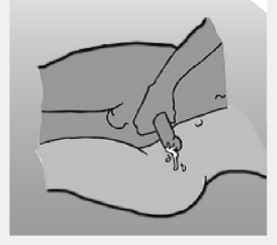

\section{Withdrawal}

Coitus Interruptus/“Pulling Out”

\section{EFFECTIVENESS}

\section{$78 \%$ Typical use}

22 pregnancies per 100 women

\section{GENERAL INFORMATION}

- The man withdraws his penis from his partner's vagina before ejaculation and he ejaculates outside of the vagina.

- Is one of the least effective methods, yet offers better protection than no method at all.

- Not suitable for men who cannot sense consistently when ejaculation is about to occur or ejaculate prematurely.

- Does not protect against sexually transmitted infections (STIs), including HIV and Zika.

- Requires partner's cooperation.

\section{HOW THE METHOD WORKS}

- Works be keeping sperm out of the woman's vagina.

\section{IMPORTANT FACTS}

- Effectiveness depends on willingness and ability of the male partner to use withdrawal with every act of intercourse.

- Pre-ejaculatory fluid contains sperm and may flow out during intercourse.

- Couples can use withdrawal as a backup method.

- May be appropriate for couples who need temporary method while awaiting the start of another method.

- Requires no supplies and no clinic or pharmacy visit. 


\section{METHOD NOT ADVISED IF...}

- Male partner cannot sense consistently when ejaculation is about to occur.

- Male partner ejaculates prematurely.

- Couple is at high risk of infections, they should use a condo with each act of sex. Withdrawal does not protect from STIs, including HIV and Zika.

\section{SIDE EFFECTS}

None

\section{HEALTH BENEFITS}

- Promotes male involvement and couple communications.

- No delay in return to fertility after use of withdrawal is stopped.

\section{HOW TO USE}

- When the man feels close to ejaculation he should withdraw his penis from the woman's vagina and ejaculate outside the vagina.

- The man should keep his semen away from the woman's genitals.

- If the man has ejaculated recently, he should urinate and wipe the tip of his penis, to remove any remaining sperm, before sex.

- Learning to properly use withdrawal may take time. The couple can also use another method until the man feels that he can use withdrawal correctly with every act of sex.

\section{RETURN TO THE HEALTH CARE FACILITY AT ANY TIME IF...}

- You have any questions or problems.

- Your male partner has difficulty predicting and/or controlling the timing of his ejaculation. You may want to choose another method.

- Your partner has ejaculated inside your vagina before withdrawing. You can take emergency contraceptive pills (ECPs).

- You want an additional or alternative method of family planning for greater protection from pregnancy. You think you may be pregnant. 
POPULATION

COUNCIL

Ideas. Evidence. Impact. 


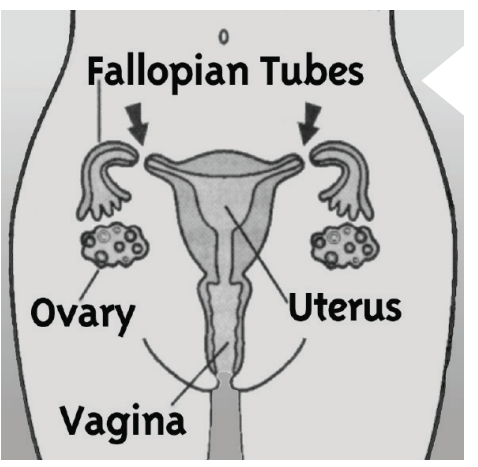

Tubal Ligation

Female Sterilization 


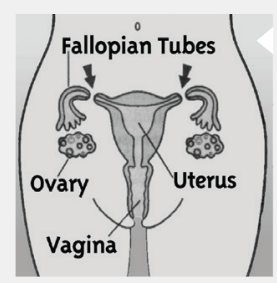

Tubal Ligation

Female Sterilization

\section{EFFECTIVENESS}

In first year

Less than 1 pregnancy per 100 women

Over 10 years

2 pregnancies per 100 women

\section{GENERAL INFORMATION}

- Permanent method for women who do not want more children.

- Involves a surgical procedure. There are both benefits and certain risks i the procedure.

- Protects against pregnancy right away.

- Safe for a woman with HIV/AIDS, even if she takes antiretroviral (ARV) medicines.

- Does not protect against sexually transmitted infections (STIs), including HIV and Zika.

\section{HOW THE METHOD WORKS}

- A trained provider makes a small incision on your abdomen. S/he then ties off (or cuts) the two fallopian tubes. These tubes normally carry eggs from the ovaries to the uterus.

- With the tubes blocked, the eggs cannot move down the tubes. They cannot meet with the man's sperm.

- The method is intended to be permanent.

\section{SIDE EFFECTS}

None 


\section{IMPORTANT FACTS}

- No need to worry about contraception again. The method is very effective.

- Easy to use, nothing to do or remember.

- Does not affect sexual desire.

- Complications of surgery and anesthesia are possible. But they are uncommon and extremely rare.

- Special arrangements are needed to perform a tubal ligation on a woman with AIDS.

- Use condoms (male or female) if you feel you are at risk of STIs, including HIV and Zika.

\section{METHOD NOT ADVISED IF YOU...}

- Are pregnant

- Are depressed

- Have certain medical conditions that make it necessary to delay the procedure.

\section{HEALTH BENEFITS}

- Protects against risks of pregnancy and pelvic inflammatory infections (PID).

- May help protect against ovarian cancer.

\section{INFORMED CONSENT}

- Informed consent is required for this method.

- Before you give informed consent, you must understand the following points:

- Temporary contraceptives are also available

- Tubal ligation is a surgical procedure

- There are certain risks of the procedure as well as benefits (both risks and benefits must be explained in a way that you understand them).

- If successful, the procedure will prevent you from ever having any more children.

- The procedure is considered permanent and probably cannot be reversed.

- You can decide against the procedure at any time before it takes place. You will not lose rights to other medical, health, or other services or benefits.

- Before the procedure you may need to sign a consent form. If you cannot read or write, someone will read the form to you and a witness can sign for you. 


\section{FOLLOW-UP}

- After the procedure, rest for 2 days.

- Avoid vigorous work and heavy lifting for 1 week.

- Abdominal pain and swelling after the procedure is common. It usually goes away within a few days.

- Take paracetamol or ibuprofen in case of pain. Do not take aspirin. It slows healing. You rarely need a stronger pain reliever.

- Keep the incision clean and dry for 1 or 2 days. Avoid rubbing the incision for 1 week.

- Do not have sex for at least 1 week. If pain lasts more than 1 week, avoid sex until all pain is gone.

- If possible, after 7-14 days, return to the health care facility. The health care provider will check the incision site. S/he will look for signs of any infection and remove any stitches.

\section{RETURN TO THE HEALTH CARE FACILITY ANY TIME IF...}

- You have any questions or problems.

- You develop any health problems.

- You think you may be pregnant. 


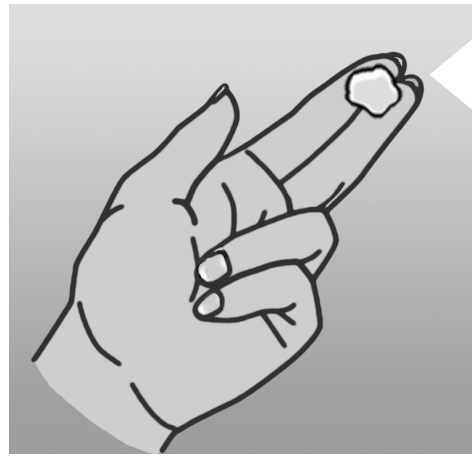

TwoDay Method ${ }^{\circledR}$ 


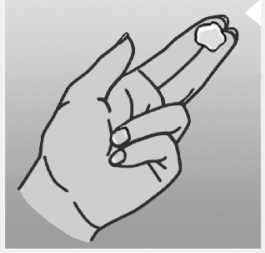

\section{TwoDay Method $®$}

\section{EFFECTIVENESS}

\section{Typical use}

14 pregnancies per 100 women

\section{GENERAL INFORMATION}

- Ideal for women who have healthy cervical secretions.

- Healthy secretions do not have a foul smell or cause itchiness or pain.

- You have to check your cervical secretions at least once a day to know which days you can get pregnant (fertile days).

- If you note secretions of any type, color, or consistency on the day you check, then this is a fertile day and you can get pregnant.

- On days you can get pregnant, you must abstain from unprotected sex or you can use a condom or other barrier method.

- Does not protect against sexually transmitted infections (STIs), including HIV and Zika.

- Requires partner's cooperation.

\section{HOW THE METHOD WORKS}

- Check your secretions at least twice a day.

- For this method, any type of cervical secretions indicates the woman is fertile. Secretions are anything that you perceive as coming from your vagina, except menstrual bleeding.

- If you saw or felt any secretions either today or yesterday, you can get pregnant today.

- If today or yesterday you had secretions, abstain from sex or use a condom or other barrier method today.

\section{SIDE EFFECTS}

None 


\section{IMPORTANT FACTS}

- No costs and no supplies needed.

- Can be used by women with any cycle length and can be started at any point in their cycle.

- You will need some counseling on how to use the method correctly.

- If you have a vaginal infection or another condition that changes your cervical secretions, the TwoDay Method will be difficult to use.

- On fertile days, yo must abstain form unprotected sex or use a barrier method. This may be difficult for some couples.

- Use condoms (male or female) if you feel at risk of STIs, including HIV and Zika.

\section{METHOD NOT ADVISED IF YOU...}

- Are not willing or able to abstain from sex or use a condom or other barrier method during the days you can get pregnant.

- Cannot tell whether or not you have cervical secretions.

- Have an infection that may affect your cervical secretions.

- Have not had at least 3 consecutive menstrual cycles since giving birth.

- Have not resumed menstruation after discontinuing a hormonal method.

\section{HEALTH BENEFITS}

- It is natural, there are no hormones, devices or medical procedures required.

- Promotes male involvement and couple communications.

- No delay in return to fertility

\section{HOW TO USE}

1. Check for secretions as soon as your monthly bleeding stops. Check every day for any secretions. Secretions are anything that you perceive as coming from your vagina, except menstrual bleeding.

2. You may feel wetness at the opening of your vagina or see secretions on your finger, underpants, or tissue paper.

3. If you did not notice any secretions today AND yesterday (two days in a row without secretions), it is not likely you can get pregnant today.

4. If you are not sure whether or not you have secretions, avoid sex or use a condom or other barrier method.

Note: Secretions may change in quantity or look different on different days. ANY type of secretion indicates that you can get pregnant. 


\section{RETURN TO THE HEALTH CARE FACILITY ANY TIME IF...}

- You have difficulty knowing whether or not you have secretions.

- You or your partner has difficulty using condoms or abstaining from sex during the days you can get pregnant. You may want to choose another method.

- You have fewer than 5 days with secretions.

- You have more than 14 days in a row with secretions.

- You have sex on a fertile day and want to avoid pregnancy. You can take emergency contraceptive pills (ECPs).

- You think you may be pregnant.

- You have any questions or problems. 


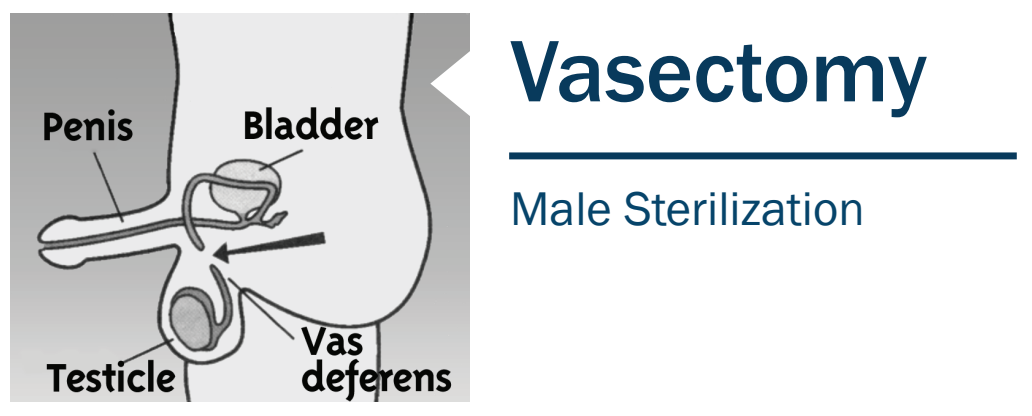




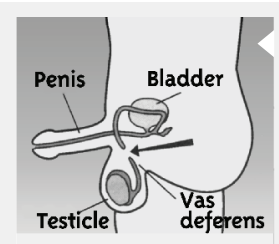

\section{Vasectomy}

Male Sterilization

\section{EFFECTIVENESS}

In first year

Less than 1 pregnancy per 100 women whose partner has had a vasectomy

Over 3 years

4 pregnancies per 100 women whose partner has had a vasectomy

\section{GENERAL INFORMATION}

- Permanent, safe method for men who do not want more children.

- A safe, simple surgical procedure.

- Does not affect male sexual performance.

- Does not protect from pregnancy immediately. There is a 3-month delay before the method takes effect.

- You must use condoms or another method for 3 months after the procedure.

- Safe for a man with HIV/AIDS, even if he takes antiretroviral (ARV) medicines.

- Does not protect against sexually transmitted infections (STIs), including HIV and Zika.

\section{HOW THE METHOD WORKS}

- You undergo a safe, simple, and quick surgical procedure.

- A trained provider makes a simple cut and closes off the tubes from the testicles to the penis (vas deferns).

- Closing off the tubes keeps sperm out of the semen.

- You can still have erections and ejaculate semen. Your semen does not have sperm in it, so you cannot make a woman pregnant. 


\section{IMPORTANT FACTS}

- One of the most effective methods, but it carries a small risk of failure.

- Vasectomy is not fully effective until 3 months after the procedure. You must use condoms or another method for 3 months.

- Pregnancies can occur within the first year for several reasons:

- During the first 3 months after the procedure, you do not always use a condom or other method during sex.

- The provider makes a mistake during the procedure.

- The cut ends of the vas deferens grow back together.

- Increases enjoyment and frequency of sex because there are no worries about pregnancy.

- There are no particular health risks or benefits from this procedure.

- Special arrangements are needed to perform the procedure on a man with AIDS.

- Use condoms (male or female) if you feel at risk of STIs, including HIV and Zika.

\section{METHOD NOT ADVISED IF...}

- You have a medical condition where it may be necessary to delay this procedure.

\section{INFORMED CONSENT}

- Informed consent is required for this method.

- Before you give informed consent, you must understand the following points:

- Temporary contraceptives are also available to you

- Voluntary vasectomy is a surgical procedure

- There are certain risks of the procedure as well as benefits (both risks and benefits must be explained in a way that you understand them).

- If successful, the procedure will prevent you from ever having any more children.

- The procedure is considered permanent and probably cannot be reversed.

- You can decide against the procedure at any time before it takes place. You will not lose rights to other medical, health, or other services or benefits.

- Before the procedure you may need to sign a consent form. If you cannot read, a witness can sign for you. 


\section{HOW TO USE}

- A trained medical provider performs the procedure in a place that has the necessary medical supplies and equipment.

- The provider injects a local anesthetic into your scrotum. You will stay awake during the procedure.

- The provider performs the procedure.

- You can usually leave the clinic within an hour.

\section{FOLLOW-UP}

- It is common to feel discomfort in the scrotum. This usually lasts 2 to 3 days.

- Take paracetamol or ibuprofen for pain. Do not take aspirin. It slows healing.

- Rest for 2 days, if possible.

- Keep incision clean and dry for 2 or 3 days.

- Do not have sex for at least 2 or 3 days.

- During the first 3 months after the procedure, use condoms or another effective family planning method.

- If possible, return to the clinic to have your semen examined. If it does not contain sperm, the vasectomy is working. This is helpful but not required.

\section{RETURN TO THE HEALTH CARE FACILITY ANY TIME IF...}

- You have questions or problems.

- You develop any health problems.

- Within the first 3 months of having the vasectomy you and your partner have unprotected sex and want to avoid pregnancy. Your partner can take emergency contraceptive pills (ECPs).

- Your partner thinks she may be pregnant. 


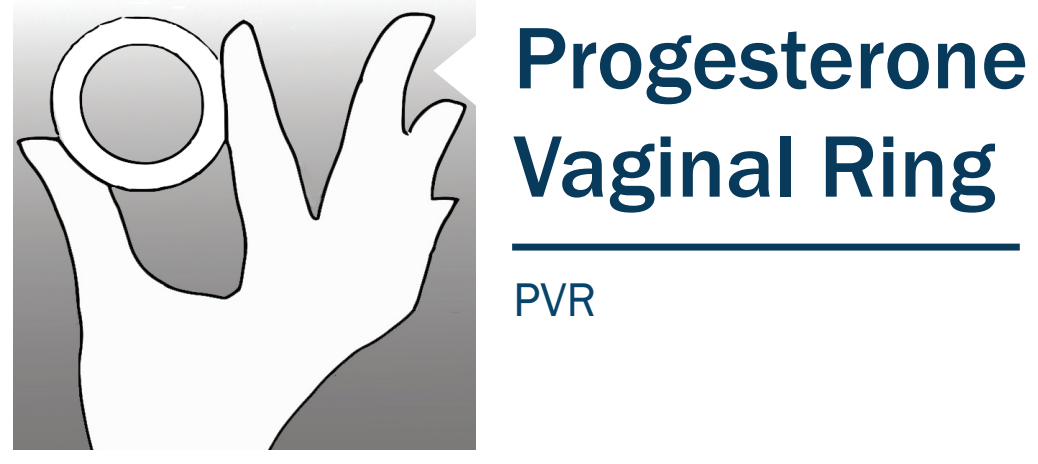




\section{Progesterone Vaginal Ring}

PVR

\section{EFFECTIVENESS}

\section{Correct use}

Consistent use every 3 months:

2 pregnancies per 100 women

\section{GENERAL INFORMATION}

- Can help prevent pregnancy in women who breastfeed at least 4 times per day for the first year postpartum.

- Soft, flexible ring-shaped device made of silicone rubber and containing natural progesterone hormone.

- Can begin using method $\geq 4$ weeks after childbirth.

- Each ring can be used continuously for 90 days; 4 rings can be used consecutively, each changed every 3 months, for up to 12 months.

- Self-inserted and removed from the vagina.

- Safe for mothers and baby.

- Does not protect against sexually transmitted infections (STIs), including HIV and Zika.

\section{HOW THE METHOD WORKS}

- It releases a constant level of the hormone progesterone that spreads to the walls of the vagina and then into the blood stream.

- Progesterone prevents the start of ovulation. It reinforces the inhibitory effect of breastfeeding on ovulation suppression.

- Inhibits growth of follicles (which contain an egg) and therefore prevents ovulation.

- Extends the period of lactational amenorrhea which means you will likely not get your menses.

- Progesterone makes the mucus around your cervix get thick. This makes it difficult for sperm to meet the egg. 


\section{IMPORTANT FACTS}

- No harmful effects on frequency of breastfeeding, volume of breast milk or infant growth.

- Does not interfere with sex although your partner may be able to feel the ring.

- User-initiated and reversible.

- Natural progesterone hormone is released in a continuous low dose which results in few side effects.

- Can be stopped at any time without a provider's help.

- Removing the ring for any period of time may reduce efficacy.

- The ring might become discolored with use.

\section{METHOD NOT ADVISED IF YOU...}

- Are not breastfeeding at least 4 times per day.

- Have a genital or urinary tract infection (method can be initiated after treatment), or have had pelvic inflammatory disease or salpingitis since delivery

- Have a history of uterine disease (endometrial or cervical) or recurrent urinary tract infections

- Have sensitivity to silicone.

\section{POSSIBLE SIDE EFFECTS}

- Vaginal discharge

- Spotting or bleeding

- Breast discomfort

- Lower abdominal pain

\section{HEALTH BENEFITS}

- Efficacy of the method depends on continued breastfeeding which has benefits for baby and mother. 


\section{HOW TO USE}

- Using proper hygiene, place the ring as far back into the vagina as possible with your fingers until you do not feel it.

- If experiencing difficulty with insertion try inserting while in a different position (for example, one leg raised on a stool, or on your back).

- If you feel the ring slipping, use your fingers to push up and reposition the ring so you no longer feel it.

- If the ring comes out, reinsert it as soon as possible. Be sure the ring is clean enough to reinsert. If necessary wash with mild soap or water. Do not use bleach or other cleaning products.

- If constipated, ring can be removed briefly before toileting. Reinsert using proper hygiene.

- If the ring continues to come out, this method may not be appropriate for you. It may not be suitable for women with severe pelvic relaxation problems.

- If the ring is removed for more than 2 hours, reinsert if possible, and contact your health care provider (use another method of contraception such as condom until you get proper advice).

- Replace the ring with a new one after 90 days if continued birth spacing is desired, and you are continuing to breastfeed at least 4 times per day.

\section{RETURN TO THE HEALTH CARE FACILITY ANY TIME IF...}

- You have questions or problems.

- You think you might be pregnant.

- Your menses returns.

- More than 12 months have passed since starting the method.

- You discontinue breastfeeding and/or wish to choose another method. 


\section{Caya ${ }^{\circledR} /$ SILCS Diaphragm}




\section{Caya ${ }^{\circledR} /$ SILCS Diaphragm}

\section{EFFECTIVENESS}

\section{Typical use}

Not used consistently:

18 pregnancies per 100 women

\section{GENERAL INFORMATION}

- The diaphragm is a soft flexible cup that a woman inserts into her vagina to cover her cervix.

- Caya must be used in combination with contraceptive gel.

- It is controlled by the woman, has no hormonal effects and is inserted ahead of time so does not interfere with sex.

- It is made of silicone and can be re-used for up to 2 years.

- When a woman inserts the diaphragm correctly she should not feel any pain of discomfort.

- It is safe for breastfeeding women.

- Women should wait until 6 weeks after childbirth or second trimester abortion before using the diaphragm so that the cervix has returned to normal size.

\section{HOW THE METHOD WORKS}

- The diaphragm covers the cervix. It blocks the sperm from entering the cervix.

- The diaphragm can be reused. Wash it with soap and water and let it dry.

- You can store it in its case until next time you want to use it.

- Never leave the diaphragm for more than 24 hours without taking it out and washing it. 


\section{IMPORTANT FACTS}

- Private. No one else can tell you are using it.

- Does not interfere with sex.

- You will need counseling/ instructions on how to use it correctly.

- Can be stopped at any time without providers help.

- Has no hormonal side effects.

- Does not protect against STIs, including HIV.

- Use condoms (male or female) if you feel at risk of STIs or Zika.

\section{METHOD NOT ADVISED IF YOU...}

- Gave birth in the last 6 weeks.

- Had an abortion (second trimester) in last 6 weeks

\section{SIDE EFFECTS}

None

\section{HOW TO USE}

- Wash your hands with soap and water.

- Check diaphragm for holes and tears.

- Place $4 \mathrm{ml}$ of contraceptive gel into silicone diaphragm.

- Insert the diaphragm into your vagina and cover the cervix.

- For greatest protection, insert the diaphragm before sex begins and wear it for at least 6 hours after sex ends.

- Six hours after sex, remove diaphragm. Wash with soap and water and let dry.

- Store Caya diaphragm in the original case.

\section{FOLLOW-UP}

None

\section{RETURN TO THE HEALTH CARE FACILITY ANY TIME IF...}

- You have any questions or problems.

- You develop any health problems.

- You had sex in the past 5 days, did not use any method and want to avoid pregnancy. You can take emergency contraceptive pills (ECPs).

- You think you may be pregnant. 
The Balanced Counseling Strategy Plus A Toolkit for Family Planning Service Providers Working in High STI/HIV Prevalence Settings

\section{COUNSELING CARDS}

Third Edition, 2015 
Checklist to be Reasonably Sure a Woman is not Pregnant

Monthly Injectable

\section{鸟 Emergency Contraception}

ら乌 Female Condoms

こ乌 Hormonal Implants

Ђ

П Levonorgestrel Intrauterine

乌 System

Lactational Amenorrhea Method

Male Condoms

Minipill

The Pill

Progestin-only Injectables
Zika Transmission and Prevention

Withdrawal

STI and HIV Risk Assessment

Positive Health, Dignity and

Tubal Ligation

TwoDay Method

Vasectomy

Progesterone Vaginal Ring

Caya ${ }^{\circledR} /$ Silcs Diaphragm

گ Healthy Timing and Spacing of

\section{几 Promoting a Healthy Postpartum} Period for the Mother

\section{乌 Post Abortion Care}

\section{几 Promoting Newborn and nfant Health}

几 STI and HIV Transmission and

Prevention
Dual Protection

HIV Counseling and Testing

Screening for Cervical Cancer

Adolescent Counseling

Women's Support and Safety

Male Services

Breast Cancer Information and Awareness 


\section{Effectiveness Ratings}

\section{METHODS ARE DEFINED FOR TYPICAL USE AS FOLLOWS:}

HIGHLY EFFECTIVE <5 pregnancies per 100 women in designated time period

EFFECTIVE

5-10 pregnancies per 100 women in designated time period

$>10$ pregnancies per 100 women in designated time period 
HIGHLY EFFECTIVE <5 pregnancies per 100 women in designated time period
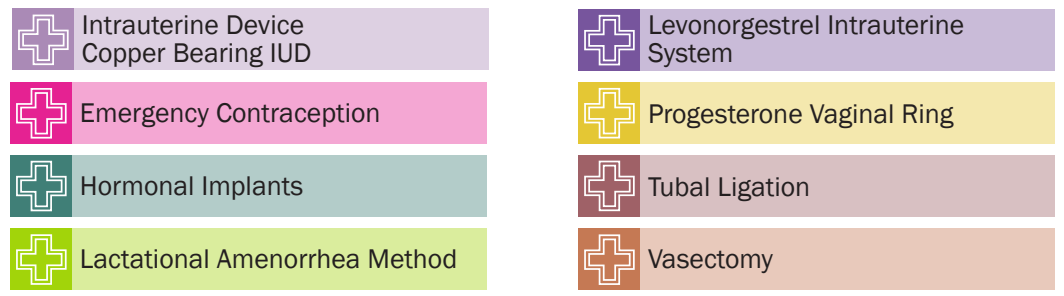

\section{$\square$ Tـ The Pill}

$\square$ Monthly Injectable

\section{كص Progestin-only Injectables}

局 Minipill

\section{ص包 Caya®/Silcs Diaphragm}

ص局 Female Condoms

$\square$ Male Condoms

\section{Standard Days Method $®$}

TwoDay Method

Withdrawal

LESS EFFECTIVE >10 pregnancies per 100 women in designated time period 


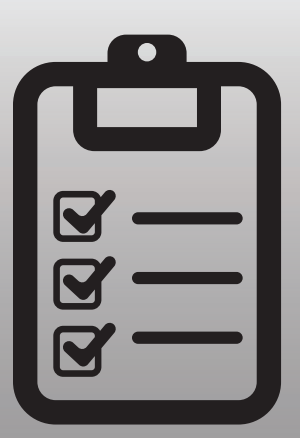

Checklist to be Reasonably Sure a Woman is not Pregnant 


\section{Checklist to be \\ Reasonably Sure a \\ Woman is not Pregnant}

The goal of FP provision is to provide the client with her preferred method on the same day as her visit. It is preferable to give a contraceptive method instead of having her leave and becoming pregnant. The risks associated with offering any contraceptive method to a woman who may be pregnant and not aware of it are low.

\section{ASK THESE 6 QUESTIONS:}

1. Did you have a baby less than 6 months ago? If so, are you breastfeeding? Have you had no menstrual bleeding since giving birth?

2. Have you abstained from unprotected [no method of FP] sex since your last menstrual bleeding or delivery?

3. Have you given birth in the last 4 weeks?

4. Did your last menstrual bleeding start within the past 7 days (or within 12 days if you plan to use a copper-bearing IUD)?

5. Have you had a miscarriage or abortion in the past 7 days?

6. Have you been using a reliable contraceptive method consistently and correctly?
If "Yes" to any of these questions, and client is free of signs and symptoms of pregnancy,

*Once the client has answered yes to one of the questions, it is not necessary to continue asking the remaining questions

1. Pregnancy is unlikely

2. Continue to Step 5
If "No" to all of the questions:

1. Pregnancy cannot be ruled out. 2. Give client pregnancy test if available, or refer her to an antenatal clinic.

3. Provide her with a back-up method, such as condoms, to use until she has her menstrual bleeding.

4. Provide in advance her preferred method (where possible) to use on the 1st day of her menses $O R$ request that she return at that point to receive her preferred method.

5. Go to Step 13 


\section{Monthly Injectable}

Combined Injectable Contraceptives (CICs) 


\section{Monthly Injectable}

Combined Injectable Contraceptives (CICs)

\section{EFFECTIVENESS}

\section{Typical use}

94\% Some missed or late injections: 6 pregnancies per 100 women
- Requires that the client get an injection every 4 weeks (30 days) to prevent pregnancy.

- More regular monthly bleeding than with DMPA or NET-EN injectables.

- Delayed return of fertility after woman stops method. It takes an average of about 1 month longer than with most other methods.

- Not advised if woman is within 21 days of giving birth, regardless of breastfeeding status.

- Not advised if woman is breastfeeding an infant less than 6 months old.

- Not advised if a woman has migraines and is 35 years or older.

- Safe for a woman living with HIV/AIDS, even if she takes antiretroviral (ARV) medicines.

- Not advised if woman has a history of breast cancer or if woman has major risk factors for venous cardiovascular disease, including older age, stroke, smoking, diabetes, hypertension or known dyslipidaemia.

- Does not protect against sexually transmitted infections (STIs), including HIV and Zika. Emphasize the need for dual protection with the client. 


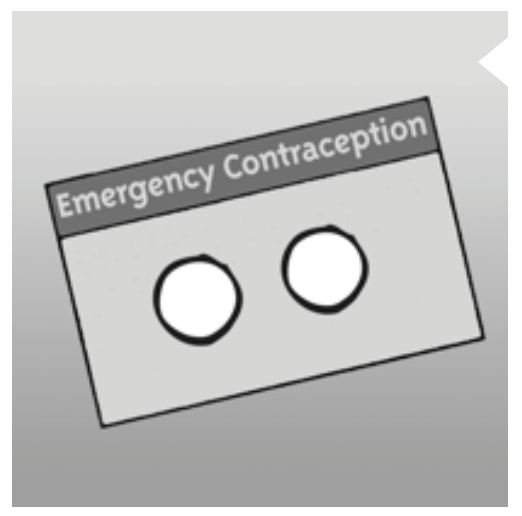

\section{Emergency} Contraceptive Pills

\section{ECPs}




\section{Emergency \\ Contraceptive Pills}

\section{ECPs}

\section{TYPES}

- Progestin only

- Combined progestin and estrogen

- Ulipristal acetate (UPA)

\section{EFFECTIVENESS}

\section{Correct use}

Most effective if taken within first 24 hours; can be taken within 5 days of having unprotected sex:

1-2 pregnancies per 100 women after one instance of unprotected sex depending on the ECP
- One of the only methods that can help prevent pregnancy after a woman has had unprotected sex. Other effective emergency contraception includes Copper-bearing or LNG-containing IUDs.

- Not recommended for regular use, but there is no harm to the user if used repeatedly. However, a woman using ECPs repeatedly should receive additional family planning counseling in order to select the most appropriate continuous method.

- Breastfeeding not recommended for one week after using UPA.

- Must be used within 5 days (120 hours) of unprotected sex.

- Safe for women who cannot use regular hormonal contraceptive methods, including postpartum breastfeeding women.

- ECPs do not disrupt existing pregnancy.

- Safe for a woman living with HIV/AIDS, even if she takes any type of antiretroviral (ARV) medicines.

- Does not protect against sexually transmitted infections (STIs), including HIV and Zika. Emphasize the need for dual protection with the client. 


\section{Female Condoms}

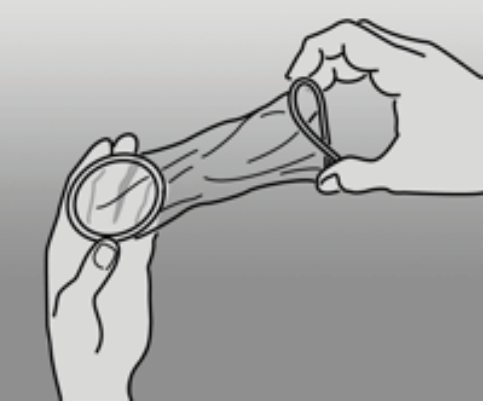




\section{Female Condoms}

\section{TYPES}

- Female Condom 2 / FC2

- Cupid

\section{EFFECTIVENESS}

\section{Typical use}

Not used consistently:

21 pregnancies per 100 women
- The female condom is a sheath made of transparent plastic film (polyurethane). FC2 has a flexible ring at both ends. Cupid has a medical grade sponge at one end. It is the same length as a male condom.

- Before having sex, the woman places the female condom into her vagina up to eight hours before an anticipated sexual act. It fits loosely inside the vagina.

- The client must use a new condom for each act of sex.

- Protects against pregnancy and sexually transmitted infections (STIs), including HIV and Zika, if used consistently and correctly.

- Preserves feeling of sex for men and women.

- Requires partner's cooperation. 


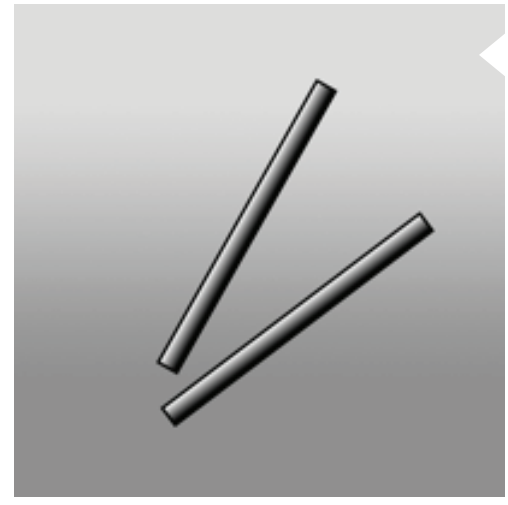

\section{Hormonal Implants}




\section{Hormonal Implants}

\section{TYPES}

- Single rod (Implanon, Nexplanon/Implanon NXT)

- Double rod (Jadelle, Sino-plant II)

\section{EFFECTIVENESS}

First year of use

99\% Less than 1 pregnancy per 100 women
- Either 2 small rods or 1 small rod (about the size of a matchstick) put under the skin.

- Provides long-term protection from pregnancy. Length of protection depends on the implant:

- Jadelle: 5 years

- Sino-plant II: 4 years

- Implanon or Nexplanon: 3 years

- A trained provider must insert and remove implants.

- If a woman has unexplained vaginal bleeding, she should be further evaluated and treated prior to initiating this method.

- Safe for women who are breastfeeding. Women may get implants after giving birth.

- Not advised if a woman has a history of breast cancer.

- Causes changes in monthly bleeding. May cause absence of bleeding or temporary heavy bleeding for a few months.

- Safe for a woman living with HIV/AIDS, even if she takes antiretroviral (ARV) medicines.

- Does not protect against sexually transmitted infections (STIs), including HIV and Zika. Emphasize the need for dual protection with the client. 


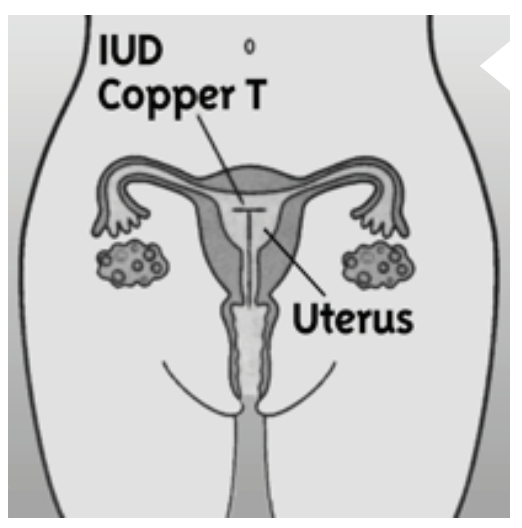

\section{Intrauterine Device}

Copper-bearing IUD 


\section{Intrauterine Device}

\section{Copper-bearing IUD}

\section{EFFECTIVENESS}

\section{First year of use}

99\% Less than 1 pregnancy per 100 women
- Provides long-term protection against pregnancy for 5 - 12 years.

- Is a small, flexible, plastic and copper device placed in the uterus. Most IUDs have 1 or 2 thin strings that hang from the cervix into the vagina.

- It is a safe and effective method for almost all women, including women in the postabortion or postpartum period.

- A trained provider must insert and remove the IUD. This method can be used as emergency contraception.

- Can be inserted immediately after childbirth (within 48 hours) or after 4 weeks postpartum.

- Typically causes slightly longer and heavier bleeding and more cramps or pain during monthly bleeding.

- If a woman has unexplained vaginal bleeding, she should be further evaluated and treated prior to initiating this method.

- Safe for a woman living with HIV/AIDS who is clinically well (WHO Stage 1 or 2 of HIV clinical disease) on antiretroviral (ARV) medicines.

- Not advised for a woman with very high risk of having sexually transmitted infections (STIs), particularly chlamydia or gonorrhea. Evaluate the client for STI risk prior to initiating this method. (See STI and HIV Risk Assessment Card).

- Does not protect against sexually transmitted infections (STIs), including HIV and Zika. Emphasize the need for dual protection with the client. 


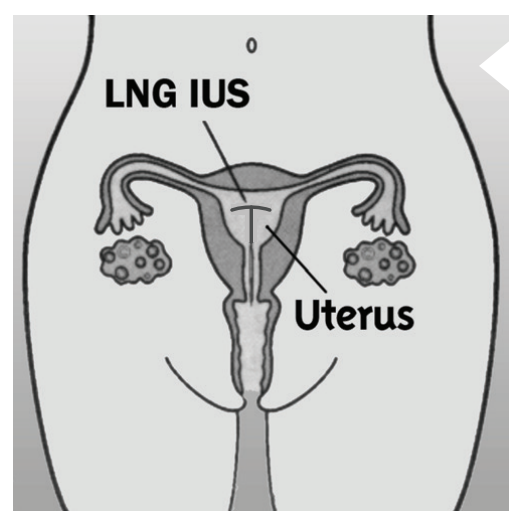

Intrauterine Device/System

Levonorgestrel LNG IUD/IUS 


\section{Intrauterine \\ Device/System}

Levonorgestrel LNG IUD/IUS

\section{EFFECTIVENESS}

First year of use

99\% Less than 1 pregnancy per 100 women
- Provides long-term protection against pregnancy for up to 5 years.

- Is a small, flexible, plastic device placed in the uterus with an inner reservoir of levonorgestrel, a progestin hormone. The LNG IUS has 1 or 2 thin strings that hang from the cervix into the vagina.

- A trained provider must insert and remove the LNG IUS.

- Can be inserted immediately after childbirth (within 48 hours) or after 4 weeks postpartum.

- Typically causes lighter and shorter monthly periods of bleeding and may cause periods to stop all together.

- If a woman has unexplained vaginal bleeding, she should be further evaluated and treated prior to initiating this method.

- Not advised if a woman has a history of breast cancer.

- Safe for a woman living with HIV/AIDS who is clinically well (WHO Stage 1 or 2 of HIV clinical disease) on antiretroviral (ARV) medicines.

- Not advised for a woman with very high risk of having sexually transmitted infections (STIs), particularly chlamydia or gonorrhea. Evaluate the client for STI risk prior to initiating this method. (See STI and HIV Risk Assessment Card).

- Does not protect against sexually transmitted infections (STIs), including HIV and Zika. Emphasize the need for dual protection with the client. 


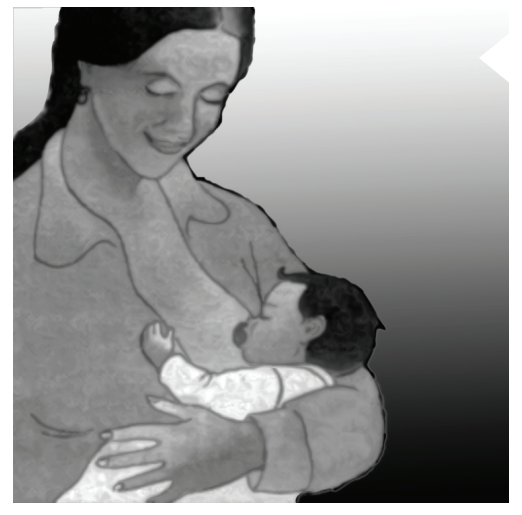

Lactational Amenorrhea Method

LAM 


\section{Lactational}

\section{Amenorrhea Method}

\section{LAM}

\section{EFFECTIVENESS}

\section{Typical use}

$98 \%$

First 6 months after childbirth when all 3 criteria are met: 2 pregnancies per 100 women
- LAM is for women who are exclusively breastfeeding their baby. All women who have infants six months or younger should be encouraged to exclusively breastfeed for the well-being of their baby.

- LAM requires 3 conditions. All 3 must be met:

1) The client's monthly bleeding has not returned since giving birth

2) The baby is exclusively breastfed, day and night

3) The baby is less than 6 months old

- LAM is a temporary family planning method used after pregnancy. A woman using LAM should plan to visit her provider before she starts to use supplemental feeding to talk about switching to another modern method once the 3 conditions for LAM are no longer met. If the woman is willing, initiate the conversation now about what method she plans to use once LAM is no longer effective.

- Safe for a woman living with HIV/AIDS when she exclusively breastfeeds. There is a chance, however, that mothers with HIV may transmit HIV to their infants through breastfeeding if they are not on ARVs. Does not protect against sexually transmitted infections (STIS), including HIV and Zika. Emphasize the need for dual protection with the client.

- Dispensing ECP when counseling on LAM increases pregnancy protection and timely transition to another method. Counseling on ECP should suggest to clients to use it as a backup if they fail to meet one of the LAM criteria before they are able to obtain another method. 


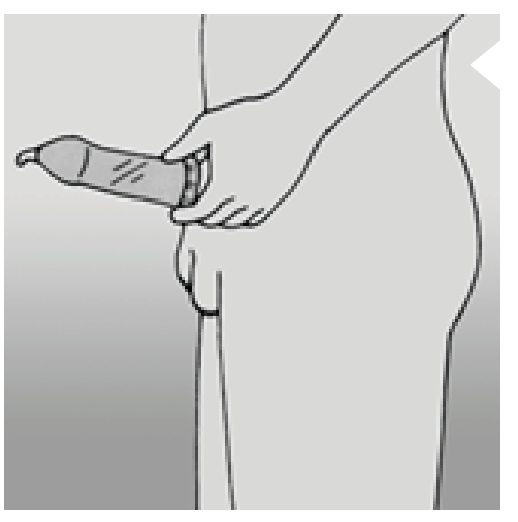

\section{Male Condoms}




\section{Male Condoms}

\section{EFFECTIVENESS}

Typical use

Not used consistently:

18 pregnancies per 100 women
- Most condoms are made of thin latex rubber. Some condoms are coated with a lubricant and/or spermicide.

- If the client has had an allergic reaction to latex rubber, they should not use latex condoms. Use polyurethane condoms as a safe and effective alternative for people with a latex allergy.

- Before having sex, place the condom over the erect penis.

- The client must use a new condom for each act of sex.

- Protects against pregnancy and sexually transmitted infections (STIs), including HIV and Zika.

- Requires partner's cooperation to use consistently and correctly. 


\section{Minipill}

Progestin-only Oral Contraceptives 


\section{Minipill}

Progestin-only Oral

Contraceptives

\section{EFFECTIVENESS}

Typical use in first year

Some missed pills:

3 to 10 pregnancies per 100 women

For breastfeeding women in first year

1 pregnancy per 100 women
- Requires that the client takes 1 pill every day.

- Safe for women who are breastfeeding. Women may begin the minipill after giving birth.

- May cause irregular monthly bleeding. For breastfeeding women, causes delayed return of monthly bleeding.

- Safe for a woman living with HIV/AIDS, even if she takes antiretroviral (ARV) medicines.

- Not advised if a woman takes medicine for seizures or takes Rifampicin (for tuberculosis or other infections).

- Does not protect against sexually transmitted infections (STIs), including HIV and Zika. Emphasize the need for dual protection with the client. 


\section{The Pill}

Oral contraceptives

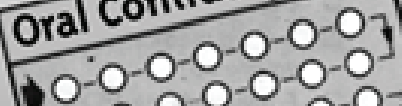

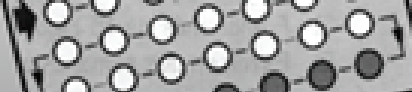

$[00000000$

\section{Combined Oral Contraceptives}




\section{The Pill}

Combined Oral Contraceptives

\section{EFFECTIVENESS}

\section{Typical use}

Some missed pills:

9 pregnancies per 100 women
- Requires that the client takes 1 pill every day.

- Not advised if breastfeeding an infant less than 6 months old.

- Not advised if woman is within 21 days of giving birth, regardless of breastfeeding status.

- May cause irregular bleeding during the first few months of use, after which users may experience lighter and more regular bleeding.

- In some cases, may cause other side effects including nausea, headache, bloating, breast tenderness, or weight change.

- Not advised if woman takes medicine for seizures or takes Rifampicin (for tuberculosis or other infections).

- Not advised if a woman has history of breast cancer.

- Not advised if a woman has migraines and is 35 years or older.

- Not advised if woman has major risk factors for venous cardiovascular disease, including older age, stroke, smoking, diabetes, hypertension or known dyslipidaemia.

- Safe for a woman living with HIV/AIDS, even if she takes antiretroviral (ARV) medicines.

- There are many different brands and formulations of combined oral contraceptives. Discuss available and most appropriate method with the client.

- Does not protect against sexually transmitted infections (STIs), including HIV and Zika. Emphasize the need for dual protection with the client. 


\section{Progestin-only Injectables}

DMPA or NET-EN 


\section{Progestin-only}

\section{Injectables}

\section{DMPA or NET-EN}

\section{TYPES}

- Intramuscular DMPA $150 \mathrm{mg}$ or NET-EN

- Subcutaneous DMPA 104mg (Sayana Press)

\section{EFFECTIVENES}

Typical use in first year

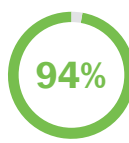

Some missed or late

injections:

6 pregnancies per 100 women
- The client gets an injection every 2 or 3 months, depending on type of injection.

- Safe for women who are breastfeeding a baby. For a woman who is breastfeeding but not using LAM, injectables can be started after 6 weeks. Fertility can return as early as 3 weeks postpartum, so clients should use a backup method such as condoms until they begin injectables.

- May cause irregular or no menstrual bleeding.

- There is a delayed return to fertility after the client stops the method. It takes longer than with most other methods. Return to fertility is, on average, 1 month for NET-EN and 4 months for DMPA.

- Safe for a woman living with HIV/AIDS, even if she takes antiretroviral (ARV) medicines. Does not protect against sexually transmitted infections (STIs), including HIV and Zika. Emphasize the need for dual protection with the client.

- If a woman has unexplained vaginal bleeding, she should be further evaluated and treated prior to initiating this method.

- Not advised if woman has a history of breast cancer or if woman has major risk factors for venous cardiovascular disease, including older age, stroke, smoking, diabetes, hypertension or known dyslipidaemia.

- NET-EN:

- NET-EN is not advised if a woman takes medicine for seizures or takes Rifampicin (for tuberculosis or other infections).

- If on NNRTIs (specifically Efavirenz or Nevirapine) or Ritonavir-boosted protease inhibitors as part of HAART, there may be lower effectiveness of NET-EN injectables. Emphasize dual protection if using NET-EN to reduce chance of pregnancy. 


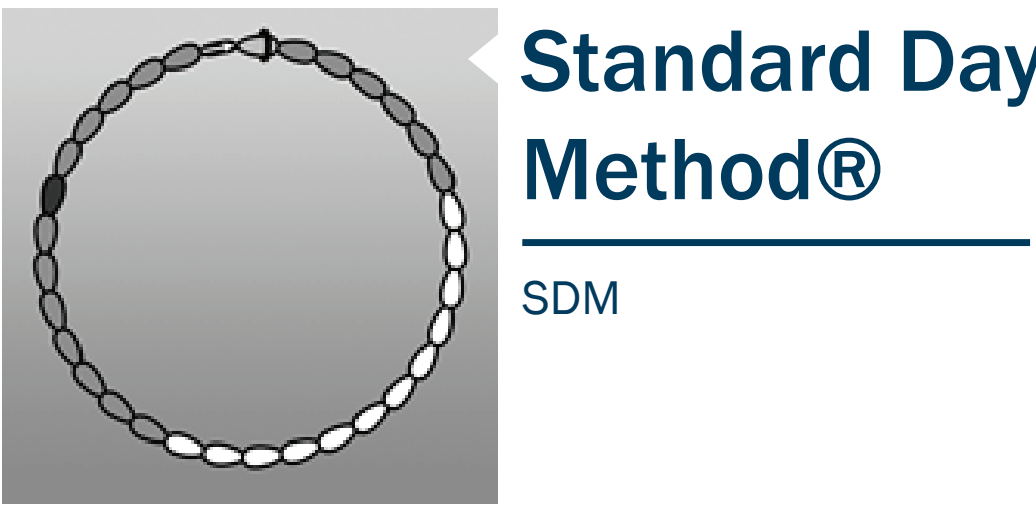




\section{Standard Days \\ Method $®$}

\section{SDM}

\section{EFFECTIVENESS}

Typical use in first year

$88 \% 12$ pregnancies per 100 women
- Ideal for women whose menstrual cycles are usually between 26 and 32 days long. Women who have regular monthly bleeding fall within this range.

- The client keeps track of their menstrual cycle to know the days they can get pregnant (fertile days).

- The client uses a calendar or CycleBeads $®$, a string of color-coded beads, to track the days they can get pregnant and the days they are not likely to get pregnant.

- On the days the client can get pregnant, they must abstain from having unprotected sex. Or, they can use a condom or other barrier method.

- Postpartum or breastfeeding women must have 3 regular menstrual cycles before they can use SDM. An alternate method should be used in the interim.

- Does not protect against sexually transmitted infections (STIs), including HIV and Zika. Emphasize the need for dual protection with the client.

- Requires partner's cooperation. 


\section{Withdrawal}

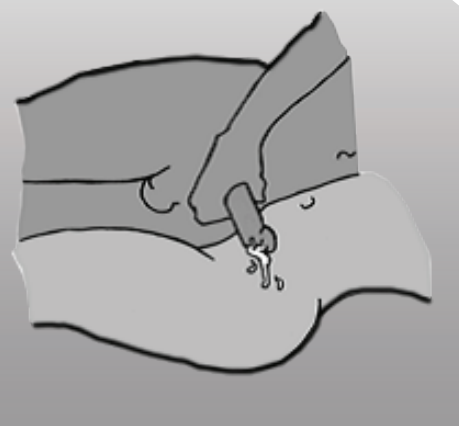

Coitus Interruptus/“Pulling out” 


\section{Withdrawal}

\section{Coitus Interruptus/}

"Pulling Out"

\section{EFFECTIVENESS}

\section{Typical use}

$78 \% \quad 22$ pregnancies per 100 women
- The man withdraws his penis from his partner's vagina before ejaculation, and he ejaculates outside of the vagina.

- Is one of the least effective methods, yet offers better protection than no method at all.

- Not suitable for men who cannot sense consistently when ejaculation is about to occur or ejaculate prematurely.

- Does not protect against sexually transmitted infections (STIs), including HIV and Zika. Emphasize the need for dual protection with the client.

- Requires partner's cooperation. 


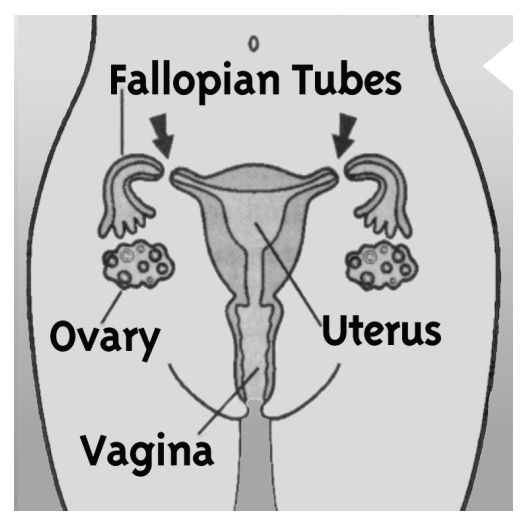

\section{Tubal Ligation}

Female Sterilization 


\section{Tubal Ligation}

\section{Female Sterilization}

\section{EFFECTIVENESS}

In first year

99\% Less than 1 pregnancy per 100 women

Over 10 years

98\% 2 pregnancies per 100 women
- Permanent method for women who do not want more children.

- Involves a surgical procedure. There are both benefits and certain risks involved in the procedure.

- Protects against pregnancy right away.

- Safe for a woman with HIV/AIDS, even if she takes antiretroviral (ARV) medicines.

- Does not protect against sexually transmitted infections (STIs), including HIV and Zika. Emphasize the need for dual protection with the client. 


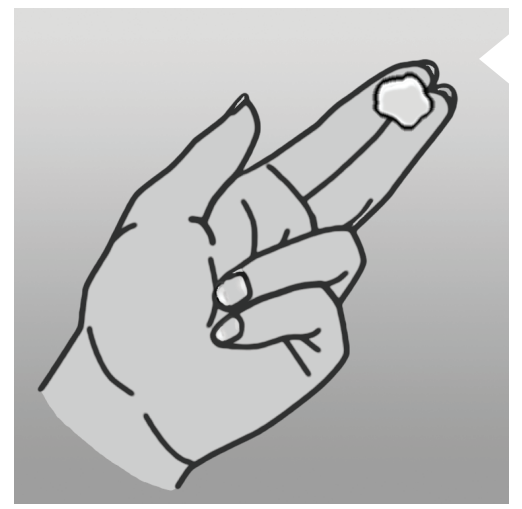

\section{TwoDay Method ${ }^{\circledR}$}




\section{TwoDay Method ${ }^{\circledR}$}

\section{EFFECTIVENESS}

\section{Typical use}

14 pregnancies per 100

women
- Ideal for women who have healthy cervical secretions.

- Healthy secretions do not have a foul smell or cause itchiness or pain.

- The client monitors her cervical secretions at least twice a day. If she notices secretions of any type, color or consistency the day of her monitoring or the day prior to her monitoring, she can likely get pregnant (fertile days).

- On days the client can get pregnant, they must abstain from unprotected sex or they can use a condom or other barrier method.

- Does not protect against sexually transmitted infections (STIs), including HIV and Zika. 


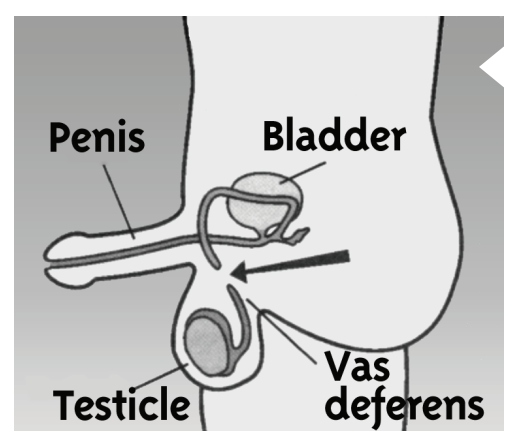

\section{Vasectomy}

Male Sterilization 


\section{Vasectomy}

\section{Male Sterilization}

\section{EFFECTIVENESS}

In first year

Less than 1 pregnancy per 100 women whose partner has had a vasectomy

\section{Over 3 years}

4 pregnancies per 100 women whose partner has had a vasectomy
- Permanent, safe method for men who do not want more children.

- A safe, simple surgical procedure.

- Does not affect male sexual performance.

- Does not protect from pregnancy immediately. There is a 3-month delay before the method takes effect.

- The client must use condoms or another method for 3 months after the procedure.

- Safe for a man with HIV/AIDS, even if he takes antiretroviral ARV) medicines.

- Does not protect against sexually transmitted infections (STIS), including HIV and Zika. Emphasize the need for dual protection with the client. 


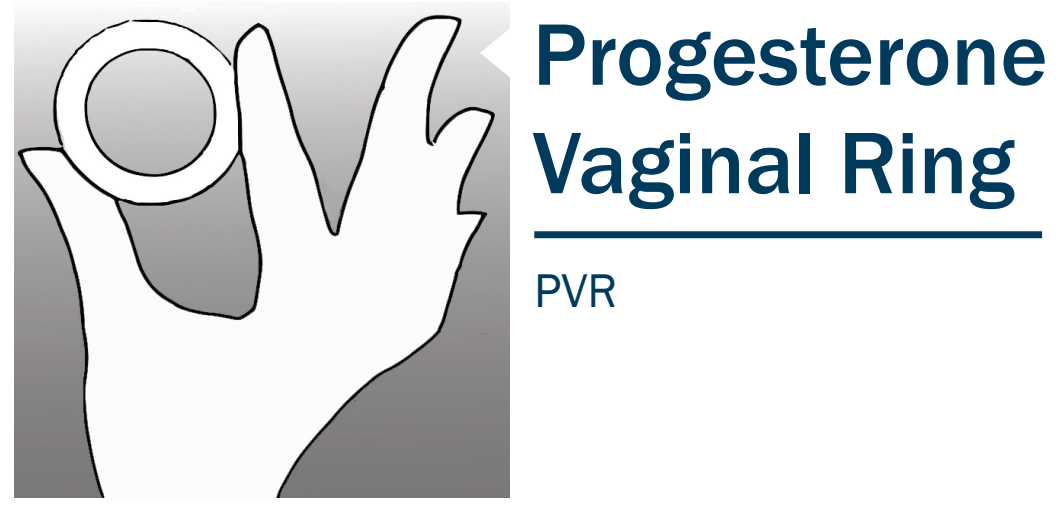

Balanced Counseling Strategy Plus ( $3^{\text {rd }}$ ed.) 


\section{Progesterone \\ Vaginal Ring}

PVR

\section{EFFECTIVENESS}

Correct use

Consistent use every 3

months:

2 pregnancies per 100 women
- Used to space pregnancies for up to one year.

- Smooth, soft, flexible, silicone ring containing natural progesterone.

- Easily inserted and removed from the vagina by the woman.

- Each ring is effective up to 3 months; method can be used successively up to one year (4 rings in 1 year).

- For use by women beginning 30-90 days postpartum who breastfeed at least 4 times per day.

- Initiation of method should be inclusive of counseling on proper use (including insertion and removal).

- May cause irregular or no menstrual bleeding.

- As with other progesterone only methods, spotting or irregular bleeding can occur.

- There is no effect on breastmilk production; method supports continued breastfeeding/infant nutrition.

- Rapid return to fertility following discontinuation.

- Partner may be able to feel the ring.

- Safe for a woman living with HIV/AIDS, even if she takes antiretroviral (ARV) medicines.

- Does not protect against sexually transmitted infections (STIs), including HIV and Zika. Emphasize the need for dual protection with the client. 


\section{Caya ${ }^{\circledR} /$ SILCS Diaphragm}




\section{Caya ${ }^{\circledR} /$ SILCS \\ Diaphragm}

\section{EFFECTIVENESS}

$82 \%$

\section{Typical use}

Not used consistently:

18 pregnancies per 100 women
- The diaphragm is a soft, flexible cup that a woman inserts in her vagina to cover her cervix. It blocks sperm from entering the cervix. The diaphragm is recommended for use with a contraceptive gel.

- The diaphragm is controlled by the woman, has no hormonal side effects, and is inserted ahead of time so it does not interfere with sex.

- The diaphragm should be used each time the client has sex. For greatest protection, insert the diaphragm before sex begins and wear the diaphragm for at least 6 hours after sex ends. Then remove the diaphragm, wash it with soap and water, rinse and let it dry. The client can store the diaphragm in its case until next time she wants to use it. Never leave the diaphragm in the vagina for more than 24 hours without taking it out to wash it.

- The Caya diaphragm is made of silicone and is very strong. It is reusable for up to 2 years.

- The Caya diaphragm fits most women. When the woman correctly inserts the Caya, she should not feel pain or discomfort. Practice inserting, checking that the client's cervix is covered, and removing the Caya to ensure the client is comfortable with this method.

- The diaphragm can be used by almost all women, and it is safe for breastfeeding women. Women should wait 6 weeks after childbirth or second-trimester abortion before using a diaphragm so the cervix and uterus have returned to normal size.

- Does not protect against sexually transmitted infections (STIs), including HIV and Zika. Emphasize the need for dual protection with the client. 


\section{Healthy Timing and Spacing of Pregnancy}




\section{Healthy Timing and Spacing of \\ Pregnancy}

Advise on healthy timing and spacing of pregnancy.
- For women who want to have additional children after a live birth, advise:

- For the health of the mother and baby, wait at least 2 years (24 months) before trying to become pregnant again.

- Use of a family planning method of her choice allows a woman to plan for a healthy pregnancy and provides better health outcomes for her newborn baby and any other children she may have.

- For women who decide to have a child after a miscarriage or abortion, advise:

- For the health of the mother and baby, wait at least 6 months before trying to become pregnant again.

- Use of a family planning method of her choice allows a woman to plan for a healthy pregnancy.

- For adolescents, advise:

- For the health of the mother and the baby, wait until 18 years of age before trying to become pregnant. For teen parents, counsel on waiting until 18 years of age for next pregnancy.

- If sexually active, early adoption and initiation of a FP method of her choice allows a young woman to prevent unintended pregnancy and preserve her health.

- For women over 35 or with 5 or more term pregnancies, additional pregnancies carry higher risks for both the mother and the baby. 


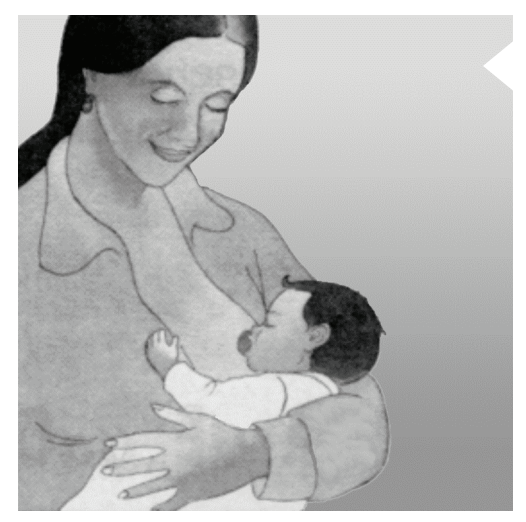

\section{Promoting a Healthy} Postpartum Period for the Mother 


\section{Promoting a Healthy Postpartum Period for the Mother}

- Ensure that the mother has support for the first few days after birth; encourage rest and sleep.

- Recommend a nutritious diet for the mother that includes plenty of fluids and micronutrients (including Vitamin A and iron).

- Discuss normal postpartum bleeding and lochia. Counsel on maternal danger signs, such as heavy bleeding or vaginal discharge that has a foul smell and fever, severe headaches, or convulsions.
- Discuss the need for four postnatal care visits: at 24-48 hours, 3 to 7 days, 4 to 6 weeks, and 4 to 6 months.

- If a woman plans to start supplemental feeding before 6 months postpartum, discuss transition to a FP method prior to starting supplemental feeding.

- Advise on maintaining personal hygiene, including care of perineum and breasts.

- Counsel on return to sexual activity, which should be whenever the mother feels ready and usually after lochia stops. After that she can become pregnant again even before her menses returns. Pregnancy can occur even if she is still partially breastfeeding and is more likely with older infants.

- Encourage her to use FP. Most methods are safe for breastfeeding mothers. Consider providing emergency contraception with instructions to use if she stops exclusively breastfeeding or if she resumes menses and has sex before starting another family planning method.

- Counsel on postnatal depression, which may entail: crying easily; feeling tired, agitated, or irritable; lacking motivation; having difficulty sleeping; rejecting the baby. 


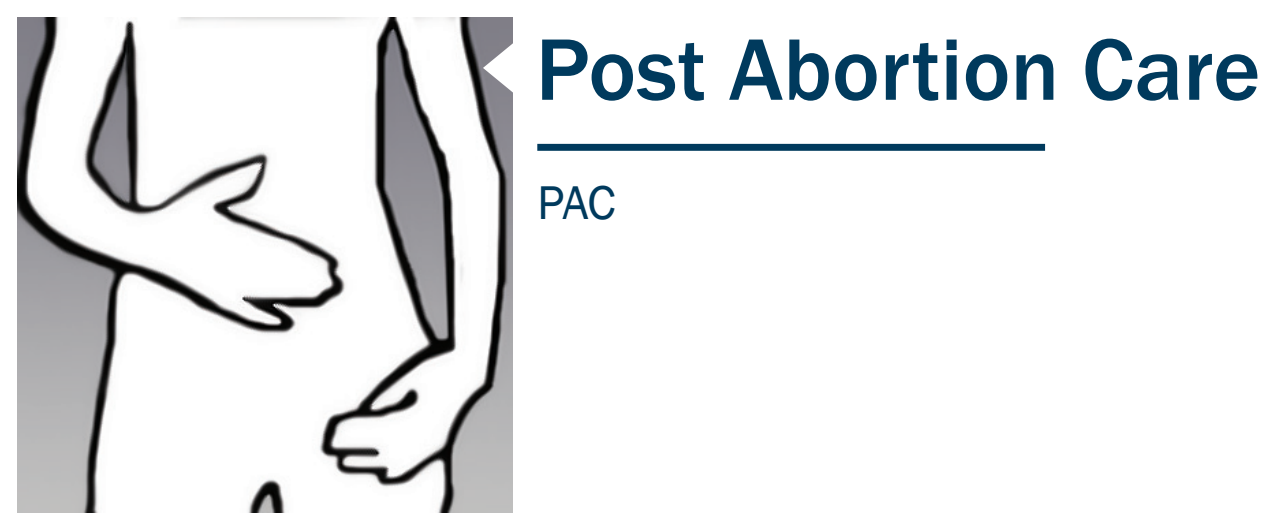




\section{Post Abortion Care}

\section{PAC}

- Inform client on the quick return to fertility, within 2 weeks after the event, for a 1st trimester miscarriage.

- For better health of mother and child, couples should wait 6 months before trying to get pregnant.

- Counsel on return to sexual activity, which should be when the woman feels ready (unless the woman has a history of infection or trauma, then wait until condition is treated and resolved).

- Advise that she can become pregnant even before her menses returns. Encourage her to use FP.

- Most contraceptive methods can be used by a woman presenting for PAC with the exception of tubal ligation and IUD if there is infection or trauma to the cervix or vagina.
- After any evacuation of the uterus, discuss and help the woman pick a contraceptive method of her choice. If it is not available or she is undecided, provide her with either condoms or emergency contraception, and offer to refer her to the nearest health center if she hasn't decided before being discharged.

- Inform the woman of the advantage of condoms as a dual-protection method.

- A woman who has been treated with misoprostol can be immediately offered any contraceptive method except an IUD. If the woman prefers an IUD, ask her to return following complete evacuation of the uterus and verification that she does not have any infections.

- Discuss normal post-abortion bleeding. Counsel on maternal danger signs, such as heavy bleeding or vaginal discharge that has a foul smell.

- Ensure that the woman has support for the first few days. Encourage rest and sleep.

- If the woman is a survivor of rape and sexual assault, refer her to other supportive care services.

- Recognize that accessing PAC can be emotionally traumatic and inform her what psychosocial services are available and offer for her to share her feelings about the process. 


\section{Promoting Newborn and Infant Health}




\section{Promoting Newborn and Infant Health}

- Discuss careful hand washing to prevent infection prior to handling the baby and after cleaning the baby's bottom or changing diapers.

- Put nothing on the baby's cord and do not get the cord area wet until it dries up and falls off, about 2 weeks after birth.

- Counsel the mother on newborn danger signs and when to seek care immediately. Danger signs include: difficulty feeding and/or breathing; feeling too hot or too cold; being irritable for an extended period of time.

- Discuss the importance of providing good ventilation and keeping the baby warm.
- Encourage exclusive breastfeeding for 6 months. Nothing else is necessary, not even water. Introduce complementary foods at 6 months and continue to breastfeed. Exclusive breastfeeding during the first 6 months and the absence of a period/menses during this time is the Lactational Amenorrhea Method (LAM) (see LAM card).

- For infants exposed to HIV:

-Advise mother to give infant antiretroviral (ARV) medicines daily while breastfeeding and to continue for 1 week after cessation of breastfeeding (around 1 year), or for mother to continue ARV treatment per national protocols.

-Recommend that HIV-exposed infants get tested for HIV at 6 weeks and start co-trimoxazole prophylaxis (CTX).

-Link mother and infant to HIV clinic.

- Explain immunization schedule for infants using national or global guidelines, and include recommendation for Vitamin A at 6 months.

- Discuss the need to attend child-welfare clinic (including key activities such as growth monitoring). 


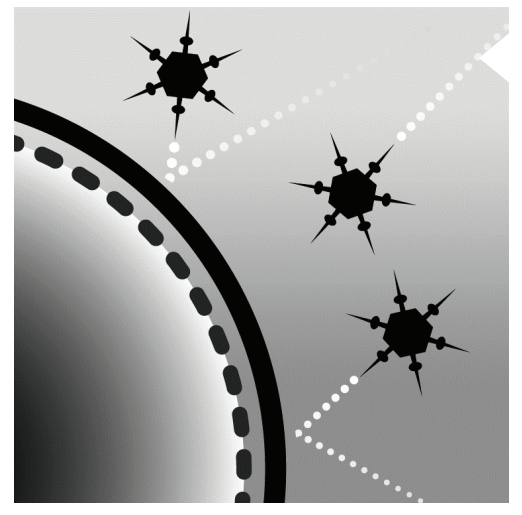

STI/HIV Transmission \& Prevention 


\section{STI/HIV}

\section{Transmission \&}

\section{Prevention}

Discuss the following about all sexually transmitted infections (STIs), including HIV:

- A person can become infected with STIs, including HIV, through unsafe or unprotected sexual activity.

- STIs are common.

- A person living with STIs (including HIV) may have no symptoms, may look healthy and may not be aware that $\mathrm{s} /$ he is infected.

- Common STI symptoms include vaginal discharge, discharge from the penis, sores in the genital area, burning on urination for men, lower abdominal pain for women.
- Some STIs can be treated. To avoid re-infection, both partners must be treated and must abstain from unprotected sex unti lboth partners have completed treatment.

- Risk of infection can be reduced by using a condom, limiting the number of sex partners, and delaying sex.

\section{Discuss the following facts specifically about HIV:}

- HIV is a sexually transmitted infection. HIV is transmitted through an exchange of bodily fluids such as semen, blood, breast milk, and during delivery.

- Knowing the client's HIV status protects them, their partner, and their family. Clients can be offered testing today if it is available, or offered a referral to a testing facility

- Although HIV cannot be cured, early identification and treatment can allow a person to live a long productive life and prevent his/her partner from becoming infected.

- Male circumcision significantly reduces the risk of HIV infection in heterosexual couples.

- Maternal transmission of HIV to the child can be substantially reduced by identifying women living with HIV and providing treatment or prophylactic ARV medicines during pregnancy and breastfeeding, should the woman choose to breastfeed. 


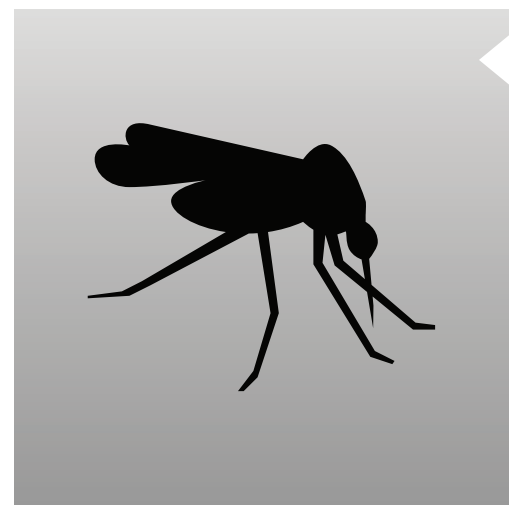

\section{Zika Transmission and Prevention}




\section{Zika Transmission and Prevention}

\section{In regions with NO active Zika virus transmission:}

- Men and women returning from areas with active Zika transmission should use a condom or abstain from sex for at least 6 months on return to prevent Zika transmission through sexual activity.

- Sexual partners of pregnant women returning from areas with active Zika transmission should use a condom or abstain from sex for the rest of the pregnancy.

- Couples or women planning pregnancy who are returning from areas with active Zika transmission are advised to wait at least 6 months before trying to conceive.

\section{Discuss the following facts about Zika virus transmission:}

- Zika is spread mostly by the bite of an infected Aedes species mosquito BUT a person can become infected with Zika through unsafe or unprotected sexual activity

- Zika is transmitted through an exchange of bodily fluids such as semen, blood, and breast milk

- Zika virus infection can be passed from a pregnant women to her baby and cause microcephaly (small brain) and other severe nervous system defects in the baby

- A person who has been infected by Zika virus may have no symptoms, may look healthy and may not be aware they are infected with the virus. They can transmit the virus before, during and the symptoms have resolved. Symptoms include fever, rash, joint pain, or conjunctivitis (red eyes). Zika virus can also cause neurological complications.

- Risk of Zika virus infection can be reduced by using a condom consistently and correctly, limiting the number of sex partners, delaying sex and abstaining from sex

- Women who have had unprotected sex and do not want to become pregnancy due to concerns about Zika infection should have access to emergency contraception and counseling

- Pregnant women and women who could become pregnant, and their partners, should use a condom or abstain from sex.

- A blood or urine test can confirm a Zika infection (is this likely to happen?)

- There is no vaccine or medicine for Zika. 


\section{STI and HIV Risk}

Assessment 


\section{STI and HIV Risk Assessment}

\section{Discuss the following issues to} assess the client's risk of STIs and HIV:

- Ask client about past and present condom use (including perception of partner's attitude) and ask whether $\mathrm{s} /$ he is aware that condoms protect against both STIS/HIV and pregnancy.

- Ask the client whether they know their HIV status and the HIV status of partner(s). If partner is positive, ask whether $\mathrm{s} /$ he is taking ARV medicines.
- Discuss risks associated with multiple or concurrent partners. This includes increased risk for sexually transmitted infections (STIS) and HIV.

- Ask whether the client has knowledge of their male partner's circumcision status. Explain that male circumcision reduces the transmission risk of STIs or HIV to the male's partner.

- Discuss with clients the types of sex or sexual activities and behaviors that can increase risk for getting an STI or HIV (for example, if partner or self has multiple sexual partners, oral sex, anal sex, dry sex, use of detergents or spermicides).

- Discuss whether the client has knowledge of partner's sexual history, including multiple or concurrent partners. If partner or self has history of multiple or concurrent partners, counsel client to attend couples' counseling or voluntary testing and counseling (VCT) to determine HIV status.

- Ask about client's home-life situation (for example, partner violence and social support). If they mention violence, refer to Women's Support and Safety card.

- Ask whether client has ever used PMTCT during pregnancy. Discuss benefits of PMTCT to prevent HIV transmission during pregnancy. 


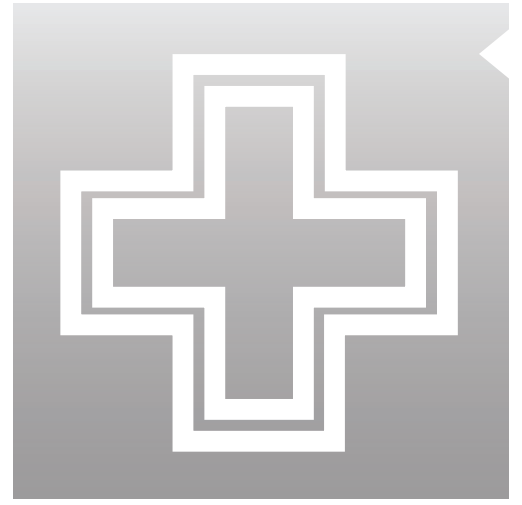

Positive Health, Dignity \& Prevention 


\section{Positive Health, \\ Dignity \& Prevention}

\section{Provide support and counseling on issues relating to disclosure of HIV status. Be sure that client knows it is her/his decision to disclose her/his status and that the provider will not share status without consent.}

Discuss the following with the client:

- People living with HIV need regular checkups to see if they need antiretroviral (ARV) medicine, to evaluate how they are doing on $A R V s$, and to rule out other infections or illnesses. Visits may be frequent when ARV medicine is started.

- A person on ARVs should do her/his best to take the medication as prescribed and should not share medication.

- Partners should get tested as well. The client can bring her/his partner in for counseling and to talk together.

- If currently taking medication for tuberculosis, $\mathrm{s} /$ he should follow up with the provider.

- If a woman with HIV wants to get pregnant:

- The risk of passing HIV to her newborn may be greatly reduced by taking ARV medicine and having a safe delivery. It is important to receive care at an antenatal clinic and an HIV treatment center.

- If a woman is in a serodiscordant relationship (one partner has HIV and the other doesn't) and is trying to get pregnant:

- The risk of transmitting HIV can be reduced by only engaging in unprotected sex (sex without condoms) during a woman's fertile period. The seropositive partner should continue ARVs to reduce the amount of virus in her/his body.

- Positive health results from taking care of oneself and being alert to health concerns that need attention, which may include physical and mental health issues as well as social support. 


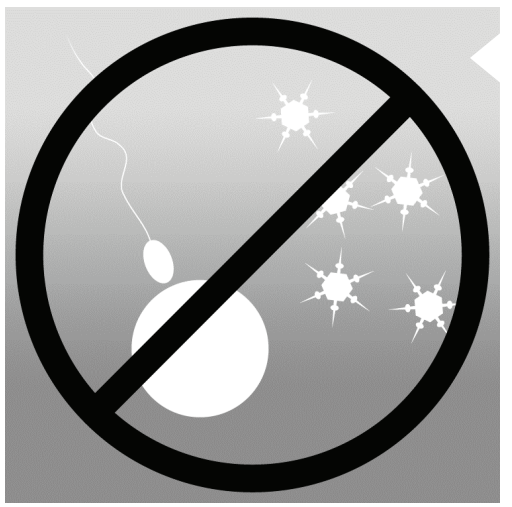

\section{Dual Protection}




\section{Dual Protection}

\section{Discuss the following with the client:}

- Dual protection is the use of condoms consistently and correctly in combination with another family planning method. This provides added protection against pregnancy in case of condom failure.

- Use a male or female condom correctly and consistently with every act of sex. This one method protects against STIs and pregnancy.

- Only engage in safer sexual intimacy that prevents semen and vaginal fluids from coming in contact with partner's genitals or other vulnerable areas, such as the mouth and anus.

- Delay or avoid sexual activity, especially with a partner whose STI/HIV status is not known.

- Delay or avoid sexual activity if partner has been susceptible to Zika. 


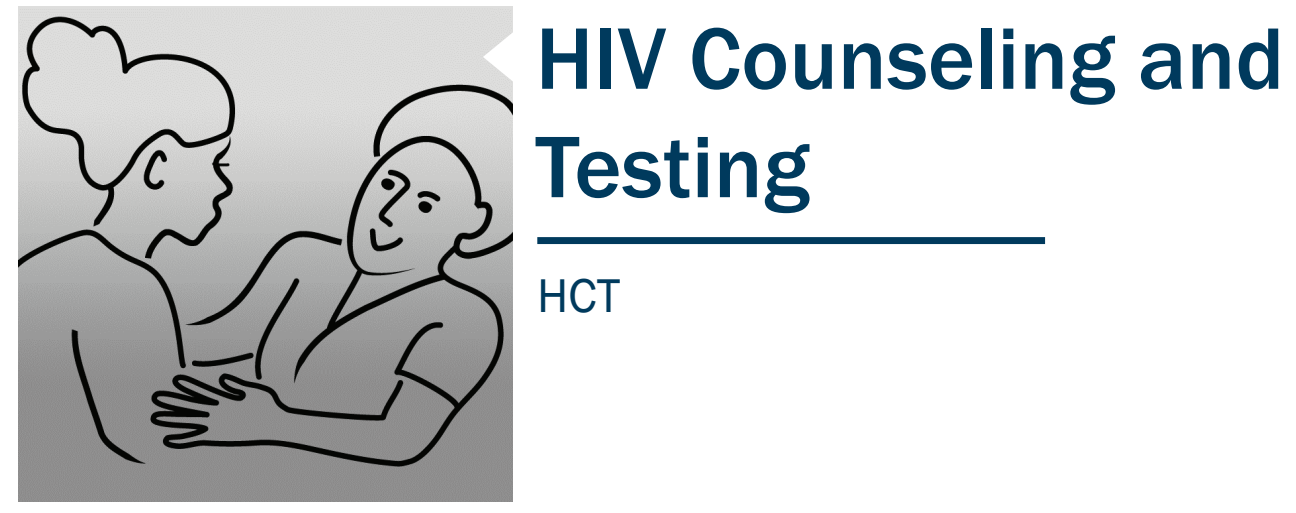




\section{HIV Counseling and Testing}

HCT

\section{Discuss the following with the client:}

- Knowing the client's HIV status can help them make decisions about protecting themselves and their sexual partner(s).

- Testing permits people living with HIV to seek treatment so that they can live a full life. The test involves taking a small sample of blood. The test is free and available at clinics, hospitals, and HIV counseling and testing sites.

- Test results are kept confidential.

- When a person is first infected with HIV, it can take 3 or more months for the test to detect the infection. This is called the "window period" and is the reason why repeat testing is important.

- A positive test result means the person is infected with HIV and can transmit the virus to others.

- A negative test result can mean the person is not infected or that $\mathrm{s} /$ he is in the "window period". Another test should be taken within 3 months. If the second test is still negative, the person is currently not living with HIV but can still become infected with HIV.

- HIV is a sexually transmitted infection (STI). It is important to ask their sexual partner(s) to be tested too. 


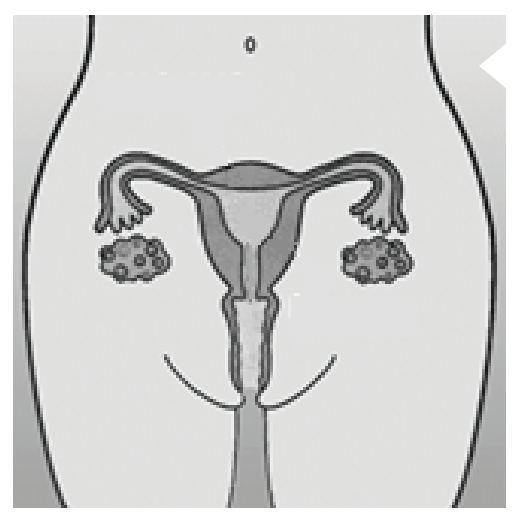

Screening for Cervical Cancer 


\section{Screening for Cervical Cancer}

If the client is 30-49 years of age or HIV positive at any age, ask if the client has ever been screened for cancer of the cervix.
- Cancer of the cervix is a common cancer of the reproductive tract. It is preventable, easily detectable, and curable in the early stages.

- Cervical cancer results from infection with a virus known as HPV.

- Most infections clear up, but those that are persistent may lead to cervical cancer.

- Describe how cervical cancer presents:

- Cancer of the cervix is painless and progresses slowly.

- It occurs at the opening of the uterus.

- When advanced, a woman may experience an abnormal/unusual smell or odor from her vagina, painful sexual intercourse, bleeding after sex and lower abdominal and back pain.

- Detection is through a quick, simple, and generally not painful test done by a trained provider (HPV test, VIA or Pap smear).

- Screening for cancer of the cervix should be done every 3-5 years (depending on national guidelines). Women living with HIV should be screened every 3 years. If the test is positive, then treatment is recommended. Early treatment involves freezing pre-cancerous sores (cryotherapy) and can be done as an outpatient procedure.

- Clients with advanced cancerous sore/s are referred for special treatment. 


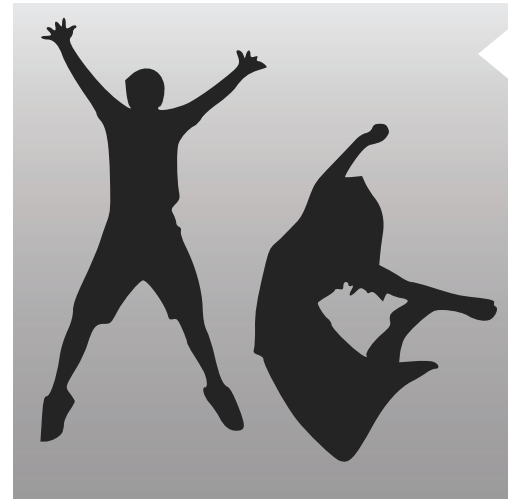

Adolescent Counseling 


\section{Adolescent \\ Counseling}

\section{If a client is younger than 18} years, discuss adolescent health needs.

- Adolescence is a time of transition marked by physical, psychological and social milestones.

- Adolescents have unique reproductive health needs that can be addressed through health services, including counseling.

- Ask clients about resources in their communities:

- Are there supportive and positive individuals that you can go to for advice or support? These can include partners, parents, teachers and community leaders.
- All modern contraceptive methods are generally safe for adolescents.

- For married adolescents, discuss desired family size (refer to HTSP card).

- For unmarried adolescents, describe the importance of delaying marriage and pregnancy:

- For the health of the mother and baby, wait until at least age 18 before trying to become pregnant.

- Early marriage and pregnancy should be avoided in order to allow for girls' full mental and physical development.

- To prevent unintended pregnancy, it is important for a young woman to consistently use a modern contraceptive method.

- Describe other health issues facing adolescent girls:

- Adolescent girls who are sexually active are at risk for STIs, including HIV and Zika. Using a condom in addition to another family planning method can provide added STI and HIV prevention, (refer to STI/HIV Transmission \& Prevention).

- Girls have important nutritional needs to ensure their healthy development.

- Discuss available youth-focused services, including sports clubs, support clubs, young mothers clubs, faith groups or community-based groups. Refer the client to services as needed. 


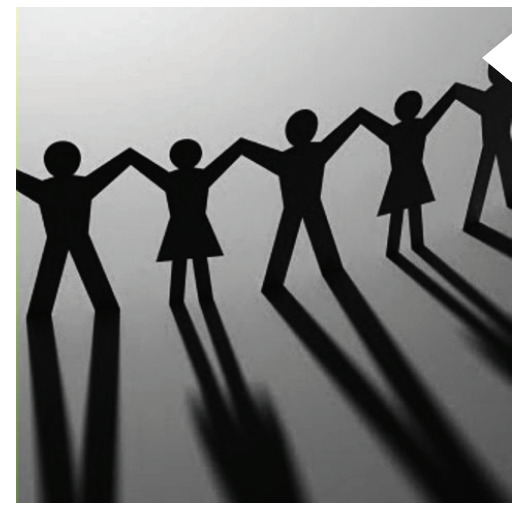

Women's Support and Safety 


\section{Women's Support and Safety}

Take the time to assess the woman's risk for intimate partner violence and the potential risks that accompany FP use for the woman.

Begin by sharing some information on intimate partner violence with the client:

- We want to ensure that women and their families thrive in a safe and supportive environment. This includes ensuring that women feel that they and their children are safe at home. We share the following information with all of our clients and ask some confidential questions.

- 1 out of 3 women worldwide have experienced either intimate partner violence or non-partner sexual violence in their lifetime.
- Any intimate partner violence involves harm to a human that can evolve into other health risks, not only for the woman but for her child or children as well. This includes increased risk for: chronic diseases, depression, suicide, lowered immune system, low birth weight, child abuse and intergenerational violence.

Ask the following questions to screen for IPV:

- Are you currently in a relationship with a person who threatens, frightens, or insults you, or treats you badly?

- Is there anyone who forces you to participate in sexual activities that are unwanted or make you feel uncomfortable?

If the client mentions fear of or experience with intimate partner violence OR if the client exhibits clinical indications of intimate partner violence (including chronic or acute pain with unknown origin, frequent sexual or gynecological problems, or depression and anxiety), follow these steps:

- Be supportive and validate their experience.

- Assess whether the client is living in a situation of risk-if she is, and if you have been appropriately trained, develop a safety plan or refer to another resource that can provide immediate assistance.

- Assess whether the client is in crisis, e.g. if she is in extreme emotional distress-if she is, provide her with the necessary emotional support or immediately refer her to another resource that can provide immediate assistance.

- Counsel the client on available referral services in their community. These can include: women's centers, shelters or safe houses, psychological counseling, couples counseling programs, and legal and medical services. Provide client with support and referral to the service(s) of her choice. 


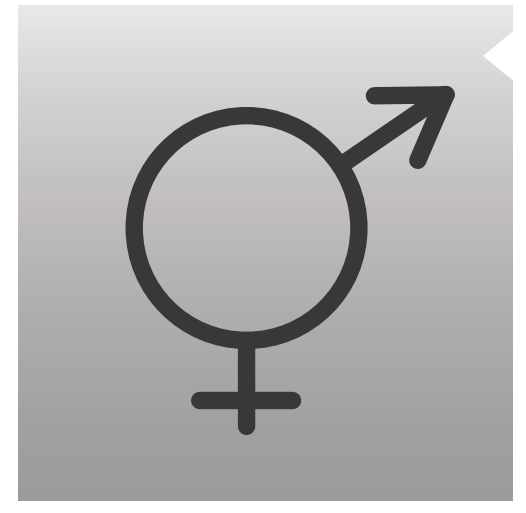

\section{Male Services and} Support for their Partners 


\section{Male Services and Support for their Partners}

Discuss men's responsibility in sexual and reproductive decision-making

- Men can also use contraception

- Men should be active in parenting and being fathers. Men can jointly decide with their partners:

- The number of children they want to have.

- When and how to use family planning methods.

- Where to seek family planning services, maternity services and child health services.

- They are also partners in preventing and treating sexually transmitted infection (STIs), including HIV and Zika.

- Men should use condoms throughout pregnancy if living in an area with active Zika transmission.
If the man is present during an FP and HIV services consultations:

- Congratulate the man for his presence and tell him about the services available for men, and explain the benefits of family planning and birth spacing.

- Family planning allows the client(s) to plan the number of children they want to have and when they want to have them. Waiting for 24 months between the births of their children improves their partner's health, all of their children's health, and the available resources they have to support their family.

- Describe services that are available to men, in addition to family planning, such as STI screening and treatment, HIV testing and counseling, hypertension screening, obesity counseling, and smoking counseling.

- If the clinic has any of the services mentioned above, including contraceptives for men, offer the services or refer the man within the facilities. If these services are not available, inform the man where the services are available and offer a referral to these facility. 


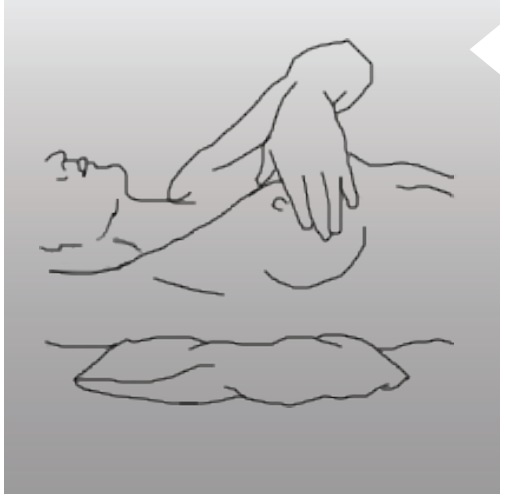

\section{Breast Cancer}

Information and

Awareness 


\section{Breast Cancer}

\section{Information and}

\section{Awareness}

\section{Discuss the following with the client:}

- "Breast cancer" is a malignant tumor that develops from cells in the breast.

- Breast cancer is the second leading cause of death and second most common cancer. It is curable if detected early.

- All women and men are at risk.

\section{Screening and early detection of breast} cancer

- Screening for breast cancer involves self-breast examination (SBE), clinical breast examination and breast imaging (mammography and/or ultrasound scanning).

Note: not all breast cancers are palpable therefore, clinical breast examination and imaging are recommended in combination with SBE for the best chances of detecting any breast cancer early.

\section{About self-breast examination:}

- Explain that SBE is easy to perform. It can be done at any time; when lying down, taking a shower or bathing.

- SBE is simple and important; it allows for early detection of breast lumps and clients presentating themselves for treatment.

- Early treatment increases chance of complete cure. Monthly/correct exams help detect changes in the breast early.

Women should conduct a SBE at least once every month at the same time each menstrual cycle as breast shape and feel change at different stages of the cycle. The best time is immediately after the menses (period). If she is on the pill, the best day is the first day of the new pill pack. For women who are on Depo Provera, Norplant, have reached menopause, or whose menses are not regular, SBE should be done on the first day of each calendar month. Men also should examine themselves regularly; ideally on the first day of each calendar month.

\section{Presentation of breast cancer:}

- Majority cases: a painless lump in the breast

- Other symptoms: nipple retraction, skin changes such as darkening and dimpling (appearance like the skin of an orange), and nipple discharge that may be bloody.

- Late presentations: ulceration, enlarged lymph nodes in the armpit and neck. Pain is usually a late symptom.

- Report to your nearest health care provider if you notice any of the above signs/symptoms. 



\section{Balanced Counseling Strategy Plus}

\section{Third Edition}

The Balanced Counseling Strategy Plus (BCS+) toolkit, developed and tested in Kenya and South Africa, provides the information and materials that health-care facility providers need so they can offer complete, high-quality family planning counseling to clients living in areas with high rates of HIV and STIs. The BCS+ was adapted from the Balanced Counseling Strategy (Léon 1999; Léon et al. 2003a, b, c; Léon et al. 2008). First and second editions of the Balanced Counseling Strategy and the Balanced Counseling Strategy Plus toolkits are products of Population Council's FRONTIERS program, supported by United States Agency for International Development (USAID), Cooperative Agreement HRN-A-00-98-00012-00.

This Third Edition of the BCS+ includes content updated according to the latest WHO Medical Eligibility Criteria (2015). It incorporates the most up to date evidence on clinical indications for the provision of family planning methods, including new methods, and includes four new counseling cards that address Adolescent Counseling, Male Services, Post Abortion Care, and Women's Support and Safety. These updated cards include instructions for providers, guiding them through supplemental counseling and services that family planning clients may need. Development of this Third Edition of the BCS+ counseling cards was funded by the Evidence Project and the Integra Project at the Population Council.
Note: These cards are part of a larger publication titled The Balanced Counseling Strategy Plus: A Toolkit for Family Planning Service Providers Working in High STI/HIV Prevalence Settings.

The BCS+ toolkit is comprised of the following:

- Algorithm

- Counseling cards

- Method brochures

- User's Guide

- Trainer's Guide

- WHO Medical Eligibility Criteria Wheel

We would like to acknowledge the following individuals for contributing their time and technical expertise to this edition of the BCS+: Megan Christofield, Heather Clark, Mychelle Farmer, Kamlesh Giri, Joanne Gleason, Mark Hathaway, Anushka Kalyanpur, Maggie Kilbourne-Brook, Karen Kirk, Ricky Lu, Ruth Merkatz, Charity Ndwiga, Anne Pfitzer, Saumya Ramarao, Naomi Rijo, Elizabeth Rochette, Jill Schwartz, Leigh Stefanik, John Townsend, Chi-Chi Undie, Katie Unthank, Anneka Van Scoyoc, Charlotte Warren, Ellen Weiss, Kelsey Wright.

For the full Toolkit, please visit http://www.popcouncil.org/bcsplus 